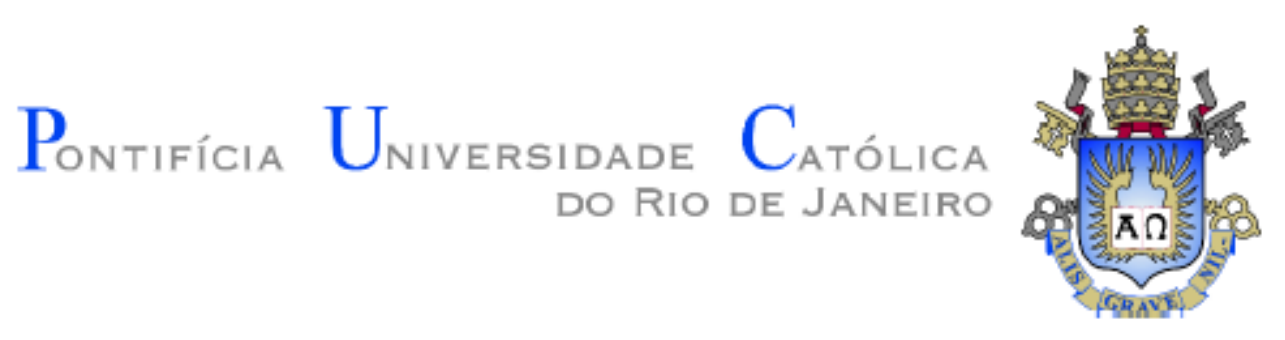

Marcio Couto Ozorio

Reologia de hidratos de ciclopentano em emulsões água em óleo modelo

Dissertação de Mestrado

Dissertação apresentada como requisito parcial para obtenção do grau de Mestre em Engenharia Mecânica pelo Programa de Pósgraduação em Engenharia Mecânica, do Departamento de Engenharia Mecânica da PUC-Rio.

Orientadora: Profa. Mônica Feijó Naccache

Rio de Janeiro

Abril de 2021 


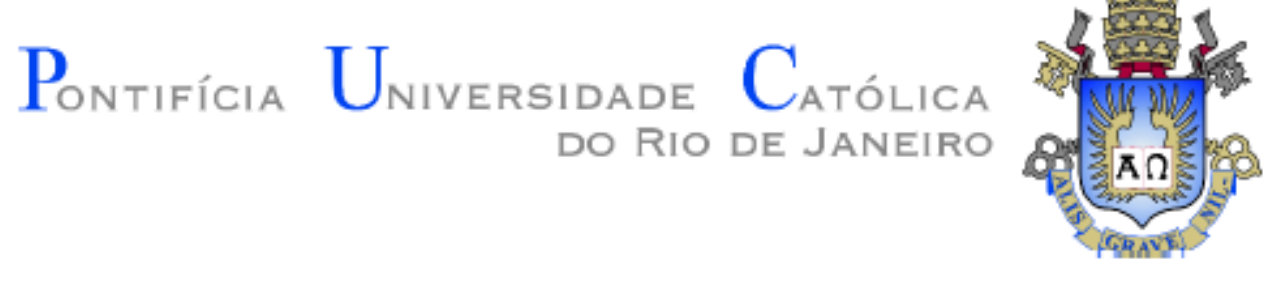

Marcio Couto Ozorio

\title{
Reologia de hidratos de ciclopentano em emulsões água em óleo modelo
}

\begin{abstract}
Dissertação apresentada como requisito parcial para obtenção do grau de Mestre pelo Programa de Pós-graduação em Engenharia Mecânica do Departamento de Engenharia Mecânica do Centro Técnico Científico da PUC-Rio. Aprovada pela Comissão Examinadora:
\end{abstract}

\author{
Profa. Mônica Feijó Naccache \\ Orientadora \\ Departamento de Engenharia Mecânica - PUC-Rio
}

Prof. Paulo Roberto de Souza Mendes

Departamento de Engenharia Mecânica - PUC-Rio

Prof. Amadeu Kun Wan Sum

Departamento de Engenharia Química e Biológica - Colorado

School of Mines

Rio de Janeiro, 05 de abril de 2021 
Todos os direitos reservados. É proibida a reprodução total ou parcial do trabalho sem autorização da universidade, do autor e do orientador.

\section{Marcio Couto Ozorio}

Graduou-se em Engenharia de Petróleo na UFF (Universidade Federal Fluminense), em 2011. No seu mestrado, desenvolveu pesquisa na área de Petróleo e Energia, como foco principal em análise reológica de hidratos formados a partir de emulsões água em óleo modelo.

Ficha Catalográfica

Ozorio, Marcio Couto

Reologia de hidratos de ciclopentano em emulsões água em óleo modelo / Marcio Couto Ozorio ; orientadora: Mônica Feijó Naccache. $-2021$.

127 f. : il. color. ; $30 \mathrm{~cm}$

Dissertação (mestrado)-Pontifícia Universidade Católica do Rio de Janeiro, Departamento de Engenharia Mecânica, 2021.

Inclui bibliografia

1. Engenharia Mecânica - Teses. 2. Hidratos. 3. Emulsões. 4. Ciclopentano. 5. Reologia. I. Naccache, Mônica Feijó. II. Pontifícia Universidade Católica do Rio de Janeiro. Departamento de Engenharia Mecânica. III. Título. 


\section{Agradecimentos}

O presente trabalho foi realizado com o apoio da Coordenação de Aperfeiçoamento de Pessoal de Nível Superior - Brasil (CAPES) - Código de Financiamento 001.

Aos meus pais, Milton (in memorium) e Zélia, que me deram o dom da vida e me deram a oportunidade de estudar e fazer as minhas próprias escolhas, acreditando, respeitando e incentivando os caminhos escolhidos.

Aos meus familiares, em especial minha irmã Mirela, minha tia Ana e minha avó Val, que sempre estiveram presentes em todas as etapas da minha vida e ajudaram a construir o ser humano que hoje sou.

Ao meu marido, Bruno, que esteve ao meu lado nos momentos mais difíceis, sempre com amor, compreensão e um ombro amigo.

Aos meus amigos, Juliana, Fernanda, Marina, Júlia, Thiago, Felipe, dentre outros, que contribuíram para que esta caminhada fosse mais leve.

À minha orientadora, Professora Mônica, pela paciência e conhecimento compartilhado, sempre disposta a ajudar, com amor e dedicação.

À Capes, à PUC-Rio e à Petrobras, pelos auxílios concedidos, sem os quais este trabalho não poderia ter sido realizado.

Ao Grupo de Reologia e todos os colegas de pesquisa, por todo o suporte, carinho e prontidão em compartilhar conhecimento.

Por fim, agradeço a Deus, por tudo que conquistei até aqui e por tudo que ainda hei de conquistar. 


\section{Resumo}

Ozorio, Marcio Couto; Naccache, Mônica Feijó. Reologia de hidratos de ciclopentano em emulsões água em óleo modelo. Rio de Janeiro, 2021. 127p. Dissertação de Mestrado - Departamento de Engenharia Mecânica, Pontifícia Católica do Rio de Janeiro.

O estudo reológico de hidratos vem se tornando cada vez mais importante graças à constante expansão da indústria de óleo e gás, principalmente em águas ultra profundas. O processo de formação de hidratos é uma grande preocupação, principalmente porque, em muitos casos, leva ao bloqueio total dos dutos de produção, causando interrupção na produção, além de perda de tempo de dinheiro. Hidratos são compostos cristalinos formados por água e pequenas moléculas de gás, em condições termodinâmicas de alta pressão e baixa temperatura. A fim de estudar este fenômeno, por analogia, compostos químicos que facilitam esta formação, à pressão atmosférica, como ciclipentano (CP) e tetrahidrofurano (THF) são utilizados. No presente trabalho, emulsões compostas por CP, óleo Primol, água deionizada e Span 80 (agente estabilizador) foram utilizadas e analisadas no reômetro Physica MCR301. A partir de uma perturbação térmica, pôde-se caracterizar vários parâmetros que influenciam a formação dos hidratos, tais como: taxa de cisalhamento, temperatura de indução, fração volumétrica da água, taxa de resfriamento etc. Além disso, foram realizados testes que avaliam a habilidade de reconstrução dos hidrato com o tempo e a existência de uma tensão limite de escoamento, a partir de testes oscilatórios.

\section{Palavras-chave}

Hidratos; Emulsões; Reologia; Ciclopentano. 


\section{Abstract}

Ozorio, Marcio Couto; Naccache, Mônica Feijó (Advisor). Rheology of cyclopentane hydrates in water-in-model oil emulsions. Rio de Janeiro, 2021. 127p. MSc. Dissertation - Departamento de Engenharia Mecânica, Pontifícia Católica do Rio de Janeiro.

The study of hydrates rheology is becoming increasingly important due to the constant expansion of the oil and natural gas industry to deeper water. The hydrate formation process is a big concern mainly because, in many cases, it ends up generating the blockage of pipelines, safety problems, and loss of time and money. Hydrates are crystals compounds formed by water and small gas molecules at typical thermodynamic conditions of high pressure and low temperature. In order to study the hydrates phenomenon by analogy, chemical compounds that facilitate their formation at atmospheric pressure are used, such as cyclopentane (CP) and tetrahydrofuran (THF). In this study, an emulsion formed from CP, Primol oil, deionized water, and Span 80 (as stabilizer agent) is employed. Initially, the results aim to characterize the several parameters that influence hydrate formation, such as: shear rate, induction temperature, water volume fraction, cooling rate etc. In another set of results, the ability of reconstruction of the $\mathrm{CP}$ hydrates and the existence of a yield strength are assessed.

\section{Keywords}

Hidrates; Emulsions; Rheology; Cyclopentane. 


\section{Sumário}

1 Introdução 15

1.1 Motivação 15

$\begin{array}{ll}1.2 \text { Objetivo } & 18\end{array}$

$\begin{array}{ll}1.3 \text { Estrutura da Dissertação } & 19\end{array}$

2 Estado da Arte $\quad 20$

$\begin{array}{ll}2.1 \text { Hidratos } & 21\end{array}$

$\begin{array}{ll}2.2 \text { Reologia } & 27\end{array}$

$\begin{array}{ll}2.3 \text { Classificação Reológica } & 28\end{array}$

2.4 Emulsões 34

2.5 Efeito Memória de Hidratos $\quad 44$

$\begin{array}{ll}2.6 \text { Efeito de Seeds } & 46\end{array}$

$\begin{array}{ll}\text { 2.7 Agentes Formadores de Hidrato } & 47\end{array}$

3 Materiais e Métodos $\quad 58$

3.1 Materiais $\quad 58$

3.2 Equipamentos e Acessórios $\quad 62$

3.3 Métodos 63

4 Resultados e Discussão 70

$\begin{array}{ll}\text { 4.1 Estabilidade das Emulsões } & 70\end{array}$

4.2 Caracterização Reológica da Emulsão 4

$\begin{array}{ll}\text { 4.3 Resultados - Emulsão } 3 & 78\end{array}$

4.4 Resultados - Emulsão 4

5 Conclusão e sugestões para trabalhos futuros 120 
$\begin{array}{ll}5.1 \text { Conclusão } & 120\end{array}$

5.2 Sugestões para trabalhos futuros 122

6 Referências bibliográficas 123 


\section{Lista de Figuras}

Figura 1 - Evolução da produção de petróleo e gás natural no Pré-Sal... 15

Figura 2 - llustração do sistema de uma FPSO no leito marítimo............. 16

Figura 3 - Hidrato de metano. ......................................................... 17

Figura 4 - Tipos de cavidades: dodecaedro pentagonal, tetradecaedro, hexadecaedro, dodecaedro irregular e icosaedro, respectivamente. (Sum,

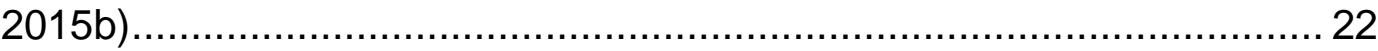

Figura 5 - Diferentes estruturas cristalinas de hidrato (Sloan e Koh, 2008)

Figura 6 - Representação da temperatura de sub resfriamento no gráfico $\mathrm{P} \times \mathrm{T}$. 25

Figura 7 - Esquema de formação de hidrato a partir de gotículas de água (Turner, 2006) 25

Figura 8 - Etapas da formação de hidratos em oleodutos (Sloan et al, 2006) 26

Figura 9 - Modelo de placas paralelas introduzido por Newton (Barnes et

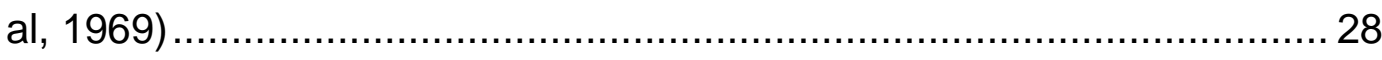

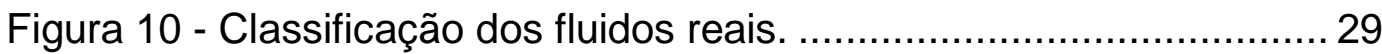

Figura 11: Flow curves para fluidos não newtonianos, tixotrópicos e reopéticos.

Figura 12. (a) Tensão de Cisalhamento, $\mathrm{T}$, e (b) Viscosidade aparente, $\eta$, em função da taxa de cisalhamento para diferentes fluidos não

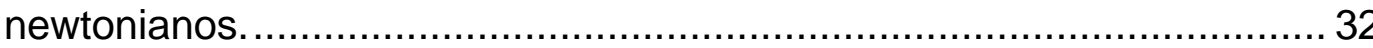

Figura 13 - Exemplo de emulsão e suas fases dispersa e contínua. ........ 35

Figura 14. Diferentes tipos de emulsão............................................ 36

Figura 15. Forças atrativas entre as moléculas no interior de um fluido. . 38

Figura 16. Molécula de surfactante - Cabeça polar e cauda apolar......... 39 Figura 17. Efeito da concentração de Span 80 na formação de hidratos. 41 Figura 18. Estabilização eletrostática e estérica a partir da utilização de tensoativos. 
Figura 19 - Efeito da adição de seeds de gelo na formação de hidratos. 46 Figura 20. a. Efeito de hidrato de metano sob o efeito de cisalhamento constante. b. Comportamento elástico durante a formação do hidrato em teste oscilatório.

Figura 21. Esquema do sistema de alta pressão utilizado no experimento.

Figura 22. Histórico de temperatura nos experimentos de formação de hidratos.

Figura 23. Evolução da viscosidade vs tempo para emulsões com diferentes frações volumétricas. Fonte: (Ahuja et al., 2014). 55

Figura 24. Viscosidade vs tempo para sistema não emulsificado. 56

Figura 25. Visualização da amostra durante o teste do sistema não emulsificado. 56

Figura 26 - Estrutura Molecular do ARQUAD 2HT-75. 60

Figura 27 - Estrutura Molecular do Monooleato de Sorbitano - Span 80. 61

Figura 28 - Estrutura molecular do Ciclopentano. 62

Figura 29 - Tratamento térmico da amostra para os testes de formação de hidrato. Os números entre parênteses indicam as etapas explicadas no texto. As etapas 3 e 7 são executadas com cisalhamento. 69

Figura 30 - Emulsão A/O 1: composta por 1\% de ARQUAD® e $8 \%$ de CP.

Figura 31 - Emulsão A/O 2: composta por 1.4\% de ARQUAD® e $8 \%$ de CP. 72

Figura 32 - Emulsão A/O 3: composta por 1.4\% de Span80 e 8\% de CP.

Figura 33 - Emulsão A/O 4: composta por 1.4\% de Span80 e 23\% de CP.

A: Após o preparo. B: 3 semanas após o preparo. 74

Figura 34 - Teste de taxa de cisalhamento constante de 0.001 1/s......... 75

Figura 35 - Teste de taxa de cisalhamento constante de 100 1/s........... 76

Figura 36 - Curve de escoamento da Emulsão 4 (Pontos experimentais e modelo mais adequado).

Figura 37 - Teste de varredura de tensão na emulsão 4. 78 
Figura 38 - Viscosidade $x$ tempo para amostra submetida a taxa de cisalhamento de 10 (1/s).

Figura 39 - Viscosidade $x$ tempo para amostra submetida a taxa de cisalhamento de 1 (1/s). 80

Figura 40 - Formação de hidratos utilizando duas temperaturas negativas diferentes.

Figura 41 - Análise da viscosidade a - $4^{\circ} \mathrm{C}$ para emulsão sem e com CP. 82 Figura 42 - Comportamento da viscosidade por tempo da emulsão 4. Curva de repetitividade. 83

Figura 43 - Comportamento da viscosidade por tempo para diferentes taxas de cisalhamento. 84

Figura 44 - Comportamento da viscosidade relativa para diferentes taxas de cisalhamento. 86

Figura 45 - Acúmulo de hidratos na parte superior do rotor para taxas de cisalhamento de (A) $50 \mathrm{~s}^{-1} \mathrm{e}$ (B) $100 \mathrm{~s}^{-1}$.

Figura 46 - Hidratos de CP com morfologia porosa e com aspecto de pelos.

Figura 47 - Comportamento da viscosidade pelo tempo em uma mesma amostra submetida a diferentes taxas de cisalhamento. 89

Figura 48 - Curva de escoamento para amostra submetida a diferentes taxas de cisalhamento.

Figura 49 - Comportamento da viscosidade dos hidratos de CP com o tempo sobre diferentes temperaturas de indução.

Figura 50 - Comportamento da viscosidade com o tempo para sistemas emulsificados e não emulsificados. 92

Figura 51 - Comportamento da viscosidade com o tempo para emulsões com e sem CP. 94

Figura 52 - Comportamento da viscosidade com o tempo para diferentes taxas de resfriamento.

Figura 53 - Comportamento da viscosidade com o tempo para diferentes taxas de resfriamento. Curvas deslocadas. 
Figura 54 - Análise da viscosidade com o tempo para uma taxa de resfriamento baixa, sem tratamento térmico

Figura 55 - Comportamento da viscosidade com o tempo para diferentes frações volumétricas de água. Taxa de cisalhamento de $0.1 \mathrm{~s}^{-1}$. 98

Figura 56 - Comportamento da viscosidade com o tempo para diferentes frações volumétricas de água. Taxa de cisalhamento de $0.1 \mathrm{~s}^{-1}$. 99

Figura 57 - Curva de escoamento após formação de hidrato para fração volumétrica de $20 \%$. 100

Figura 58 - Curva de escoamento após formação de hidrato para fração volumétrica de $30 \%$.

Figura 59 - Curva de escoamento após formação de hidrato para fração volumétrica de $40 \%$. 102

Figura 60 - Microscopia da emulsão com 50\% de fração volumétrica de água.

Figura 61 - Distribuição de gotas da emulsão com 50\% de fração volumétrica de água pré-formação de hidratos. 103

Figura 62 - Microscopia da emulsão com 40\% de fração volumétrica de água. A: Pré-formação de hidratos. B: Pós-formação de hidratos. 104

Figura 63 - Distribuição de gotas da emulsão com 40\% de fração volumétrica de água pré-formação de hidratos. 104

Figura 64 - Microscopia da emulsão com 30\% de fração volumétrica de água. A: Pré-formação de hidratos. B: Pós-formação de hidratos. 105

Figura 65 - Distribuição de gotas da emulsão com 30\% de fração volumétrica de água pré-formação de hidratos. 105

Figura 66 - Microscopia da emulsão com $20 \%$ de fração volumétrica de água. A: Pré-formação de hidratos. B: Pós-formação de hidratos. 106

Figura 67 - Distribuição de gotas da emulsão com 20\% de fração volumétrica de água pré-formação de hidratos.

Figura 68 - Microscopia de emulsão utilizada para testes de repetitividade.
A: Emulsão $30 \%$ de água.
B: Emulsão $40 \%$ de água.

Figura 69 - Comportamento da viscosidade com o tempo para diferentes temperaturas finais. 
Figura 70 - Comportamento da viscosidade quando a amostra é submetida a diferentes tempos de descanso.

Figura 71 - Comportamento da viscosidade com o tempo após formação de hidrato e após tempo fora do envelope de formação. Taxa de $1 \mathrm{~s}^{-1} .111$ Figura 72 - Comportamento da viscosidade com o tempo após formação de hidrato e após tempo fora do envelope de formação. Taxa de $10 \mathrm{~s}-1$.

Figura 73 - Varredura de Tensão para pasta de hidrato formada a partir de uma taxa de cisalhamento de $1 \mathrm{~s}^{-1}$ 114

Figura 74 - Varredura de Tensão para pasta de hidrato formada a partir de uma taxa de cisalhamento de $5 \mathrm{~s}-1$

Figura 75 - Varredura de Tensão para pasta de hidrato formada a partir de uma taxa de cisalhamento de $10 \mathrm{~s}-1$ 115

Figura 76 - Varredura de Tensão para pasta de hidrato formada a partir de uma taxa de cisalhamento de $50 \mathrm{~s}-1$ 116

Figura 77 - Varredura no tempo para pasta de hidrato. Tensão de cisalhamento de $5 \mathrm{~Pa}$.

Figura 78 - Varredura no tempo para pasta de hidrato. Tensão de cisalhamento de $10 \mathrm{~Pa}$.

Figura 79 - Varredura no tempo para pasta de hidrato. Tensão de cisalhamento de $5 \mathrm{~Pa}$ e temperatura final de $8^{\circ}$.C 


\section{Lista de Tabelas}

Tabela 1. Aplicação de surfactante de acordo com a faixa de HLB (Adaptado de Griffin, 1949) ........................................................... 42

Tabela 2 - Propriedades da Vaselina Branca a $25^{\circ} \mathrm{C}$............................. 58

Tabela 3 - Propriedades e Especificações do Primol 352. (ExxonMobil) . 59

Tabela 4 - Propriedades físico-químicas do ARQUAD® 2HT-75 ..............60

Tabela 5 - Propriedades do Monooleato de Sorbitano. ............................. 61

Tabela 6 - Propriedades do Ciclopentano (Sigma-Aldrich, 2015c). ......... 62

Tabela 7 - Composição das Emulsões utilizando Vaselina e ARQUAD®.65

Tabela 8 - Composição das Emulsões utilizando Primol 352 e Span80 .. 66

Tabela 9 - Parâmetros Reológicos da Emulsão 4. ................................. 77

Tabela 10 - GR das pastas de hidrato para diferentes taxas de cisalhamento 


\section{1 \\ Introdução}

1.1.

Motivação

Graças à evolução tecnológica e ao constante aumento da demanda energética, a busca por novas formas de energia tem se tornado um dos principais objetivos da indústria. No caso da indústria do óleo e gás natural, mais especificamente em ambientes offshore, a exploração em águas ultra profundas e geladas já é uma realidade. Em meio a tais condições, a garantia do escoamento do óleo é um dos principais desafios encarado pelas empresas.

No Brasil, aproximadamente $94 \%$ da produção de petróleo e gás natural são provenientes de poços marinhos e, além disso, graças às descobertas mais recentes e a série de leilões que ocorreram nos últimos 5 anos, a maior parte dessa produção offshore é realizada em poços do Pré-Sal (aproximadamente 63\%), que estão submetidos a condições termodinâmicas mais severas, devido às maiores profundidades e menores temperaturas (IBP, 2019).

A Fig.1 mostra a evolução da produção de petróleo e gás natural nas camadas do Pré-Sal, estabelecendo um aumento de 16\% para 63\% nos últimos 5 anos e, assim, ratificando a busca por novas formas de extração do óleo e gás.

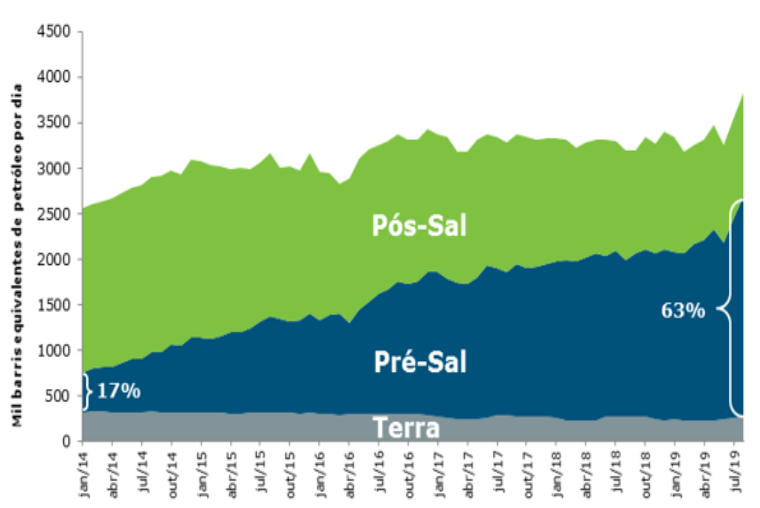

Figura 1 - Evolução da produção de petróleo e gás natural no Pré-Sal. Fonte: IBP, 2019. 
Em águas profundas e ultra profundas, a produção ocorre através de navios-sonda, mais conhecidos como FPSO (Floating, Production, Storage, Offloading). O Sistema que compõe tais navios é bastante extenso e complexo, compreendendo longos trechos de equipamentos e linhas de tubulação que permitem o escoamento do óleo e do gás (Fig. 2).

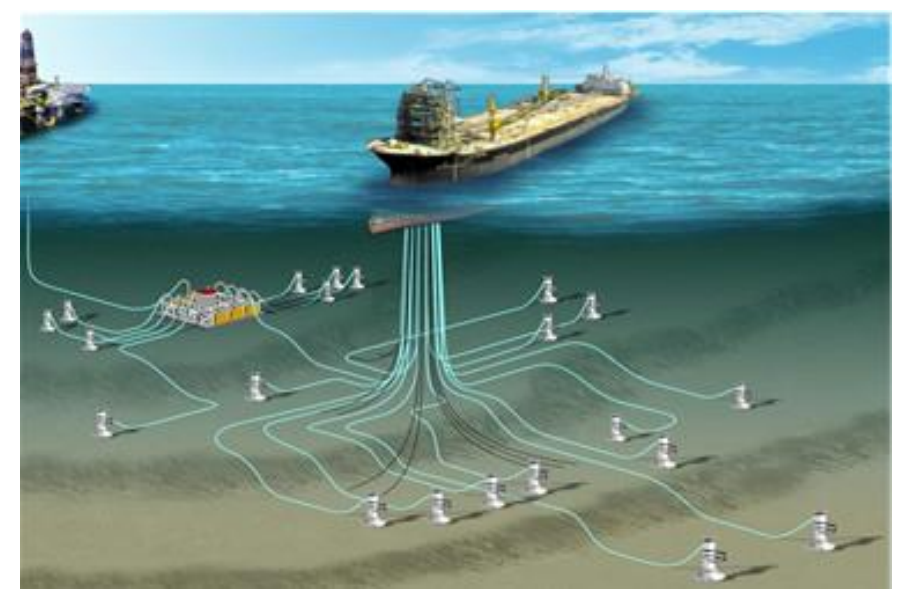

Figura 2 - llustração do sistema de uma FPSO no leito marítimo. Fonte: PETRONOTICIAS, 2017.

Devido às condições mais adversas, os grandes trechos de tubulações são submetidos a grandes variações termodinâmicas, as quais facilitam a formação, principalmente, de parafinas, asfaltenos e hidratos. Essas deposições são muito críticas, pois podem acarretar em uma obstrução parcial ou total das linhas de produção, resultando na queda da vazão e, nos piores casos, interrupção do fluxo e danos nas válvulas e tubulações (Bai, 2010).

Hidratos são compostos cristalinos sólidos formados basicamente de água e moléculas pequenas de gás, principalmente metano e etano. Devido às condições de altas pressões (acima de $5 \mathrm{Mpa}$ ) e baixas temperaturas (próximas a $0^{\circ} \mathrm{C}$ ) as quais as linhas estão submetidas, ocorre a solidificação da água e, nesse processo, o gás fica aprisionado em seu interior em pequenas cavidades, formando, então, o hidrato (Sloan, 2003). A Fig.3 mostra um bloco de hidrato que bloqueou as linhas de produção num campo da Petrobras. 


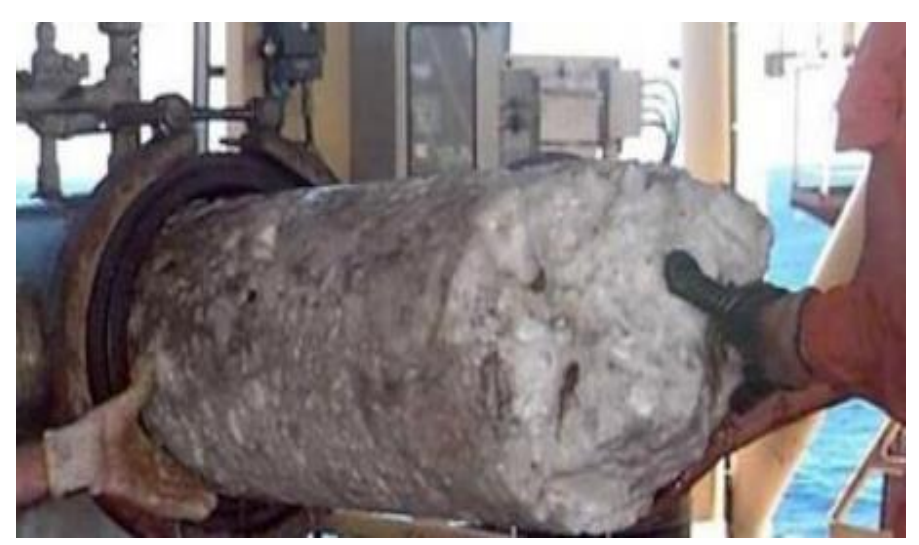

Figura 3 - Hidrato de metano. Fonte: Petrobras.

Apesar de haver frentes que consideram os hidratos como importante fonte energética (Abay, 2011), os hidratos são vistos como muito prejudiciais à produção, principalmente pelos elevados custos necessários para mitigar a sua acumulação. Quando comparado com parafinas e asfaltenos, os hidratos são mais críticos principalmente porque: (i) a acumulação ocorre muito rapidamente, muitas vezes, em questão de horas, causando maiores transtornos; (ii) o custo para eliminar tal problema é muito alto e a presença de água é uma das poucas certezas em todos os poços (Sloan e Koh, 2008).

A formação de hidratos pode ser inibida por diferentes métodos, os quais tem como premissa o controle ou eliminação dos elementos necessários para a formação destes. Os principais elementos são: (i) a presença dos componentes no gás natural que proporcionam a formação de hidratos (ex: metano); (ii) presença de água; (iii) alta pressão; (iv) baixas temperaturas.

No caso da temperatura, pode-se usar técnicas de aquecimento externo ou sistemas de isolamento. Similarmente, pode-se reduzir a pressão no interior das linhas, através do método de choking-back e, no caso da água, a desidratação do gás natural (Fu et al., 2001). Entretanto, a maioria desses métodos não são muito desejados em ambientes offshore.

Os principais métodos utilizados na indústria são os inibidores químicos (termodinâmicos), tais como metanol e etileno-glicol. Eles funcionam deslocando a curva de equilíbrio dos hidratos para maiores pressões e menores temperaturas, mudando a atividade das moléculas de 
água. Por custarem menos e terem uma maior disponibilidade, são os métodos mais populares (Fu et al., 2001).

Entretanto, o volume de inibidores termodinâmicos a ser utilizado em águas profundas e ultra profundas é muito elevado e, por isso, alguns outros métodos foram implementados:

- LDHI (“Low Dosage Hydrate inhibitors”);

- $\mathrm{KHI}$ ("Kinetic hydrate inhibitors");

- AA ("anti-agglomerants");

Esses inibidores não utilizam 0 mesmo princípio dos termodinâmicos. No primeiro caso, eles interferem no processo de formação a partir de uma série de mecanismos propostos e necessita de uma dose muito menor que os inibidores convencionais. Os inibidores $\mathrm{KHI}$ inibem a formação por um longo período, estendendo o tempo de indução para formação dos hidratos. Já os anti aglomerantes não impedem a formação, mas sim, a aglomeração dos cristais, formando suspensão dos hidratos (Camargo et al., 2000).

\section{2.}

Objetivo

O presente trabalho tem como principal objetivo realizar a caracterização reológica de uma emulsão A/O modelo, utilizando o agente formador de hidratos, ciclopentano (CP). Os resultados experimentais têm como objetivo avaliar o efeito de diversos parâmetros na reologia das pastas de hidrato de ciclopentano, tais como: temperatura de subresfriamento, taxa de cisalhamento, fração de volume de água, entre outros. Elasticidade, tixotropia e tensão limite de escoamento serão avaliados a partir dos testes reológicos, ajudando a entender o comportamento dos hidratos nos campos de óleo e gás natural. 


\section{3.}

\section{Estrutura da Dissertação}

O presente trabalho apresenta a seguinte estrutura: O capítulo 1 introduz a dissertação, expondo as motivações e objetivos do estudo. No capítulo 2, o estado da arte é abordado, trazendo os principais conceitos necessários para a elaboração dessa dissertação, tais como: emulsões, fluidos não newtonianos, hidratos etc. $O$ capítulo 3 apresenta os materiais e métodos utilizados durante os experimentos. O capítulo 4 traz os resultados e análises, como por exemplo, caracterização reológica da emulsão, comportamento da viscosidade em função de parâmetros como taxa de cisalhamento, temperatura de subresfriamento, taxa de resfriamento, fração de volume da água etc. No capítulo 5 será exposta a conclusão do trabalho. 


\section{2 \\ Estado da Arte}

Os hidratos foram primeiramente descobertos em 1778 por Joseph Priestley, mas ele não chegou a nomear o fenômeno. Em 1811, durante experimentos no laboratório, Humphry Davy observou que moléculas de água e Cloro (Cl2) formavam substâncias cristalinas quando submetidas a certas condições de pressão e temperatura. Até aquele momento tal descoberta não havia sido endossada por nenhum caso encontrado na natureza (MAKOGON et al., 2007).

Mais de uma século depois, em 1934, foi notada a presença de plugs, bloqueando o fluxo, na indústria do óleo e do gás, durante o inverno, por Hammerchmidt e, então, provou-se que se tratavam de hidratos de metano (MAKOGON et al., 2007). Ele escreveu um trabalho reportando o caso e explicitando que não se tratava de gelo e, além disso, associando a formação dos hidratos às condições de temperatura, pressão e composição da mistura (\% de água e de gás).

A partir de então, a pesquisa em torno dos hidratos começou a ganhar mais força, principalmente pela necessidade da aplicação de técnicas para inibição na indústria. Na década de 60 , foi descoberto em um reservatório de gás na Sibéria, por cientistas russos, a existência de hidratos de metano (MAKOGON et al., 2007).

Em 1965, graças ao aumento significativo de trabalhos sobre o tema, foi possível fazer estudos comparativos entre a prática e a teoria e, então, foi formulada a ideia da existência de acumulações de hidrato de metano na natureza. Finalmente, em 1966, tais estudos foram confirmados, por meio de experimentos, a partir da formação de hidratos de metano em meio poroso e em amostras reais de sedimentos (MAKOGON et al., 2007).

Devido à grandeza de composições de gás natural, foi muito difícil fazer um mapeamento experimental abrangente. Portanto, inicialmente, as principais ferramentas utilizadas nas pesquisas sobre o tema tiveram foco nas propriedades de equilíbrio termodinâmico independentes do tempo. Com a evolução das pesquisas, pôde-se definir melhor o equilíbrio de 
fases, voltando as pesquisas para medidas dependentes do tempo (Sloan \& Koh, 2008).

As principais frentes que foram elaboradas para essa área foram: (i) prevenção da formação dos hidratos e (ii) gestão dos riscos da formação de hidratos. No primeiro caso, o princípio é de evitar que os hidratos entrem na zona de estabilidade termodinâmica. Já na gestão dos riscos, a utilização de métodos transientes para retardar a formação dos hidratos e/ou impedir a formação de clusters, evitando, então, o bloqueio das linhas e, consequentemente, a interrupção do escoamento (Baptista, 2007).

\section{1.}

\section{Hidratos}

Hidratos de gás, também conhecidos como claratos, são compostos cristalinos formados por água e moléculas de gás, fisicamente parecidos com gelo. As moléculas de água funcionam como "cavidades" e aprisionam as moléculas de gás, tais como hidrocarbonetos gasosos com baixo peso molecular $\left(\mathrm{C}_{1}-\mathrm{C}_{4}\right)$ e outros gases: $\mathrm{H}_{2}, \mathrm{~N}_{2}, \mathrm{CO}_{2}$ e $\mathrm{H}_{2} \mathrm{~S}$ (Karanjkar et al., 2016).

Apesar de apresentarem ligações intermoleculares parecidas com a estrutura do gelo comum, o arranjo geométrico proporciona o aparecimento de cavidades que são capazes de aprisionar os gases originalmente encontrados em solução na água. A presença das moléculas de gás leva à estabilização da estrutura cristalina, permitindo que os hidratos existam a temperaturas mais elevadas que o gelo (Bai, 2010).

Normalmente os hidratos são formados sob condições de altas pressões e baixas temperaturas. Entretanto, podem ser formados, à pressão atmosférica, na presença de agentes formadores, tais como: tetrahidrofurano (THF) e ciclopentano (Peixinho et al., 2010).

As estruturas dos hidratos possuem repetitividade nas unidades de cristais, que são compostas por poliedros convexos, chamados de cavidades. A nível microscópico, podem apresentar três tipos de estruturas cristalinas: estrutura I, II e H. Essas estruturas são nomeadas de acordo 
com os polígonos planos que formam o poliedro e a quantidade de vezes que o poliedro se repete (Sloan, 2008).

Essas cavidades não são encontradas nos estados líquido e sólido da água, mas sim quando os hidratos são formados. Existem cinco tipos principais de cavidades: dodecaedro pentagonal, tetradecaedro, hexadecaedro, dodecaedro irregular e icosaedro (Sum, 2015b).

As estruturas são determinadas pelas diferentes combinações de cavidades. Além disso, a molécula de gás aprisionada também determina o tipo de estrutura formada. A Fig.4 apresenta as cinco principais cavidades.

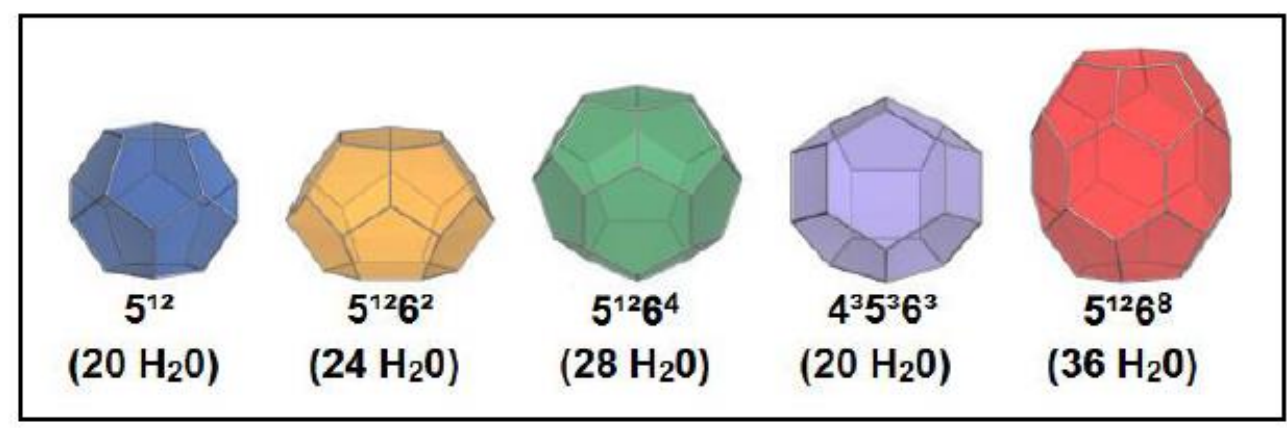

Figura 4 - Tipos de cavidades: dodecaedro pentagonal, tetradecaedro, hexadecaedro, dodecaedro irregular e icosaedro, respectivamente. (Sum, 2015b)

A numeração abaixo de cada cavidade pode ser explicada da seguinte forma: no caso da primeira, dodecaedro pentagonal, entende-se $5^{12}$ como sendo 12 pentágonos. Já no caso da segunda, tetradecaedro, entende-se $5^{12} 6^{2}$ como 12 pentágonos e 6 hexágonos; e assim por diante.

A aglomeração de diferentes cavidades e quantidades de cristas irá determinar o tipo de estrutura apresentado. A estrutura mais encontrada na indústria do óleo e gás é a estrutura II, enquanto a mais rara é a estrutura H. A estrutura I, composta por 46 moléculas de água, aprisiona moléculas de gás menores (de 4.2 a $6 \AA$ de diâmetro), como metano, etano, dióxido de carbono e sulfeto de hidrogênio (Sum, 2015b).

A estrutura II é composta por 136 moléculas de água e pode aprisionar moléculas como: nitrogênio e hidrogênio (com diâmetro menor 
que $4.2 \AA$ ) e hidrocarbonetos gasosos maiores como propano e isobutano (com diâmetro entre $6 \AA$ e $7 \AA$ ) (Sum, 2015b).

Diferente das estruturas anteriores, a estrutura $\mathrm{H}$ é uma rede hexagonal composta por 34 moléculas de água e só é formada quando há uma junção de moléculas maiores, como iso-pentano ou 2,2-dimetil-butano (diâmetro entre $7 \AA$ e $9 \AA$ ), com moléculas menores, como o metano, nitrogênio e sulfeto de hidrogênio (Sloan e Koh, 2008).

Além disso, a natureza da molécula também tem um papel importante na estabilização das cavidades. Para que seja estável, a molécula a ser aprisionada não pode competir com as ligações de hidrogênio formadas pela água, como em casos em que a molécula tem grupos funcionais com pontes de hidrogênio forte, tais como carboxilato ou amida (Sum, 2015b).

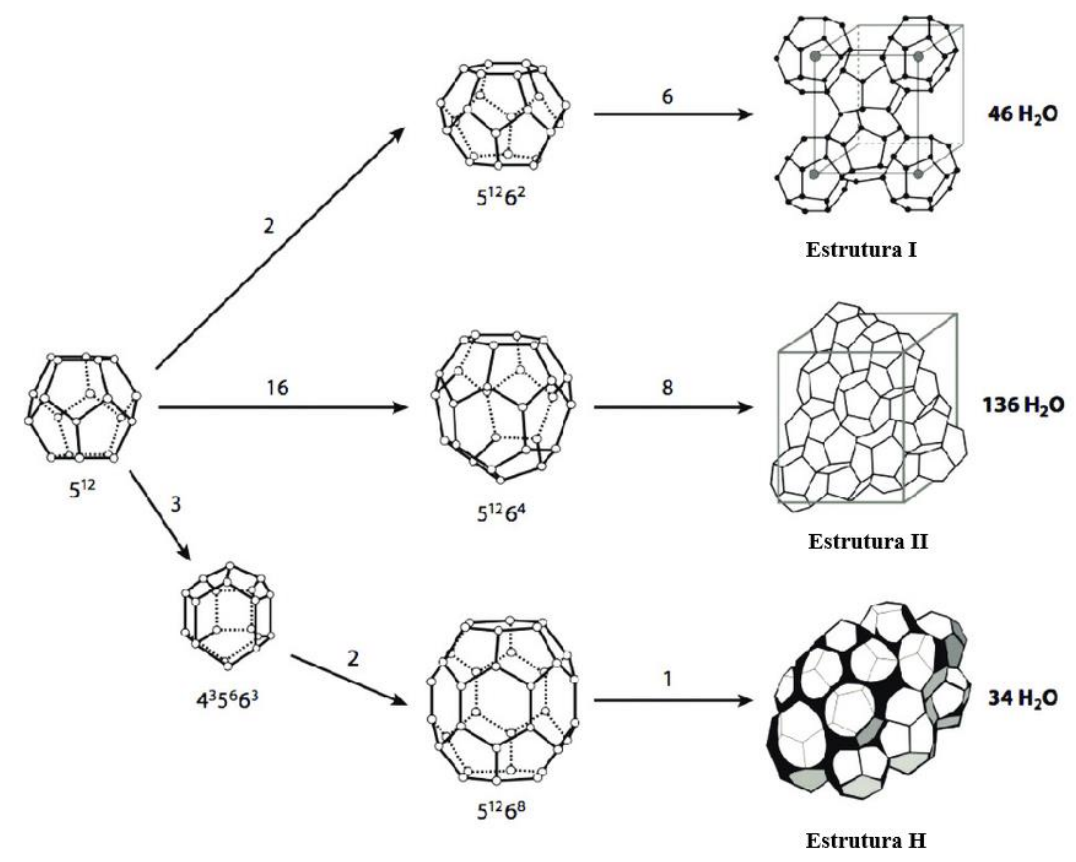

Figura 5 - Diferentes estruturas cristalinas de hidrato (Sloan e Koh, 2008)

A Fig.5 ilustra as 3 diferentes estruturas e os números acima de cada seta representam a quantidade de unidades de cristais necessários para formar cada tipo diferente de estrutura. 


\subsection{1.}

\section{Formação de hidratos de gás}

O processo de formação de hidratos é dividido em duas etapas principais: a nucleação e o crescimento (Abay, 2011). Durante a nucleação, tanto as moléculas de água, quanto as moléculas de gás tentam atingir uma dimensão crítica. Já na etapa do crescimento há uma multiplicação e um desenvolvimento dos núcleos que são estáveis (Bishnoi e Natarajan, 1996).

A nucleação é um fenômeno microscópico que ocorre quando pequenos núcleos de cristais crescem e dispersam, atingindo um tamanho específico e, então, possibilitando o crescimento contínuo do cristal. Caso esses núcleos não atinjam o tamanho crítico, eles podem chegar a se desfazer; esse estado é conhecido como metaestável (Bishnoi e Natarajan, 1996).

Para que a nucleação espontânea ocorra, o estado metastável da água e do gás deve superar uma barreira significante de energia livre. Além disso, a baixa solubilidade dos gases na água dificulta a investigação da nucleação dos hidratos (Sum et al., 2011).

Portanto, o início da nucleação de uma mistura contendo água no estado líquido e vapor de metano tem maior probabilidade de acontecer na interface vapor-líquido (Sum el al., 2011). O comportamento das moléculas de água junto à interface é muito importante no processo de formação, pois elas agem como substratos para que o gás condense. As propriedades destes são em função principalmente da pressão e da temperatura (Long, 1994).

Com a redução da temperatura, a força das interações de hidrogênio que interligam as moléculas de água aumenta e, consequentemente, o número de clusters formados pela água também aumenta. Os clusters são os aglomerados de moléculas de água que se agrupam ao redor da molécula de gás (Long, 1994).

Um conceito importante na formação dos hidratos é o tempo de indução. Sousa (2009) definiu como o tempo que leva para detectar a fase hidrato no sistema desde o instante em que há o primeiro contato da água com o gás a ser aprisionado. 
Esse tempo também sofre a influência da diferença entre as temperaturas de dissociação e de operação de hidrato, conhecida como temperatura de sub-resfriamento, mostrada na Fig. 6. Tanto a sobre pressão quanto o sub resfriamento influenciam diretamente no tempo de indução. Quanto maiores forem essas variáveis, menor será o tempo de indução (Sum et al., 2009).

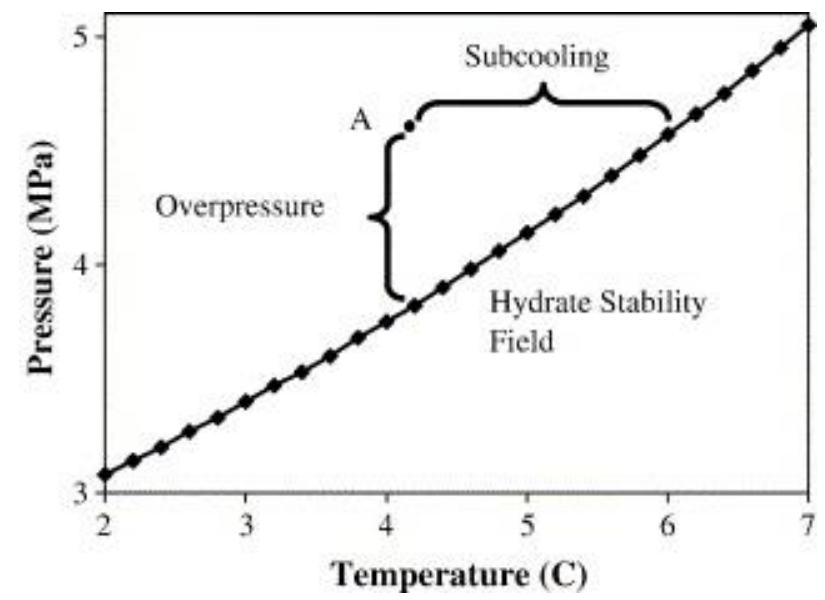

Figura 6 - Representação da temperatura de sub resfriamento no gráfico P x T. Fonte:(Sloan, 1998).

Ao estudar sistemas com emulsões água em óleo, Turner (2006) constatou que gotículas dispersas em água se convertiam diretamente em hidratos. Além disso, ele usou a hipótese de que não havia a existência de clusters, portanto, a distribuição do tamanho de gotas era mantida. Então, ele propôs o mecanismo de formação de hidratos ilustrado na Fig. 7.

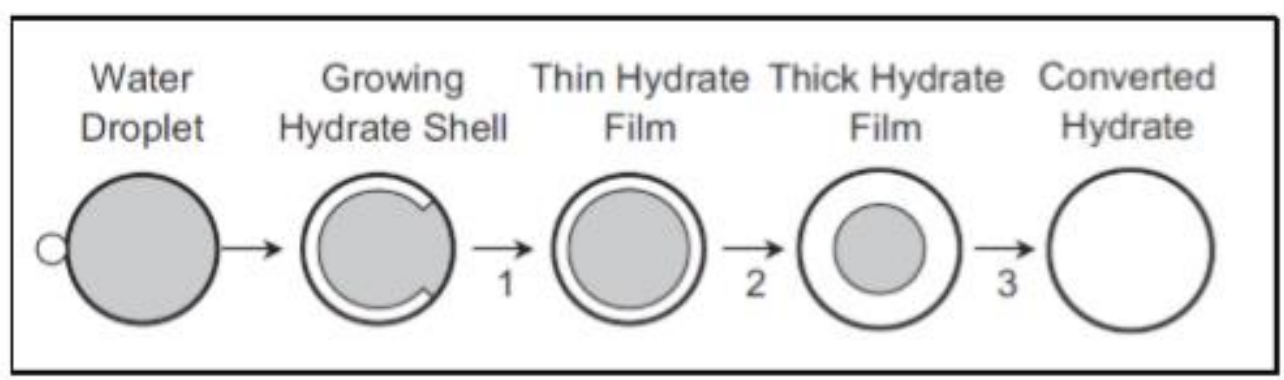

Figura 7 - Esquema de formação de hidrato a partir de gotículas de água (Turner, 2006)

Segundo esse mecanismo, a primeira etapa para a formação do hidrato é o surgimento de um filme fino e poroso de hidrato, que vai se 
propagar pela interface (onde todas as fases estão presentes). Essa etapa é a de crescimento lateral. Então, esse filme vai ganhando espessura com o passar do tempo através do crescimento radial em direção ao núcleo da gotícula.

O espessamento também ocorre com o preenchimento dos poros na interface. A última etapa se dá pela conversão total da gotícula de hidrato a partir do preenchimento dos poros que ainda não haviam sido preenchidos (Turner, 2006).

A partir desse modelo, Sloan et al. (2007) aplicou em um sistema multifásico óleo dominante e pôde sugerir as etapas que a formação de hidrato em oleodutos apresenta desde a formação até o entupimento das mesmas (Figura 8).

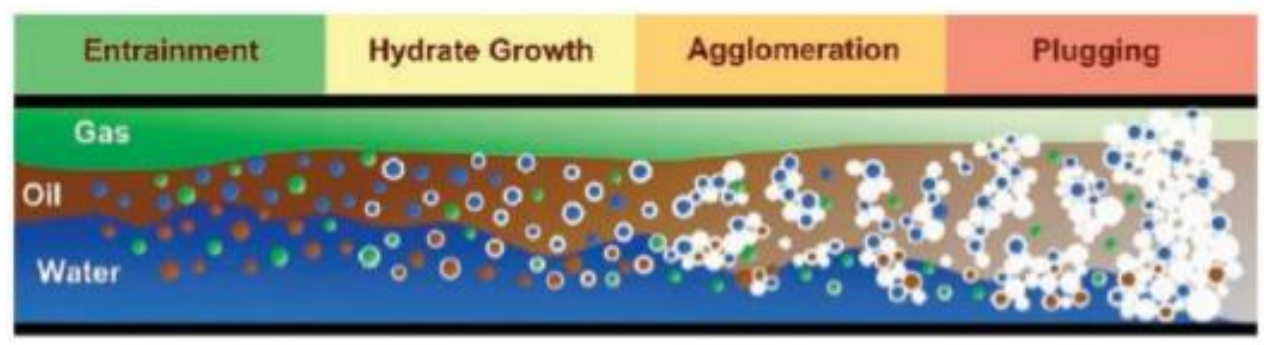

Figura 8 - Etapas da formação de hidratos em oleodutos (Sloan et al, 2006)

Basicamente o esquema se divide em quatro etapas: dispersão das gotículas de água, crescimento dos hidratos, aglomeração e entupimento total ou parcial do duto. Com as diferentes formulações de modelos de formação e crescimento de hidratos, surgiu a necessidade do surgimento de técnicas para a prevenção do bloqueio. As primeiras e principais a surgir foram as técnicas de inibição a partir de agentes químicos.

Os inibidores de hidratos podem ser classificados como:

- Termodinâmicos (THI - thermodynamic hydrates inhibitors): são capazes de mudar as condições de formação de hidratos para mais severas, deslocando a curva de equilíbrio e deixando o hidrato mais instável. Os principais exemplos são os álcoois (metanol, etano, 
isopropanol, monoetilenoglicol) e sais, sempre usados em altas concentrações.

- Inibidores de baixa dosagem (LDHI - low dosage hydrates inhibitors): eles não impedem a formação dos hidratos, mas tornam o aparecimento de bloqueios mais difícil. Se subdividem em: i) polímeros hidrossolúveis que retardam a nucleação e, consequentemente, o crescimento dos cristais de hidrato; ii) cinéticos (KHI - kinetic hydrate inhibitors) e iii) anti-aglomerantes que dificultam a junção de diferentes cristais de hidrato, impedindo que os mesmos aglomerem e cheguem a formar grandes plugs (Kelland et al., 2009).

\section{2.}

\section{Reologia}

O termo reologia vem do grego rheos (fluir) e logos (estudo) e foi inventado pelo professor Bingham de Lafayette College Easton e significa o estudo da deformação da matéria. Esse termo passou a ser aceito quando a Sociedade Americana de Reologia foi fundada, em 1929 (Barnes, 1993).

Mais especificamente, a reologia estuda a forma como os materiais respondem a partir da aplicação de uma tensão (ou deformação) e, tantos os sólidos quanto os líquidos, são estudados. No caso dos sólidos, a elasticidade é a característica de maior interesse, enquanto nos fluidos é a viscosidade (Castro et al., 2011).

O estudo do comportamento reológico dos corpos reais é muito complexo e diversificado, podendo um mesmo material ter diferentes comportamentos, dependendo das condições as quais ele esteja submetido.

A temperatura, pressão, a taxa de cisalhamento e a duração desse cisalhamento influenciam diretamente as propriedades reológicas. A caracterização reológica é de grande importância para a indústria de óleo e gás, pois a reologia afeta os fluidos de produção, perfuração, cimentação, completação e o escoamento dos fluidos nos dutos (Faerggestand, 2016). 
Quando um fluido está em movimento, várias forças atuam sobre ele. Tais forças surgem graças ao seu movimento, aos gradientes de pressão, à ação da gravidade e as interações entre as moléculas do fluido (Bretas e D’Ávila, 2000).

Em termos matemáticos, define-se a tensão de cisalhamento $(\mathrm{T})$ como sendo o quociente da força aplicada tangencialmente e a área A na qual essa força é aplicada. O modelo de placas paralelas, introduzido por Newton, exemplifica o conceito, através da Fig.9.

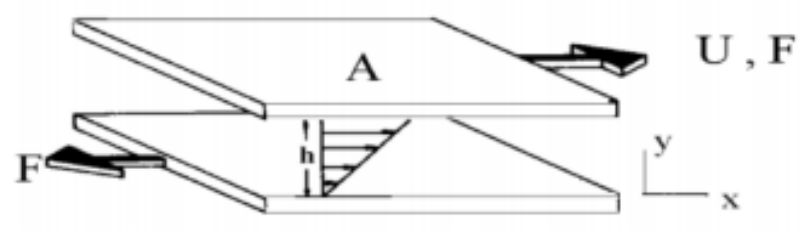

Figura 9 - Modelo de placas paralelas introduzido por Newton (Barnes et al, 1969)

A viscosidade pode ser denominada como diferencial e aparente. A viscosidade diferencial é determinada através da inclinação de um ponto específico da curva "tensão de cisalhamento versus taxa de cisalhamento", sempre para exemplos não-lineares. Já a viscosidade aparente é obtida a partir da inclinação de uma reta que liga um ponto específico da curva com a sua origem (Barnes et al., 1969).

\section{3. \\ Classificação reológica}

Os fluidos reais podem ser classificados em newtonianos e não newtonianos, sendo os últimos sendo divididos, principalmente, em três categorias: dependentes do tempo, independentes do tempo e viscoelásticos, conforme observado na Fig. 10.

Os fluidos newtonianos seguem a Lei de Viscosidade de Newton, ou seja, sua viscosidade absoluta, independente das diferentes taxas de cisalhamento aplicadas, mantém-se constante, além de não variar com o tempo. De acordo com Tanner (1988), a viscosidade é afetada apenas pela temperatura e pressão. 


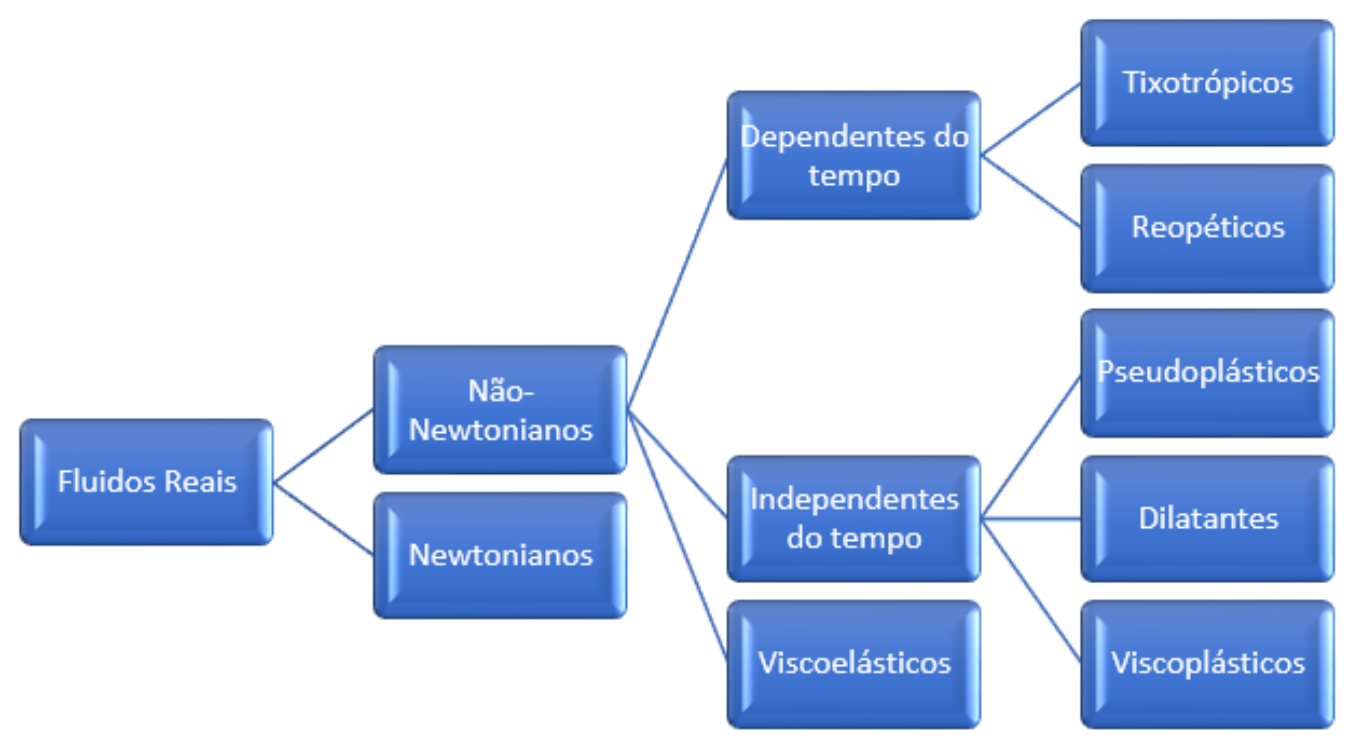

Figura 10 - Classificação dos fluidos reais. Fonte: (Adaptado de Mothé, 2009).

Os fluidos newtonianos seguem a Lei de Viscosidade de Newton, ou seja, sua viscosidade absoluta, independente das diferentes taxas de cisalhamento aplicadas, mantém-se constante, além de não variar com o tempo. De acordo com Tanner (1988), a viscosidade é afetada apenas pela temperatura e pressão.

\subsection{1.}

\section{Fluidos não newtonianos}

Os fluidos não newtonianos são aqueles cujo comportamento mecânico não pode ser expresso através da Lei de Viscosidade de Newton, ou seja, a relação entre as tensões e taxas de cisalhamento não é linear, exceto para fluidos viscoelásticos, os quais apresentam uma viscosidade constante.

De acordo com Chhabra (2010), eles são subdividos em três classes gerais:

- Dependentes do tempo $\rightarrow$ são fluidos mais complexos cuja viscosidade depende, além das taxas de cisalhamento, da duração do cisalhamento e de seu histórico cinemático; 
- Independentes do tempo $\rightarrow$ são fluidos cuja viscosidade não depende do tempo de cisalhamento, sendo a taxa de cisalhamento em qualquer ponto determinada apenas pelo valor da tensão cisalhante naquele ponto específico. Eles podem ser denominados como "independentes do tempo", "inelásticos", "puramente viscosos" ou "fluidos newtonianos generalizados";

- Viscoelásticos $\rightarrow$ fluidos que apresentam características tanto de sólidos (elasticidade), quanto de líquidos (viscosidade) e exibem recuperação elástica parcial após deformação.

Os fluidos dependentes do tempo são subdivididos em duas categorias: tixotrópicos e reopéticos. A uma taxa de cisalhamento constante, a viscosidade aparente dos fluidos diminui de acordo com o tempo de cisalhamento para fluidos tixotrópicos, enquanto que para fluidos reopéticos, a viscosidade aparente dos fluidos aumenta (Chhabra, 2010). A Fig.11 mostra um teste de histerese, que ilustra o comportamento reológico desses tipos de fluido. Observa-se que o comportamento da viscosidade é diferente ao se aumentar ou diminuir a taxa de cisalhamento. Além disso, os resultados deste teste dependem fortemente do tempo de realização.

De acordo com Vliet \& Lyklema (2005), os fluidos dependentes do tempo são bem definidos como:

- Tixotrópicos $\rightarrow$ a viscosidade diminui com o tempo de cisalhamento devido à ocorrência de mudanças reversíveis na miscroestrutura do fluido. $\mathrm{Na}$ ausência do cisalhamento, essa estrutura é reconstruída e o sistema tende a retomar sua viscosidade inicial, i.e., a quebra da estrutura é um processo reversível;

- Reopéticos $\rightarrow$ são caracterizados, principalmente, pelo aumento na viscosidade relacionado com o tempo de cisalhamento. Mas ao serem deixados em repouso, voltam a atingir baixos níveis de viscosidade; 


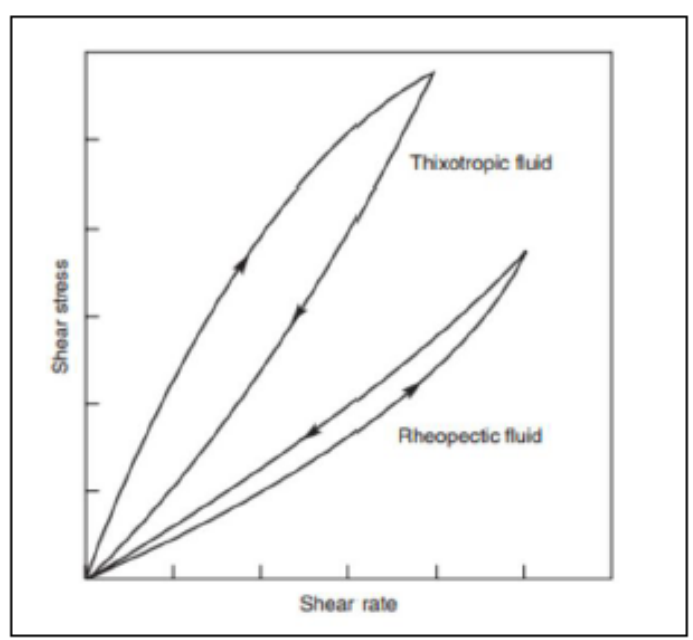

Figura 11: Flow curves para fluidos não newtonianos, tixotrópicos e reopéticos.

Fonte: (Chhabra, 2010)

Além disso, ainda existem os fluidos independentes do tempo. Esses fluidos são subdivididos em três categorias: pseudoplásticos, dilatantes e viscoplásticos (Tanner, 1988; Machado, 2002), representados na Fig. 12:

- Fluidos pseudoplásticos $\rightarrow$ são caracterizados pela diminuição da viscosidade aparente de acordo com o aumento da taxa de cisalhamento, comportamento conhecido como shear-thinning. De forma geral, tais fluidos começam a escoar sob tensões de cisalhamento infinitesimais, sem a presença de uma tensão residual.

- Fluidos dilatantes $\rightarrow$ são caracterizados pelo aumento da viscosidade de acordo com o aumento da taxa de cisalhameto, comportamento conhecido como shear thickening. A dilatação nos líquidos é considerada rara, segundo Machado (2002), podendo ser observada, principalmente, em suspensões altamente concentradas, constituídas de particulas irregulares e de difícil orientação.

- Fluidos viscoplásticos $\rightarrow$ se comportam como sólidos até que atinjam uma tensão mínima, conhecida como tensão limite de escoamento. A partir dessa tensão, o material escoa como um fluido Newtoniano ou não Newtoniano (pseudoplástico). Abaixo dessa tensão, o material é totalmente elástico e acima a estrutura do 
material quebra e flui. Esse parâmetro é muito importante em diversas indústrias, tais como de cosmético e de petróleo. No caso da indústria petrolífera, essa tensão determina a força que é necessária para o fluido começar a ser bombeado através de um oleoduto ou, então, para encher um tanque com o produto (Franck, 2004).

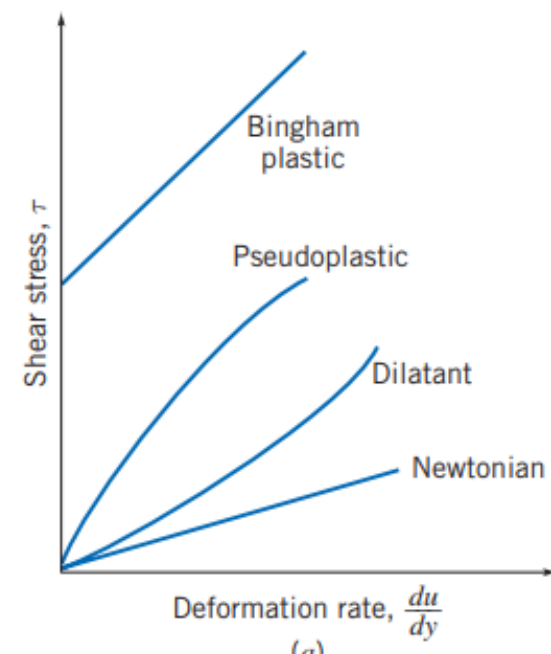

(a)

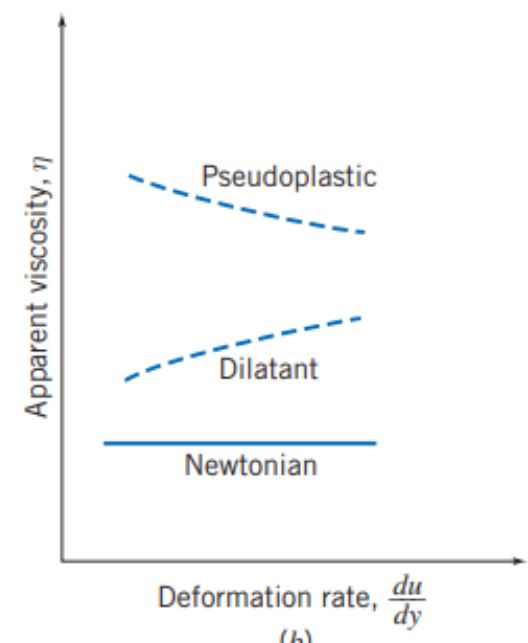

(b)

Figura 12. (a) Tensão de Cisalhamento, т, e (b) Viscosidade aparente, n, em função da taxa de cisalhamento para diferentes fluidos não newtonianos. Fonte: (Fox \& McDonald, 1998).

Por fim, existem materiais cujo comportamento é extremamente complexo, exibindo ao mesmo tempo características viscosas e elásticas. São chamados de viscoelásticos.

Uma das formas mais eficazes de caracterizar um fluido viscoelástico é através de testes oscilatórios, onde é medida a resposta mecânica do material através de um sinal senoidal de deformação ou tensão aplicado a partir do reômetro utilizado no teste.

Através de um sinal senoidal de deformação em um teste oscilatório, pode-se separar o sinal de saída em duas componentes, resposta líquida e outra resposta sólida. A segunda é descrita como sendo o módulo elástico ou de armazenamento $\left(G^{\prime}\right)$ e é a medida de elasticidade do material, apresentando a habilidade de armazenamento de energia. Já a componente líquida é caracterizada como sendo o módulo viscoso ou de 
perda $\left(G^{\prime \prime}\right)$. Tal componente representa a habilidade de dissipação de energia. Ambas componentes variam conforme a frequência préestabelecida no reômetro e a unidade de ambos os módulos é dada em Pascal [Pa] (Barnes, 2000).

\subsection{2.}

\section{Modelos reológicos para fluidos inelásticos}

De acordo com o comportamento do fluido em um escoamento de cisalhamento, diferentes expressões de função viscosidade foram elaborados através de experimentos empíricos para fluidos independentes do tempo. Um dos principais modelos é o de Herschel-Bulkley e é descrito a partir da seguinte equação (Barnes et al., 2000):

$$
\tau=\tau_{0}+k(\dot{\gamma})^{n}
$$

Onde:

$\tau$ é a tensão de cisalhamento

$\tau_{0}$ é a tensão limite de escoamento

$k$ é o índice de consistência

$\dot{\gamma}$ é a taxa de cisalhamento

n é o índice de potência power-law

Para este modelo, o fluido precisa ter uma tensão mínima, ou seja, uma tensão limite de escoamento. Abaixo da tensão limite o modelo prevê deformação nula. Nota-se que caso o valor de $\tau_{0}$ seja igual a zero e o valor de $\mathrm{n}$ igual a um, a equação se transforma na relação de viscosidade de Newton. $\mathrm{O}$ valor de $\mathrm{n}$ determina o tipo de comportamento reológico do modelo Herschel-Bulkley, se:

- $\mathrm{n}=0 \rightarrow$ o fluido é newtoniano;

- $\mathrm{n}>1 \rightarrow$ o fluido tem um comportamento dilatante; 
- $\mathrm{n}<1 \rightarrow$ o fluido tem um comportamento pseudoplástico;

- $\mathrm{n}=1$, recai-se no modelo de Bingham

Outro modelo bastante usado é o de Ostawald de Waele ou PowerLaw que pode ser descrito pela equação abaixo. $O$ índice de consistência funciona igualmente para este modelo, determinando o tipo de comportamento reológico do modelo.

$$
\tau=k(\dot{\gamma})^{n}
$$

$\tau$ é a tensão de cisalhamento

$k$ é o índice de consistência

$\dot{\gamma}$ é a taxa de cisalhamento

$n$ é o índice de potência power-law

\section{4.}

\section{Emulsões}

Dispersões são sistemas polifásicos, onde uma fase encontra-se dispersa em outra fase. As emulsões são dispersões coloidais, nas quais um líquido é disperso numa fase líquida de composição diferente. Existem vários tipos de dispersões tais como suspensões, emulsões e espumas. As emulsões são utilizadas em diversas indústrias diferentes, tais como indústria de papel, detergentes, cosméticos, farmacêutico e indústria de óleo e gás.

Um estudo detalhado das emulsões encontradas na indústria petrolífera é essencial para o controle e melhoria dos processos em cada etapa, a fim de evitar danos em linhas e equipamentos de produção, como por exemplo a formação de hidratos. A complexidade desses estudos se dá graças a composição do óleo, principalmente das moléculas tensoativas nele contidas.

A fase dispersa é conhecida como fase interna e a fase contínua como fase externa. A emulsão é uma dispersão termodinamicamente instável na qual dois líquidos que são imiscíveis ou parcialmente imiscíveis 
se misturam, geralmente óleo e água. A fase interna é composta por gotículas que se encontram dentro da fase externa (Aranberri et al., 2006). A Fig.13 mostra um exemplo de emulsão.

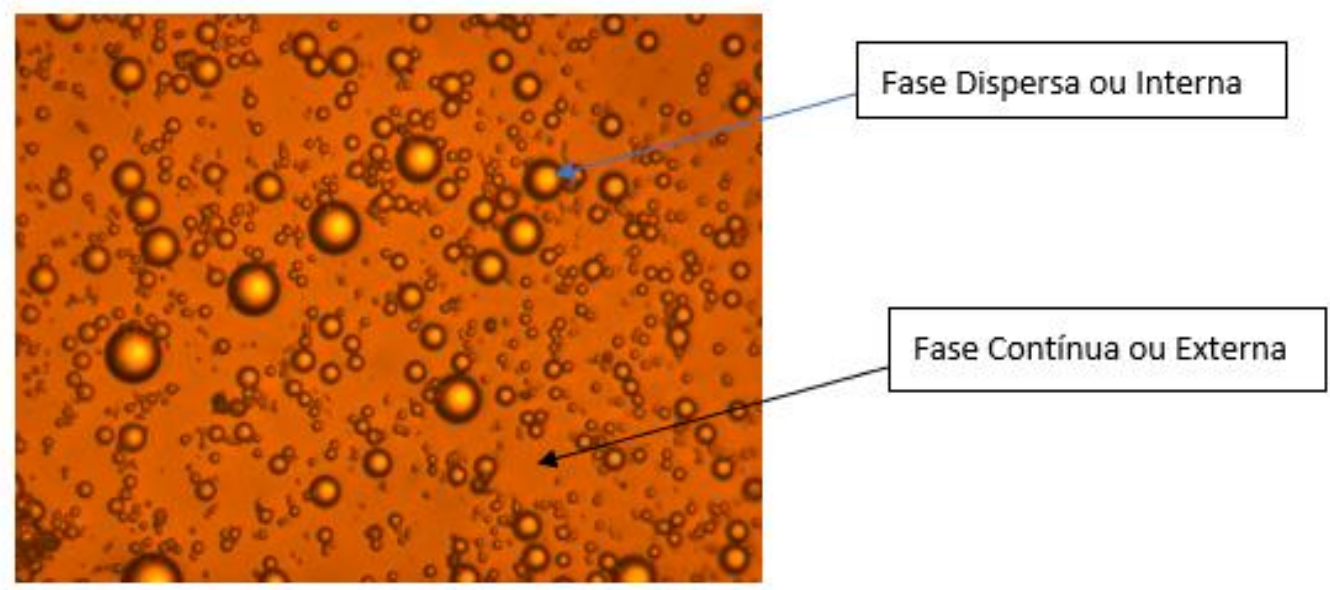

Figura 13 - Exemplo de emulsão e suas fases dispersa e contínua. Fonte: (Imagem cedida pela Dra Eliana Marin, laboratório GReo, Puc-Rio).

O diâmetro de gotas é muito importante para a caracterização da emulsão. Quando esse diâmetro é menor que 0,1 $\mu \mathrm{m}$, a dispersão é denominada micro emulsão. A utilização de tensoativos pode tornar as emulsões cineticamente estáveis e, consequentemente, retardando a separação das fases (Jacques, 1999). Para a formação da emulsão são necessárias três condições importantes:

- Imiscibilidade entre os diferentes líquidos da emulsão;

- Presença de agentes tensoativos para permitir a homogeneização;

- Agitação das fases para possibilitar a dispersão de um líquido em outro;

O agente tensoativo (ou surfactante) é um composto que altera as propriedades superficiais e interfaciais de um líquido. A estrutura química desses emulsificantes é composta por uma extremidade polar (solúvel em água) e outra parte apolar que não é solúvel em água (Mulligan, 2005). 
As emulsões variam sua composição em função da temperatura, pressão, tempo de formação, grau de agitação, dentre outros. Estas tendem a estabilizar devido à migração dos agentes tensoativos para a interface, formando um filme elástico e resistente. Essa característica se dá graças ao caráter anfifílico destes, ou seja, afinidade por ambos os componentes da emulsão (Mulligan, 2005).

As emulsões são classificadas de acordo com a natureza das fases dispersa e contínua do sistema. De acordo com Shcramm (2003), existem principalmente três tipos de emulsões:

- Óleo em água $(O / A)$ com gotas de óleo dispersas em água;

- Água em óleo $(A / O)$ com gotas de água dispersas em óleo;

- Múltiplas ou complexas (A/O/A) e (O/A/O);

De modo geral, as emulsões O/A apresentam textura cremosa, enquanto as emulsões $\mathrm{A} / \mathrm{O}$ são mais gordurosas. No caso das emulsões múltiplas, $\mathrm{O} / \mathrm{A} / \mathrm{O}$, por exemplo, apresentam gotas de óleo dispersas dentro de gotas de água, as quais estão dispersas em um meio contínuo oleoso. Embora mais raras, podem existir emulsões mais complexas, como do tipo A/O/A/O, como enumeradas por Schramm e Kutay (2000), A Fig.14 apresenta os diferentes tipos de emulsões, mostrando tanto a fase contínua, quanto a fase dispersa.
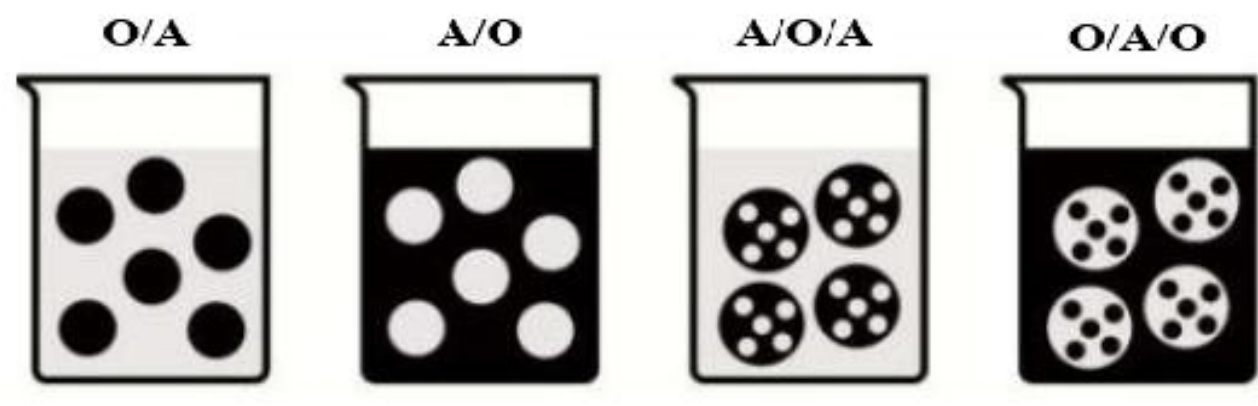

Figura 14. Diferentes tipos de emulsão. Fonte: (Adaptada de Melo, 2008). 
A aproximação das gotas pode manter a emulsão estável, a partir da geração de uma repulsão eletrostática, graças a presença de emulsificantes iônicos na interface. Por causa da baixa constante dielétrica do óleo, essas forças eletrostáticas não são tão expressivas na estabilização de emulsões A/O (Sullivan e Kilpatrick, 2002).

Outra forma de classificar as emulsões é através da concentração da fase dispersa. $O$ valor de empacotamento de esferas rígidas (com raios iguais), varia desde $64 \%$, chamado arranjo randômico, até $74 \%$, conhecido como arranjo hexagonal. Na prática, esse valor pode ser superado, pois as emulsões não têm uma distribuição uniforme dos raios das gotas, além do fato dessas gotas serem elásticas. A classificação segundo Tadros (2009) pode ser:

- Emulsões diluídas $\rightarrow$ a concentração da fase dispersa é menor que $0,1 \%$ volume/volume $(\mathrm{v} / \mathrm{v})$;

- Emulsões concentradas $\rightarrow$ a concentração da fase dispersa se encontra entre 0,1 e $74 \%$;

- Emulsões altamente concentradas $\rightarrow$ a concentração da fase dispersa é maior que $74 \% \mathrm{v} / \mathrm{v}$;

\subsection{1.}

\section{Tensão interfacial}

A tensão interfacial (ou superficial) pode ser definida como a força que contrabalanceia, na superfície do fluido, a força imposta em direção ao interior do líquido. Em outras palavras, as moléculas do fluido sofrem atração das moléculas vizinhas. As moléculas no interior do líquido são atraídas por todos os lados, sendo a resultante da soma vetorial das forças de atração nula. Mas na superfície ocorre um desbalanceamento e a força resultante perpendicular à interface e voltada para o interior do fluido, é denominada tensão interfacial (Dantin, 2011).

A tensão interfacial pode existir, também, entre dois líquidos imiscíveis. No caso de um campo de petróleo, essa tensão entre a água e o óleo é dependente da composição do óleo, da composição da rocha, da 
salinidade da água conata e de injeção. Esta tensão é a responsável pelo aprisionamento do óleo nos poros rochosos devido às forças capilares (Salas, 2014).

A tensão superficial da água é muito elevada, principalmente pelas pontes de hidrogênio intermoleculares que ajudam na formação de gotas, bolhas e meniscos. A Fig.15 ilustra como se comportam as moléculas no interior de um fluido e suas forças de atração. Os tensoativos são utilizados, principalmente, para reduzir a tensão interfacial, mesmo em baixas concentrações (Shaw, 1975).

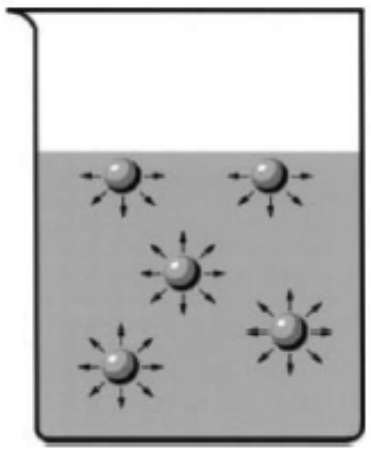

Figura 15. Forças atrativas entre as moléculas no interior de um fluido. Fonte: (Shcramm, 2006).

\subsection{1. \\ Surfactantes}

Os surfactantes (ou tensoativos) são compostos que modificam as propriedades físico-químicas das substâncias, através da diminuição da tensão superficial ou da influência na superfície de contato entre os dois fluidos em questão. Eles são muito utilizados na funcionalização de superfícies (Lima, 2013).

Podem ser classificados como emulsificantes, agentes espumantes, agentes molhantes, dispersantes e similares. Esses compostos orgânicos anfifílicos tem a capacidade de adsorver e se orientar espontaneamente nas interfaces, diminuindo, então, a energia de interação das duas fases. As principais características são:

- Baixa massa molar; 
- Constituído de duas partes: hidrofílica e hidrofóbica;

A parte polar (hidrofílica) é formada por átomos que gerem concentração de carga, resultando num polo que pode ser positivo ou negativo. A cabeça polar é responsável pela solubilidade em água, graças à atração eletrostática resultado das cargas elétricas. Os surfactantes iônicos são mais solúveis justamente por apresentares cargas (negativas ou positivas) (Daltin, 2011). A Fig.16 mostra o esquema de uma molécula de surfactante.

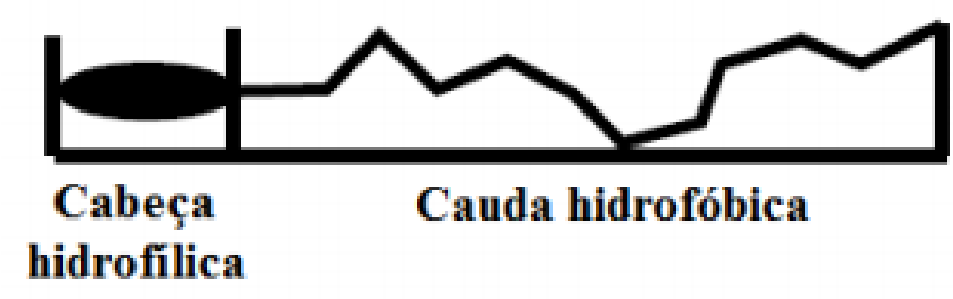

Figura 16. Molécula de surfactante - Cabeça polar e cauda apolar. Fonte: (Myers, 1999).

Já a porção apolar (hidrofóbica) é composto por uma cadeia de hidrocarbonetos com 12 átomos de carbono (linear, ramificada ou cíclica) que não forma polos de concentração eletrostática. A cauda é a parte hidrofóbica e torna possível a solubilidade em óleo (Dantin, 2011).

Em termos de classificação, esta é feita em função da natureza de sua cabeça polar, a qual interage com a água por interação iônica ou pontes de hidrogênio. Segundo Kronberg et al., (2014), são divididos em:

- lônicos Aniônicos $\rightarrow$ possuem carga negativa na região polar. Pode haver também a presença de átomos de oxigênio (com alta eletronegatividade) ou de sulfatos e fostatos.

- lônicos Catiônicos $\rightarrow$ possuem carga positiva na região polar. Em geral, são formados por cátions de um sal. São menos hidrofílicos que os aniônicos. 
- Não-iônicos $\rightarrow$ não há a presença de íons, mas existe uma parte polar capaz de interagir com a água através de pontes de hidrogênio. Os mais comuns são formados a partir de um poliéter ou polihidroxilo;

- Anfóteros (ou zwitteriônicos) $\rightarrow$ possuem tanto moléculas positivas quanto negativas em uma mesma molécula sob condições normais. Os aminoácidos e as betaínas são os principais representantes dessa classe;

Para garantir a estabilidade de uma emulsão é importante que seja adicionado, no mínimo, um tensoativo. Uma das funções importantes dos tensoativos é a determinação do tipo de emulsão a ser formada (por exemplo, A/O ou O/A). Também contribuem para a formação de gotas menores, o que aumenta a estabilidade (Schramm, 2000).

Uma forma mais eficiente de garantir emulsões estáveis é a utilização de uma mistura de tensoativos, adicionando um que tenha caráter mais hidrofílico junto a outro que apresente um caráter mais lipofílico.

Outra característica importante do tensoativo é a concentração micelar crítica $(\mathrm{CMC})$. Basicamente é a concentração a partir da qual ocorre a formação de micelas na emulsão. $\mathrm{O}$ valor de $\mathrm{CMC}$ indica a concentração a partir da qual a interface se torna saturada pelas moléculas de surfactante, i.e., quando o valor máximo de moléculas adsorvidas é atingido. A CMC pode ser reduzida com o aumento da temperatura, adição de sais e com o aumento da cadeia polar do surfactante (Santos et al., 2007).

No caso das emulsões usadas para a formação de hidratos, a quantidade de surfactante utilizado pode determinar a quantidade e o tempo de formação deles. Karanjkar et al., (2016) realizou testes com diferentes concentrações de surfactante (Span 80), conforme Fig.17.

$\mathrm{O}$ autor constatou que para concentrações menores de surfactante, a viscosidade aumenta indefinidamente, causando um bloqueio do fluxo no reômetro. Ainda hipotetizou que o surfactante disponível no óleo adsorve 
nos cristais de hidrato e previnem sua aglomeração e que, portanto, quanto maior a quantidade de excesso deste, menor a viscosidade de formação de hidrato (Karanjkar et al., 2016).

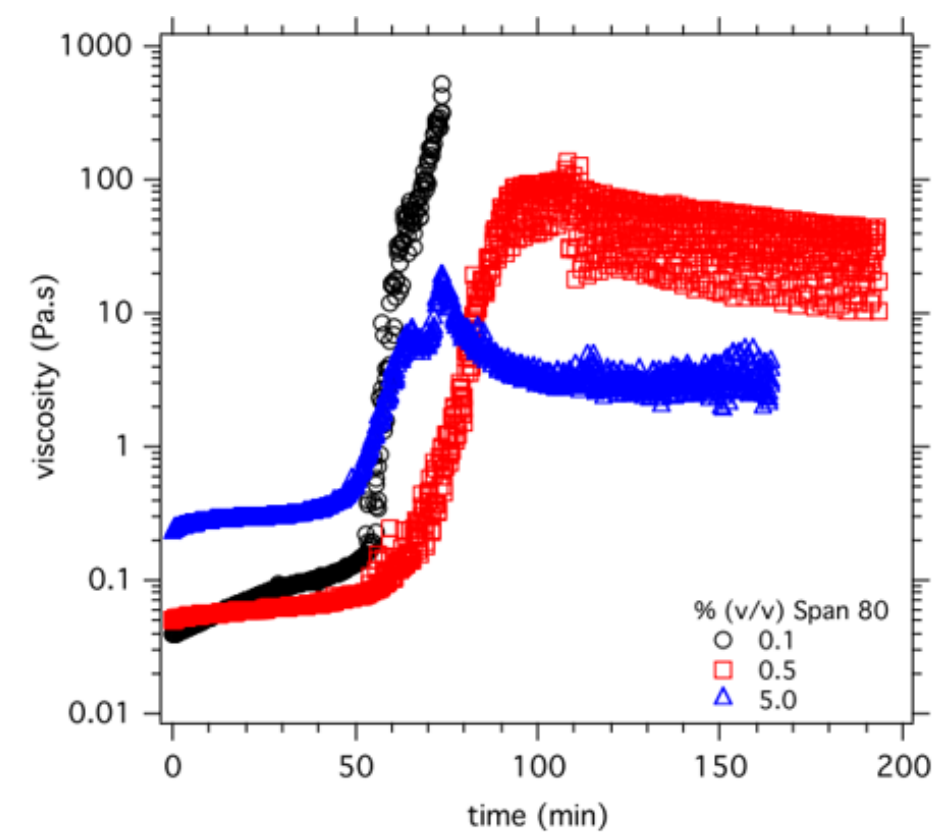

Figura 17. Efeito da concentração de Span 80 na formação de hidratos. Fonte: (Karanjkar et al., 2016).

\subsection{3.}

\section{Balanço hidrofílico-lipofílico (HLB)}

A escolha de diferentes surfactantes para a preparação de emulsões (tanto $\mathrm{A} / \mathrm{O}$, quanto $\mathrm{O} / \mathrm{A}$ ) é feita, geralmente, de forma empírica. Griffin (1949) desenvolveu uma escala semiempírica para selecionar esses tensoativos, denominada HLB. Esse número indica, de forma relativa, a tendência de solubilização em água ou óleo, consequentemente, a tendência a formar emulsões água-óleo ou óleo-água.

Essa escala empírica adimensional foi desenvolvida para caracterizar os surfactantes. A variação ocorre de acordo com o tipo de surfactante, conforme relatado por SCHRAMM (2000) e detalhado na Tabela 1. 
- HLB entre 0 e 20 são usados para surfactantes não iônicos e HLB maior que 20 para iônicos;

- HLB menor que 9 (considerado baixo) para surfactantes lipofílicos ou com alta solubilidade em óleo;

- HLB maior que 11 para surfactantes hidrofílicos ou com alta solubilidade em água;

De forma geral, o HLB representa um balanço entre as força dos grupos hidrofílicos/lipofílicos e o tamanho destes em uma molécula de tensoativo. Essa característica que é capaz de originar emulsões mais estáveis a partir da mistura de diferentes surfactantes, comparando com a utilização de somente um surfactante (Schramm, 2000).

Tabela 1. Aplicação de surfactante de acordo com a faixa de HLB (Adaptado de Griffin, 1949).

\begin{tabular}{cc}
\hline Faixa de HLB & Aplicação \\
\hline $4-6$ & Emulsificante de A/O \\
$7-9$ & Agentes de molhabilidade \\
$8-18$ & Emulsificante de O/A \\
$13-15$ & Detergentes \\
$15-18$ & Solubilizante \\
\hline
\end{tabular}

A forma principal de calcular a média do número de $\mathrm{HBL}$ é dada a partir da seguinte equação:

$$
\mathrm{HLB}=\mathrm{x}_{1}{ }^{*} \mathrm{HLB}_{1}+\mathrm{x}_{2}{ }^{*} \mathrm{HLB}_{2}
$$

Onde:

X1 e X2 são as frações mássicas de cada surfactante;

$\mathrm{HLB}_{1}$ e HLB são os Balanços Hidrofílico-Lipofílico de cada surfactante;

Por fim, Daltin (2011) pontuou a algumas limitações do conceito de HLB: 
- O sistema foi desenvolvido para ser utilizado a uma temperatura de $20^{\circ} \mathrm{C}$. Caso haja alterações significativas nessa temperatura, haverá uma alteração no HLB efetivo dos surfactantes iônicos e não-iônicos;

- Esse sistema foi todo elaborado empiricamente para sistemas de emulsões do tipo óleo em água;

- Não contabiliza a concentração total dos tensoativos na emulsão, portanto, caso sejam usadas altas concentrações, há a possibilidade de ocorrer alterações reológicas do sistema;

\subsection{4.}

\section{Estabilidade das emulsões}

Um fator muito importante quando se trata de emulsões é a estabilidade. Tal noção está relacionada diretamente com o tempo necessário para poder observar visualmente a separação de fases. Quanto maior a estabilidade das emulsões, mais tempo demora para acontecer tal separação. Algumas emulsões demoram apenas minutos para separar, enquanto outras podem demorar de meses ou até anos.

Um fenômeno considerável é a repulsão estérica que representa a resistência à adsorção de espécies nas interfaces das gotas e, também, as interações entre espécies adsorvidas em outras gotas. Isso acontece quando o material adsorvido se encontra energeticamente mais favorável a interagir com a fase contínua do que com o material adsorvido em outras gotas (Sullivan e Kilpatrick, 2002).

As principais espécies que são usadas para tal estabilização (estérica) são os tensoativos não iônicos, mas também são utilizados polímeros, como proteínas, álcool vinílico, amidos, ácido acrílico, polietilenoglicóis, entre outros. Segundo Daltin (2011), os tensoativos não iônicos por não possuírem carga e exibirem cadeias polares muito longas, fazem com que a emulsão se estabilize por impedimento estérico. Para que haja uma melhor estabilização, usam-se dois mecanismos em conjunto, eletrostático e estérico (Figura 18), usando tanto tensoativos aniônicos, quanto não iônicos. 


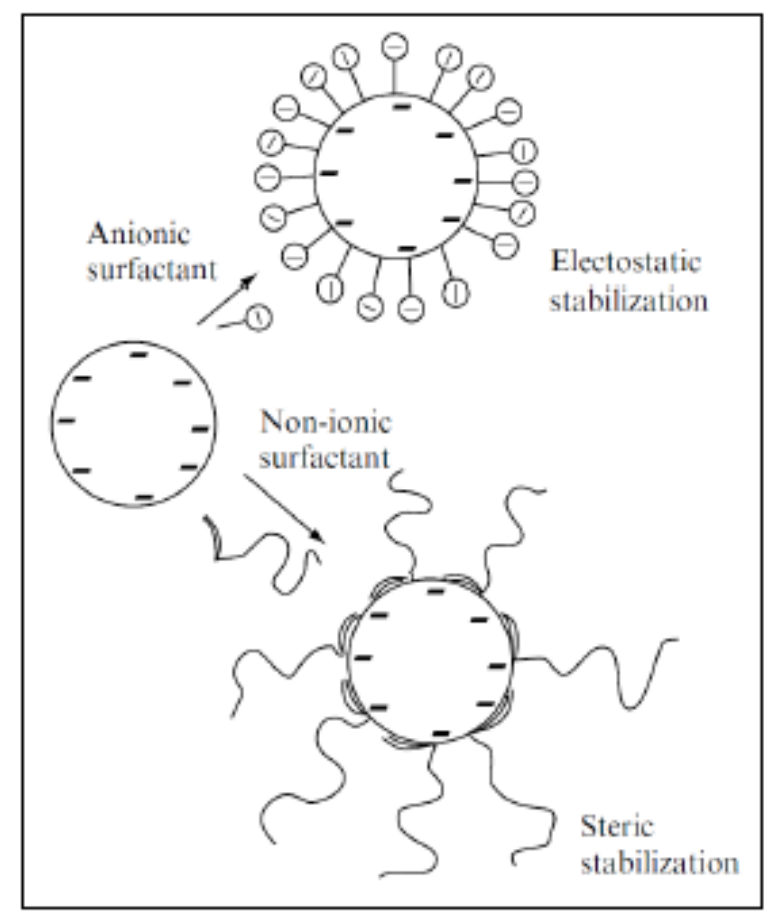

Figura 18. Estabilização eletrostática e estérica a partir da utilização de tensoativos. Fonte: (Holmberg et al., 2002).

Outro fator que interfere na estabilidade da emulsão é o Efeito GibbsMarangoni, que ocorre quando duas gotas que possuem moléculas adsorvidas com atividade interfacial se aproximam, gerando um gradiente de pressão que provoca, então, o alongamento dessas gotas. Esse fenômeno só é possível caso o equilíbrio na distribuição de tensoativos na interface seja restaurado, podendo demorar de segundos até horas. $\mathrm{Na}$ prática, esse efeito é um mecanismo de regeneração da interface das gotas contra sua coalescência, já que a sua interface se comporta de forma elástica (Coutinho, 2005; Lucassen-Reynders, 1996).

\section{5.}

\section{Efeito memória de hidratos}

Um dos efeitos bastante estudados na literatura é o de memória dos hidratos. A determinação desse fenômeno é muito importante para um melhor entendimento do processo de formação de hidratos, principalmente na avaliação e desenvolvimento de potenciais inibidores. 
Segundo Rodger (2000) o processo de nucleação ocorre muito mais lentamente na primeira vez em que a amostra é submetida ao processo de cisalhamento e, consequentemente, formação de hidratos. Acredita-se que isso acontece graças a uma ordenação residual após a amostra ser submetida à fusão.

Aglomerados metaestáveis de hidrato sobrevivem por até 24 horas e aceleram uma posterior nucleação, quando o estado termodinâmico é deslocado novamente para a região estável para a formação. Através de estudos experimentais, demonstrou-se a redução do tempo de indução em sistemas constituídos por água e metano que já haviam formado previamente hidratos (Rodger, 2000).

Ohmura et al (2003) buscou identificar e classificar a natureza estatística do processo de nucleação para, então, obter um melhor entendimento do efeito de memória. Foram utilizadas diversas amostras em tubos de ensaios contendo água (destilada e deionizada) e hidroclorofluorcarbono $\left(\mathrm{CH}_{3}-\mathrm{CCl}_{2} \mathrm{~F}\right)$. A partir da análise estatística dos dados obtidos, concluiu-se que a taxa de nucleação não é igual para as diversas amostras submetidas ao mesmo tratamento térmico, sugerindo, então, que cada teste tem o seu range de nucleação próprio, que é refletido por efeitos de memória de características distintas.

Entretanto, há estudos que contradizem a existência do efeito de memória. Wilson et al (2005), por exemplo, realizou experimentos com processos repetidos centenas de vezes para cada amostra, utilizando um equipamento especificamente projetado para isso e concluiu que não há qualquer tipo de efeito de memória e que a nucleação continua sendo um processo intrinsecamente aleatório e diretamente dependente do processo de subcooling.

Mesmo que haja alguns estudos contradizendo a existência do efeito, muitos outros reportaram algum tipo de efeito de memória com diferentes agentes formadores de hidrato. Porém, ainda não foi identificado o mecanismo exato de seu funcionamento. 


\section{6.}

\section{Efeito seeds}

O efeito de seeds é uma técnica muito utilizada para acelerar o processo de nucleação dos hidratos. Zylyftari et al. (2014) trabalharam com emulsões com a mesma densidade entra as fases, a fim de minimizar o efeito de sedimentação. $O$ procedimento se baseou no resfriamento da amostra, utilizando uma geometria couette, e na adição do seed a ser avaliado, com uma taxa de cisalhamento de $100 \mathrm{~s}^{-1}$.

O trabalho observou os diferentes comportamento: antes dos seeds serem utilizados, o sistema permaneceu estável por aproximadamente 17 horas. No momento em que foram adicionados cristais de gelo, houve uma queda imediata da viscosidade, seguido por um aumento abrupto, conforme Fig.19. A queda inicial da viscosidade é devido à quebra da floculação das gotículas de água, provocada pelos cristais de gelo que foram adicionados, segundo os autores. Já o incremento abrupto da viscosidade evidencia a formação de hidratos.

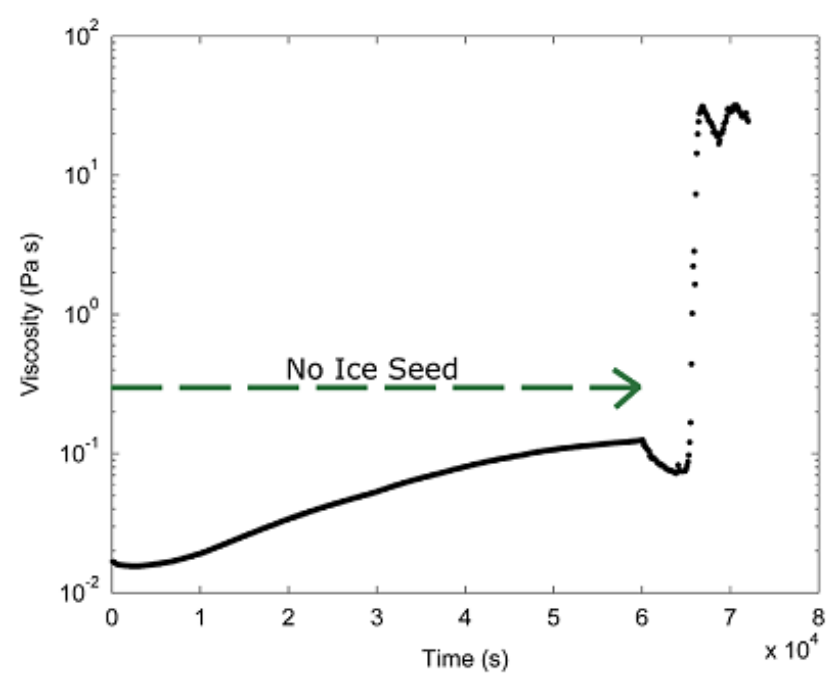

Figura 19 - Efeito da adição de seeds de gelo na formação de hidratos. Fonte: (Zylyftari et al., 2004).

Também se chegou à conclusão de que seeds de hidrato são mais eficientes na promoção da nucleação que seeds de gelo, pois o caso dos seeds de hidrato torna o tempo crítico menos estocástico. Por fim, os 
autores também compararam amostras que não utilizavam agente formador de hidrato. Nesse caso, não houve aumento abrupto da viscosidade, mas um crescimento gradual que foi atribuído à sedimentação de gotículas, floculação ou à formação de gelo.

\section{7.}

\section{Agente formadores de hidratos}

No presente trabalho os hidratos serão formados em situações controladas a partir de reômetros rotacionais, onde será feita a caracterização reológica. Os hidratos podem ser formados, laboratorialmente, tanto utilizando alta pressão, quanto utilizando temperatura ambiente. Quando utilizada pressão ambiente, se faz necessário o uso de agentes formadores como: tetrahidrofurano (THF) e ciclopentano (CP).

\subsection{1.}

\section{Reometria à alta pressão}

Uma das formas de análise e estudo de hidratos no interior de reômetros é através da formação do mesmo a partir da utilização de células de pressão, se aproximando das condições reais necessárias para formação do hidrato na produção de óleo e gás.

Sloan et al (2008), através da mistura de petróleo extraído na costa africana com água deionizada, produziu emulsões consideravelmente estáveis. A partir destas, adicionou gás metano e propôs três testes diferentes utilizando pressão e uma geometria de cilindros concêntricos. Esse trabalho identificou que todas as metodologias utilizadas indicavam claramente a formação de hidratos. A caracterização reológica foi feita a partir dos seguintes testes:

- Shear time sweep $\rightarrow$ Teste de varredura no tempo, utilizando tensão de cisalhamento constante. Esse teste foi usado para identificar a nucleação de hidrato ou qualquer outro tipo de alteração nas 
amostras utilizadas. Foi pontuado um aumento considerável na viscosidade e redução na pressão utilizada na célula, conforme ilustrado na Fig.20-a.

- Shear ramp $\rightarrow$ Aumento gradativo das taxas de cisalhamento, utilizando inicialmente taxas pequenas. O principal objetivo desse teste é a identificação do comportamento pseudoplástico e fazer uma estimativa da tensão limite de escoamento. Esse teste mostrou que o cisalhamento durante a formação de hidratos quebra os clusters, confirmado através da redução da tensão limite de escoamento;

- Time sweep oscilatório $\rightarrow$ Identificação de nucleação de hidrato ou qualquer outro tipo de alteração nas amostras utilizadas a partir de testes oscilatórios. A Fig.20-b apresenta a variação de G' e G" durante a formação do hidrato. Inicialmente, $G^{\prime}$ e $G^{\prime \prime}$ tem um aumento em seus valores iniciais para, então, $G^{\prime}$ chegar a sua estabilização e G" ter uma queda gradual. Esse comportamento elástico da curva indica que a amostra está se reorganizando ao longo do tempo.
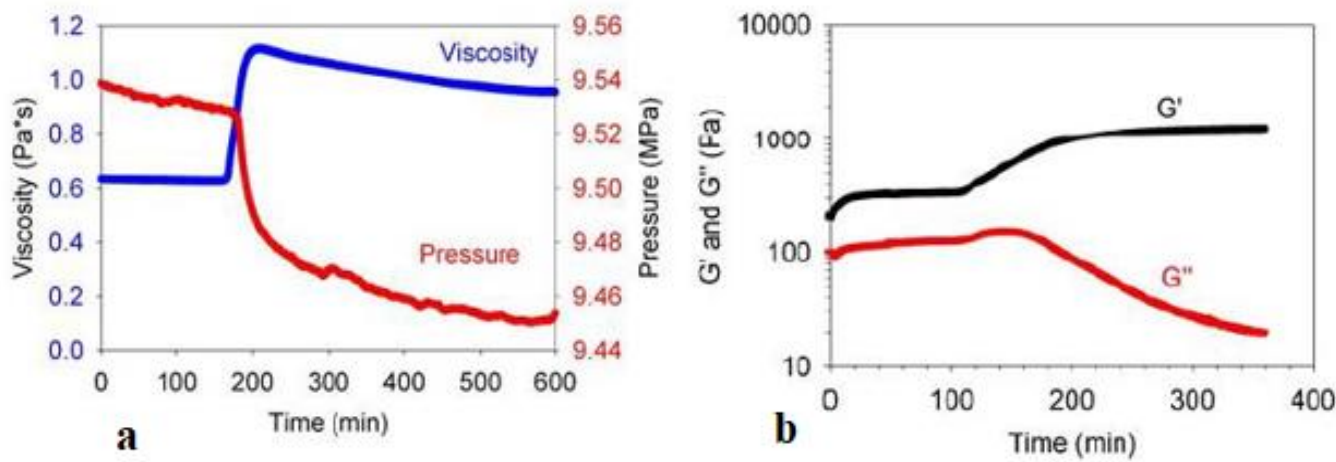

Figura 20. a. Efeito de hidrato de metano sob o efeito de cisalhamento constante. b. Comportamento elástico durante a formação do hidrato em teste oscilatório. Fonte:(Sloan et al., 2008)

Sandoval et al. (2018) também fez uma análise da formação de hidratos a partir da utilização de pressão e de dióxido carbono $\left(\mathrm{CO}_{2}\right)$ como molécula hospedeira, pois altas concentrações desse gás são reportados 
nos poços de óleo do pré-sal e tem grande potencial para formação de hidratos.

A Fig.21 ilustra o esquema utilizado no experimento com célula de pressão. Os testes foram conduzidos no reômetro Haake Mars 60, que permite uma grande faixa de velocidades rotacionais. $O$ procedimento utilizado no teste foi:

- O óleo foi levado a uma temperatura de $80^{\circ} \mathrm{C}$ por aproximadamente duas horas e depois levado à temperatura ambiente;

- Água deionizada foi adicionada ao óleo e misturada por aproximadamente 3 minutos, a 8000 rpm;

- A emulsão foi, então, pressurizada $\operatorname{com} \mathrm{CO}_{2}$, usando o sistema de alta pressão;

- A célula de pressão aqueceu a amostra até $80^{\circ} \mathrm{C}$ para saturar totalmente a fase óleo e mantida por aproximadamente 8 horas;

- Esfriamento da célula até $4^{\circ} \mathrm{C}$ (temperatura de trabalho do experimento);

- Os experimentos foram realizados a temperatura de $4^{\circ} \mathrm{C}$, pressão de $6 \mathrm{MPa}$ e velocidade angular constantes;

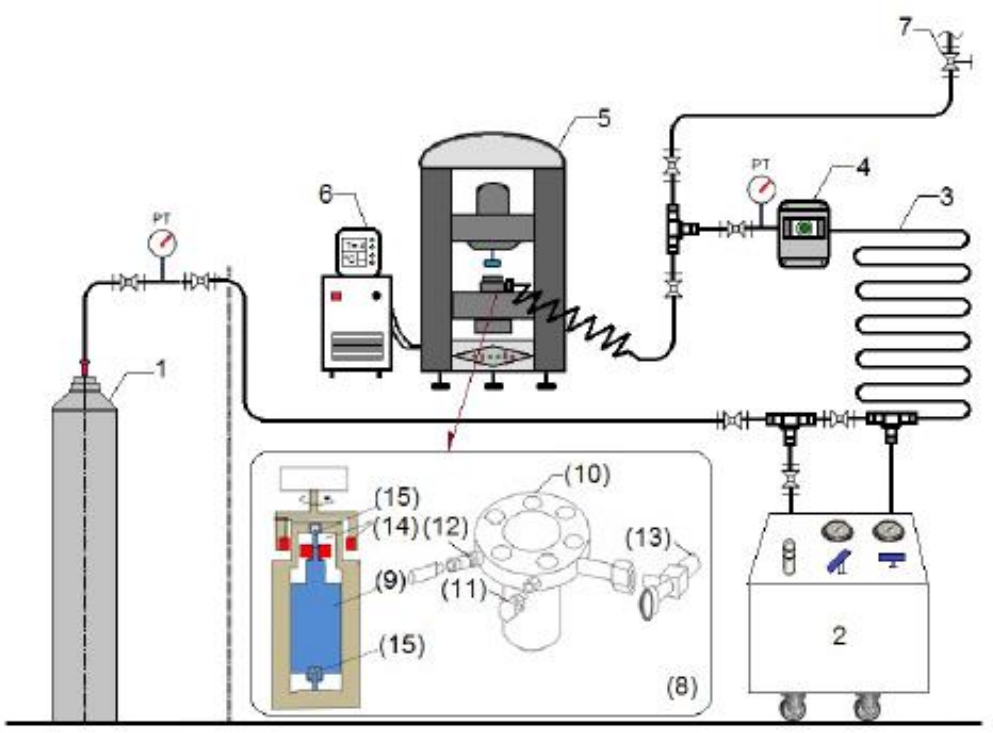

Figura 21. Esquema do sistema de alta pressão utilizado no experimento. Fonte: (Saldoval et al., 2018). 
Utilizando diferentes três diferentes amostras e taxa de cisalhamento constante, foi mostrado que o tempo de indução aumenta com a redução da taxa de cisalhamento. Os resultados indicaram que, para taxas de cisalhamento menores (100 s-1 , por exemplo), o tempo para formação de hidratos foi de até 2 horas mais demorado que para taxas de cisalhamento maiores $\left(200 \mathrm{~s}^{-1}\right)$, graças ao aumento da área de contato entre os dois fluidos (água e as gotas de $\mathrm{CO}_{2}$ líquido) (Sandoval et al., 2018)

Além disso, o trabalho mostrou a influência da pressão no momento exato da formação de hidratos. Quando a temperatura é reduzida a $4^{\circ} \mathrm{C}$, a válvula de pressão é fechada. Então, os hidratos começam a se formar a pressão de $6 \mathrm{MPa}$. Essa pressão, então, começa a cair abruptamente no início do processo de formação e tende a atingir uma assíntota depois de um longo período.

Já Webb et al. (2012), utilizou óleo morto da costa africana para medir as propriedades reológicas da suspensão de hidratos de metano. Um dos parâmetros analisados nos testes performados foi influência da variação da fração volumétrica de água nas emulsões. Quantitativamente, o experimento mostrou que, quanto maior for a fração volumétrica de água, maior o pico de viscosidade e maiores as flutuações.

Supõe-se que isso se deve, principalmente, pelo efeito do tamanho dos clusters formados, que podem crescer de tal forma a interferir na geometria, criando regiões de escorregamento e, portanto, interferindo na medição. Foram realizados testes variando a fração volumétrica de água de 0,20 até 0,45 .

Ainda para estimar a tensão limite de escoamento, o trabalho simulou um shut in de aproximadamente 8 horas, mantendo a suspensão de hidratos em repouso, de tal forma a atingir uma reorganização espontânea da estrutura. Foi observado que o comportamento da tensão limite é monotônico e que aumentou com o tempo decorrido, até atingir uma assíntota em torno do valor máximo (Webb et al., 2012). 


\subsection{2.}

\section{Reometria à baixa pressão}

\subsubsection{1.}

\section{Agente formador - THF}

O tetrahidrofurano (THF) é um éter de cadeia fechada, heterocíclico, cuja fórmula química é $\mathrm{C}_{4} \mathrm{H}_{8} \mathrm{O}$. Esse composto orgânico é totalmente solúvel em água, extremamente volátil e facilita a formação, principalmente, de hidratos de estrutura II.

O THF é sabidamente um agente formador de hidrato e muito usado no estudo em condições ambientes, já que a sua presença possibilita a formação mesmo em pressões atmosféricas. Um dos estudos realizados com THF foi feito por Sloan et al (2005) e usou uma mistura de $80 \%$ de água deionizada mais $20 \%$ de THF (em peso), resultando numa formação quase que imediata a temperaturas acima do ponto de congelamento da água, além da excelente reprodutibilidade dos testes, confirmando a validade da metodologia empregada.

Ohmura et al. (2003) também empregou o THF como formador de hidratos, a fim de estudar o efeito de memória dos hidratos, provando a natureza estocástica da nucleação em um sistema com histórico de formação/dissociação de hidratos.

Mais recentemente, de Lima et al. (2017), estudou a reologia de pastas de hidratos de THF. O trabalho focou em estudar 3 diferentes concentrações de THF: 30\%, 35\% e 40\%, misturados manualmente à água deionizada. Os testes foram realizados no reômetro Physica MCR01 (Anton Paar), com a geometria de cilindros concêntricos (Coette).

Como o processo de formação dos hidratos é exotérmico, pode ser observado que, durante sua formação, o sistema Peltier é incapaz de manter a temperatura de trabalho $\left(1^{\circ} \mathrm{C}\right)$ e quando um pico de temperatura é observado, indica o momento exato de formação dos hidratos. $O$ trabalho também explicitou que quanto maior a taxa de cisalhamento aplicada à amostra, menor o tempo de indução e, consequentemente, mais rápido se dá a formação de hidrato. 
Em termos de viscosidade, quando as diferentes amostras foram submetidas à mesma taxa de cisalhamento de $500 \mathrm{~s}^{-1}$, observou-se que quanto maior a concentração de THF na amostra, menor a viscosidade e menor a quantidade de hidrato formado (de Lima et al., 2017).

Yao et al (2007) investigou a reologia de uma suspensão de hidrato de THF em condensado de petróleo e chegou às seguintes conclusões:

- Para frações volumétricas de água de $10 \%$ e $20 \%$ é praticamente desprezível o efeito da suspensão de hidratos sobre a reologia da emulsão;

- Para frações volumétricas de 30\%, há um aumento na viscosidade da suspensão de hidratos, até que seja atingido o estado de regime permanente, onde todo THF é convertido em hidratos;

- Para suspensões com frações volumétricas superiores a $20 \%$, o comportamento pseudoplástico é observado;

\subsubsection{2.}

\section{Agente formador - Ciclopentano}

O ciclopentano $\left(\mathrm{C}_{5} \mathrm{H}_{10}\right)$ é um hidrocarboneto alicíclico extremamente volátil, solúvel em óleo, mas com baixa miscibilidade na água. É um agente formador de hidratos muito utilizado na literatura, pois não precisa ser submetido a altas pressões, e por formar hidratos de estrutura II, a qual é a mais encontrada nos campos de produção de óleo e gás.

A temperatura de dissociação foi determinada por Sloan et al (2008) como sendo em torno de $6^{\circ} \mathrm{C}$. Nakajima et al (2008) também chegou a esta conclusão e fez uma série de experimentos com diferentes amostras, as quais continham diferentes concentrações de ciclopentano, surfactante e água.

Os experimentos feitos utilizaram diferentes concentrações de ciclopentano, água e surfactante. A variação de ciclopentano foi de $17.4 \%$ até $18.6 \%$ (mássica), a de surfactante foi de $0 \%$ a $10 \%$. A formação de hidratos foi estimulada quando a temperatura atingiu $2^{\circ} \mathrm{C}$, a partir da adição de seeds de hidratos preparados previamente. Quando a cristalização 
começou a acontecer, as amostras foram aquecidas até $6^{\circ} \mathrm{C}$, temperatura essa em que a dissociação foi observada, conforme ilustrado na Fig. 22.

Nakajima et al (2008) constatou a partir de seus resultados que quanto maior a concentração de surfactante, maior é o tempo para dissociar os clusters de hidratos a temperatura de $6^{\circ} \mathrm{C}$.

Outro estudo importante foi o de Peixinho et al (2010), que estudou suspensões de hidrato de ciclopentano. Todos os experimentos foram conduzidos a temperaturas de $-10^{\circ} \mathrm{C}$ a $25^{\circ} \mathrm{C}$. A pesquisa utilizou duas diferentes amostras: uma sem ciclopentano, outra com ciclopentano (representando $50 \%$ da fase óleo), em excesso.

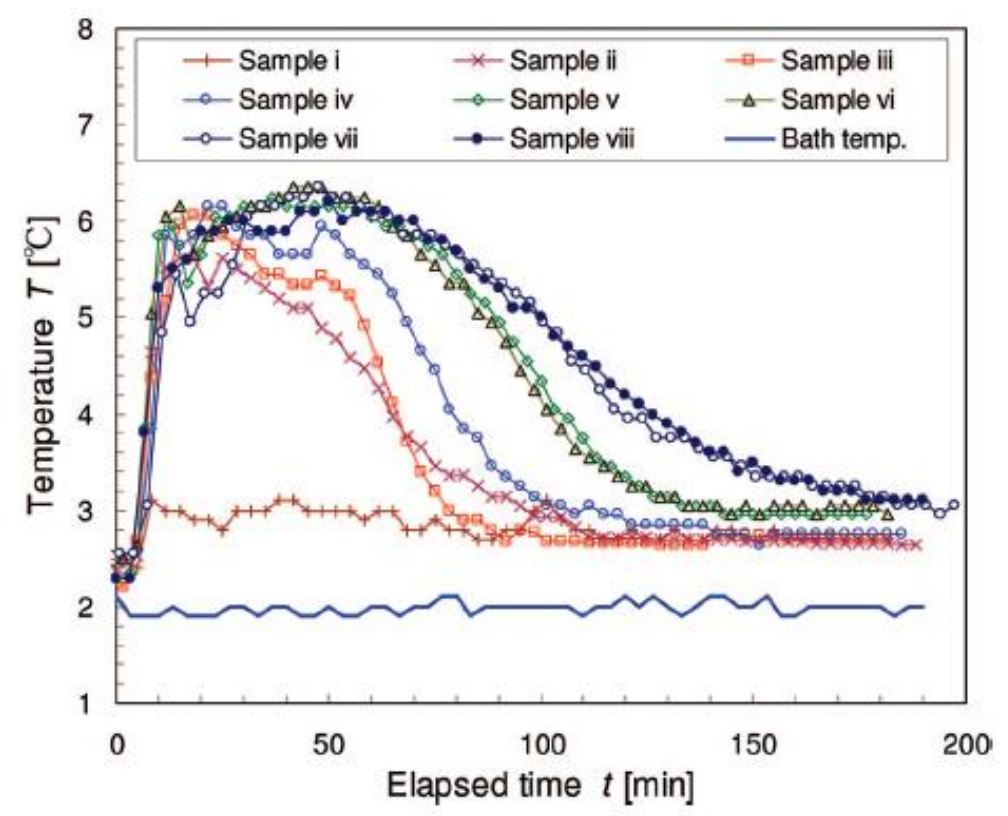

Figura 22. Histórico de temperatura nos experimentos de formação de hidratos. Fontes: (Nakajima et al., 2008).

Todas as emulsões preparadas mostraram comportamento pseudoplástico. De acordo com seus resultado, as amostras que não utilizaram CP demoraram muito mais para que a viscosidade tivesse um aumento considerável, a temperaturas negativas. Já as amostras com CP tiveram esse tempo reduzido em aproximadamente $94 \%$, mostrando a efetividade do agente formador utilizado.

Também foram realizados testes oscilatórios para avaliar a variação do módulo elástico $\left(G^{\prime}\right)$. O teste começou com temperatura negativa de 
aproximadamente $-9^{\circ} \mathrm{C}$, posteriormente aquecido a $1^{\circ} \mathrm{C}$, para que o gelo formado fosse derretido e, então, a amostra continuou a ser aquecida até $20^{\circ} \mathrm{C}$. Houve um aumento considerável do módulo elástico até que a temperatura atingisse valores positivos $\left(1^{\circ} \mathrm{C}\right)$. Quando a temperatura de trabalho atingiu $5^{\circ} \mathrm{C}$, esta foi mantida constante pelo resto do teste e, então, pode-se observar que o módulo elástico atingiu valores muitos baixos, correspondendo à desestabilização da emulsão e a dissociação dos aglomerados de hidrato.

Ahuja et al (2014) utilizou amostras variando a fração volumétrica de água e ciclopentano ( $50 \%$ da fase óleo). Uma das principais conclusões do trabalho é que quanto maior a concentração de água na emulsão, maior a quantidade de hidratos formados $\mathrm{e}$, consequentemente, maior a viscosidade. Para frações volumétricas abaixo de $18 \%$ de água, não foi observada formação de hidrato, como visto na Fig.23.

Também foram feitos testes para comparar a utilização de dois diferentes tipos de geometria: lisa e rugosa. A geometria lisa mostrou um tempo de crescimento muito maior que a geometria rugosa, atingindo o regime permanente quase 2 horas depois. Essa diferença pode ser atribuída aos efeitos de deslizamento na parede da geometria, sendo na lisa muito mais significativos.

Karanjkar (2016) também utilizou ciclopentano como agente formador de hidratos. Um dos testes realizados foi o de variação na temperatura de sub-cooling. Basicamente, o experimento compara a formação de hidrato a partir da temperatura inicial do teste (temperaturas negativas). As temperaturas utilizadas foram: $-2^{\circ} \mathrm{C}$, $4^{\circ} \mathrm{C},-6^{\circ} \mathrm{C}$ e $-8^{\circ} \mathrm{C}$; em todos os casos a taxa de cisalhamento aplicada foi de $10 \mathrm{~s}^{-1}$.

Quanto menor a temperatura $\left(-8^{\circ} \mathrm{C}\right.$, por exemplo), menor o tempo de indução e mais rápida a formação do hidrato. Em contrapartida, a temperaturas mais altas $\left(-2^{\circ} \mathrm{C}\right.$, por exemplo) a tendência é que haja um tempo maior de indução e, consequentemente, a formação de hidrato é mais demorada (Karanjkar et al, 2016). 
Majid et al (2019) propôs um experimento com a utilização de ciclopentano, mas com um sistema não emulsificado, além de utilizar uma geometria transparente, para permitir a visualização do momento em que os hidratos são formados. Também foram conduzidos testes com um sistema emulsificado, para efeito de comparação.

Todos os testes começaram com temperatura de $-1^{\circ} \mathrm{C}$ e adição de pequenos seeds de cristais de hidrato, a fim de acelerar a nucleação. A taxa de cisalhamento foi constante e de $1000 \mathrm{~s}^{-1}$ durante todo o teste. Quando começou a formar hidrato, a amostra foi aquecida até $1^{\circ} \mathrm{C}$ e, então, a viscosidade começou a ser medida.

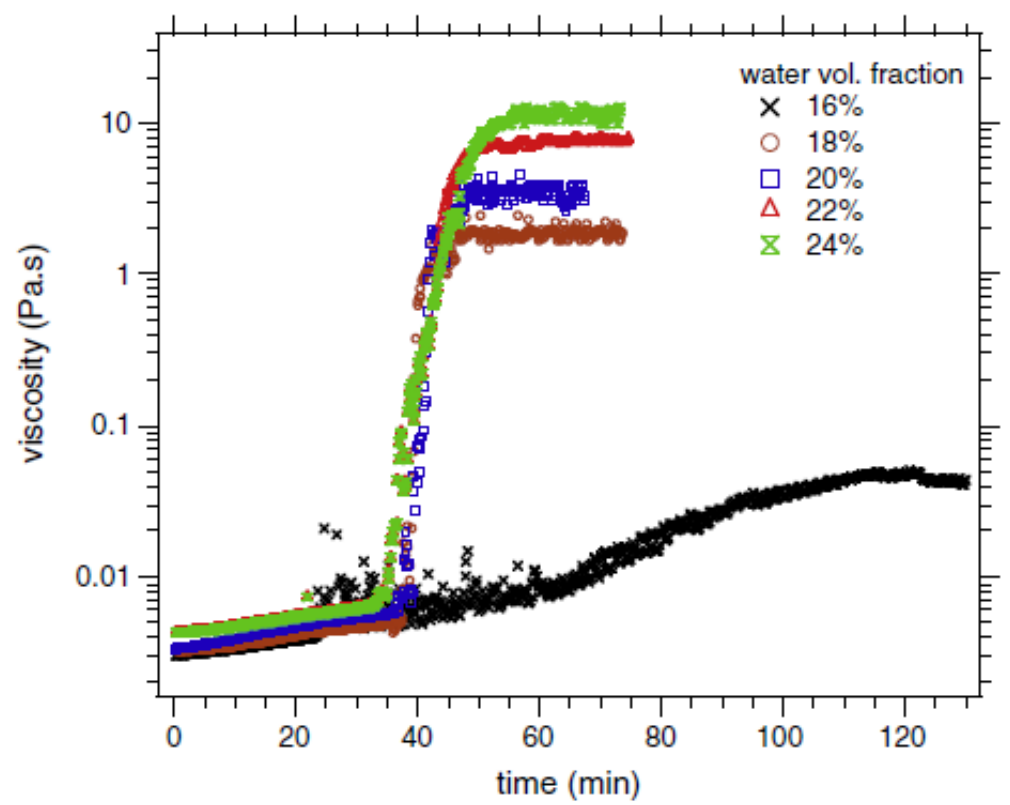

Figura 23. Evolução da viscosidade vs tempo para emulsões com diferentes frações volumétricas. Fonte: (Ahuja et al., 2014).

As Fig.24 e Fig.25 mostram o perfil de viscosidade para o sistema não emulsificado e as imagens capturadas em cada etapa apontada no gráfico. A etapa 1 é referente ao momento de aquecimento da amostra (de $-1^{\circ} \mathrm{C}$ para $1^{\circ} \mathrm{C}$ ). A etapa 2 mostra o aumento inicial da viscosidade e consequente aglomeração de hidratos. 


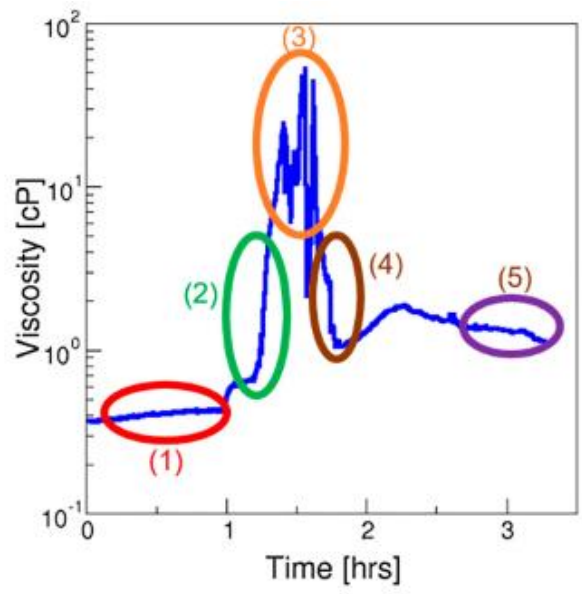

Figura 24. Viscosidade vs tempo para sistema não emulsificado. Fonte: (Majid et al., 2019).

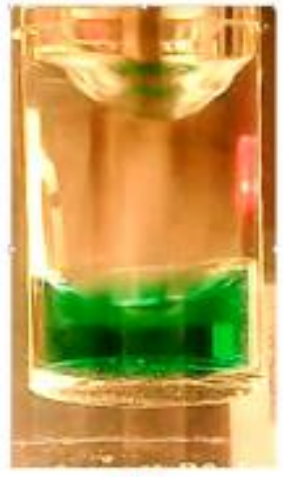

(a)

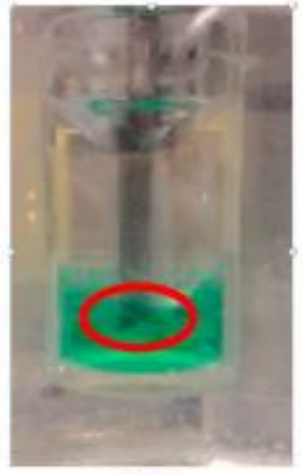

(b)

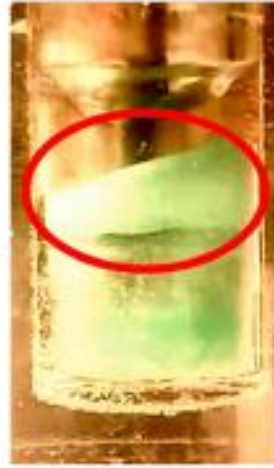

(c)

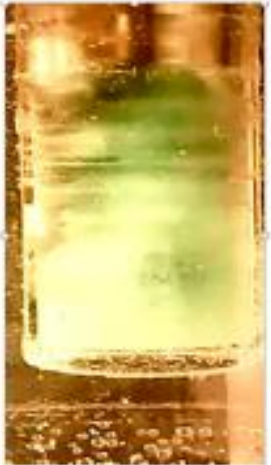

(d)

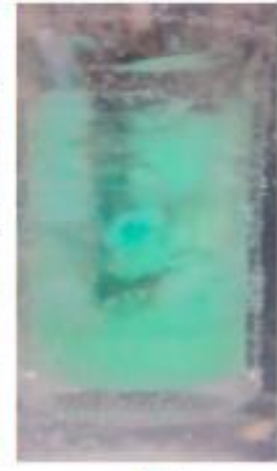

(e)

Figura 25. Visualização da amostra durante o teste do sistema não emulsificado. Fonte: (Majid et al., 2019)

A etapa 3 é quando o hidrato começa a aderir na parede da geometria, por isso existe uma maior oscilação da viscosidade. Na etapa 4 , o hidrato formado e aderido à parede começa a se desprender, principalmente graças ao efeito do cisalhamento. A etapa 5 é referente ao momento em que a amostra atinge o regime permanente.

Além do teste com o sistema não emulsificado, foi utilizado um sistema emulsificado (também usando ciclopentano). Comparando com o não emulsificado, o tempo de indução foi maior, ou seja, demorou mais para que o hidrato fosse formado. Mas quando comparado o valor final da viscosidade, o sistema que usou emulsão teve um valor consideravelmente maior ao atingir o regime permanente. 
Um ponto importante a ser notado é que o sistema emulsificado não apresentou flutuações. Com a visualização do teste, pôde-se concluir que isso se dá ao fato de que houve uma distribuição mais homogênea e mais dispersa das partículas de hidrato, com um crescimento mínimo na parede da geometria. 


\section{3 \\ Materiais e Métodos}

Nesse capítulo são descritos os materiais, os equipamentos e a metodologia utilizados para a fabricação das emulsões e para a realização dos testes reológicos e medições destas.

\section{1.}

\section{Materiais}

Nos experimentos foram utilizadas emulsões de água em óleo (A/O) e estas foram avaliadas quanto à reologia. As emulsões são compostas basicamente de duas fases, a fase aquosa e a fase oleosa. Para a fase oleosa foram testados dois diferentes tipos de óleos: O óleo mineral (vaselina branca) e o óleo Primol. Para fazer a mistura de ambas as fases, foram testados dois diferentes tipos de surfactantes: o Arquade®2HT-75 e o Span80.

\subsection{1.}

\section{Fase Oleosa}

\subsubsection{1.}

\section{Óleo Mineral (Vaselina Branca)}

Trata-se de um líquido oleoso, incolor e transparente, inodoro e produzido pela UNIÃO QUÍMICA FARMACÊUTICA NACIONAL S/A.

Tabela 2 - Propriedades da Vaselina Branca a $25^{\circ} \mathrm{C}$.

\begin{tabular}{|c|c|}
\hline \multicolumn{2}{|c|}{ Óleo Mineral a $2^{\circ} \mathrm{C}$ - Vaselina Branca } \\
\hline Propriedade & Valor \\
\hline Tensão Superficial $[\mathrm{mN} / \mathrm{m}]$ & 28,4 \\
Densidade $[\mathrm{Kg} / \mathrm{m} 3]$ & 867,6 \\
Viscosidade $[\mathrm{Pa} . \mathrm{s}]$ & 0,1339 \\
\hline
\end{tabular}


3.1.1.2.

Óleo Primol 352

Trata-se de uma mistura purificada de hidrocarbonetos saturados líquidos. É incolor, transparente e essencialmente inodoro. Este é obtido a partir do petróleo através de inúmeros estágios de refino, incluindo, por último, uma purificação por hidrogenação catalítica. O óleo é produzido pela ExxonMobil.

Tabela 3 - Propriedades e Especificações do Primol 352. (ExxonMobil)

\begin{tabular}{|c|c|c|}
\hline \multicolumn{2}{|c|}{ Primol 352 } \\
\hline Propriedade & Método & Valor (Mín-Máx) \\
\hline $\begin{array}{c}\text { Densidade }[\mathrm{Kg} / \mathrm{m} 3] \text { a } 15^{\circ} \mathrm{C} \\
\text { Viscosidade Cinemática }[\mathrm{mm} / \mathrm{s}]\end{array}$ & a \\
$40^{\circ} \mathrm{C}$ & ASTM D4052 & $863-873$ \\
$\begin{array}{c}\text { Peso Molecular Médio [g/mol] } \\
\text { Densidade Relativa a } 25^{\circ} \mathrm{C}\end{array}$ & ASTM D2502 & $65-75$ \\
$\begin{array}{c}\text { Carbonos Parafínicios [\%] } \\
\text { Carbonos Naftênicos }[\%]\end{array}$ & AM-S-1805 & 480 \\
$\begin{array}{c}\text { Carbonos Aromáticos [\%] } \\
\text { Viscosidade Dinâmica [mPa.s] a } \\
20^{\circ} \mathrm{C}\end{array}$ & AM-S-1805 & $0,861-0,872$ \\
\hline
\end{tabular}

3.1.2.

Fase Aquosa

A fase aquosa é composta por água que foi coletada a partir de um deionizador, o qual apresenta uma condutividade elétrica menor que 1,17 $\mu \mathrm{S} / \mathrm{cm}$. 


\subsection{3.}

\section{Surfactantes}

\subsubsection{1.}

\section{ARQUAD® 2HT-75}

O ARQUAD® 2HT-75 é um surfactante insolúvel em água, mas solúvel em álcoois. É estável, antiestático e bactericida, além de ser compatível com surfactantes não iônicos.

$$
\begin{array}{rr}
\mathrm{CH}_{2}\left(\mathrm{CH}_{2}\right)_{16} \mathrm{CH}_{3} \\
\mathrm{CH}_{3}-\mathrm{N}^{+}-\mathrm{CH}_{3} \quad \mathrm{Cl}^{-} \\
\mathrm{CH}_{2}\left(\mathrm{CH}_{2}\right)_{16} \mathrm{CH}_{3}
\end{array}
$$

Figura 26 - Estrutura Molecular do ARQUAD 2HT-75.

Tabela 4 - Propriedades físico-químicas do ARQUAD® 2HT-75 (Sigma-Aldrich,2015b).

\begin{tabular}{|c|c|}
\hline \multicolumn{2}{|c|}{ ARQUAD $\Theta 2$ 2HT-75 } \\
\hline Propriedade & Valor \\
\hline Aparência (Forma) & Pastosa \\
Ponto de Fulgor $\left[{ }^{\circ} \mathrm{C}\right]$ & 25 \\
$\mathrm{pH}$ & entre 5 e 9 \\
Temperatura de ignição $\left[{ }^{\circ} \mathrm{C}\right]$ & $>100$ \\
HLB (Escala Davies) & 13 \\
Ponto de Fusão $\left[{ }^{\circ} \mathrm{C}\right]$ & $30-35$ \\
Ponto de Ebulição $\left[{ }^{\circ} \mathrm{C}\right]$ & 80 \\
Pressão de Vapor [mPa.s] a $50^{\circ} \mathrm{C}$ & 170 \\
Densidade $\left[\mathrm{Kg} / \mathrm{m3}\right.$ ] a $60^{\circ} \mathrm{C}$ & 850 \\
Solubilidade em água & Dispersível \\
Viscosidade dinâmica $[\mathrm{mPa} . \mathrm{s}] \mathrm{a}$ & 70 \\
$60^{\circ} \mathrm{C}$ & \\
\hline
\end{tabular}

\subsubsection{2.}

Monooleato de Sorbitano (Span80)

O Monooleato de Sorbitano é um tensoativo não iônico, com fórmula empírica $\mathrm{C}_{24} \mathrm{H}_{44} \mathrm{O}_{6}$. Trata-se de um surfactante solúvel em óleo (lipofílico), de cor amarelada e comumente utilizada para a formação de emulsões 
A/O. Comercialmente é referido como Span 80 e foi adquirido na Sigma Aldrich.

Apresenta um balanço hidrofílico lipofílico (HLB) de 4,3, com densidade igual a $0,986 \mathrm{~g} / \mathrm{cm}^{3}\left(\right.$ a $\left.25^{\circ} \mathrm{C}\right)$.

Tabela 5 - Propriedades do Monooleato de Sorbitano (Sigma-Aldrich,2015b).

\begin{tabular}{|c|c|}
\hline \multicolumn{2}{|c|}{ Span } \\
\hline Propriedade & Valor \\
\hline HLB & 4,3 \\
Densidade $[\mathrm{g} / \mathrm{cm} 3]$ a $25^{\circ} \mathrm{C}$ & 0,986 \\
Massa Molecular [g/mol] & 428,62 \\
Viscosidade $[\mathrm{mPa} . \mathrm{s}]$ a $20^{\circ} \mathrm{C}$ & $1000-2000$ \\
\hline
\end{tabular}

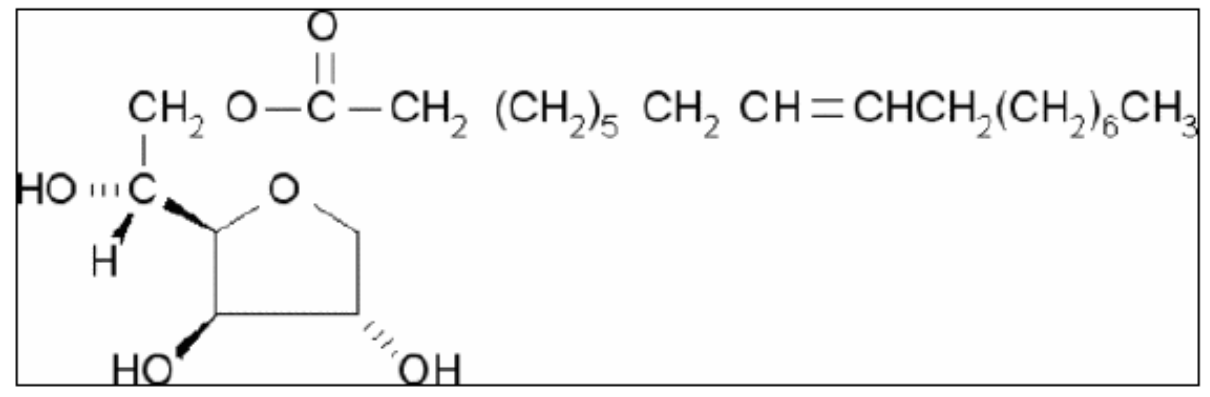

Figura 27 - Estrutura Molecular do Monooleato de Sorbitano - Span 80.

\subsection{4. \\ Ciclopentano}

O ciclopentano $\left(\mathrm{C}_{5} \mathrm{H}_{10}\right)$ é um hidrocarboneto alicíclico extremamente volátil, solúvel em óleo, em solventes orgânicos, álcool e éter, mas com baixa miscibilidade na água. Tanto a forma líquida, quanto a vapor são facilmente inflamáveis e, portanto, é necessário que seu recipiente seja mantido em um local fresco, longe de qualquer fonte de ignição. Foi obtido pela Sigma-Aldrich com $98 \%$ de pureza e, neste trabalho, será citado como CP. 


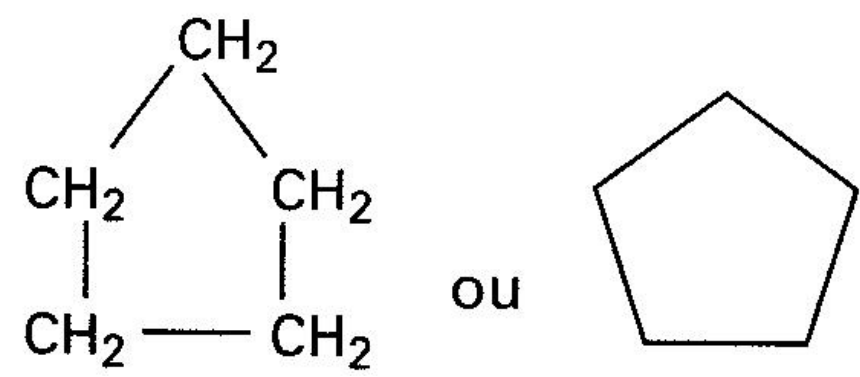

Figura 28 - Estrutura molecular do Ciclopentano.

Tabela 6 - Propriedades do Ciclopentano (Sigma-Aldrich, 2015c).

\begin{tabular}{|c|c|}
\hline \multicolumn{2}{|c|}{ Ciclopentano } \\
\hline Propriedade & Valor \\
\hline Densidade $[\mathrm{g} / \mathrm{cm} 3]$ a $25^{\circ} \mathrm{C}$ & 0,751 \\
Ponto de Ebulição $\left[{ }^{\circ} \mathrm{C}\right]$ & 50 \\
Massa Molecular $[\mathrm{g} / \mathrm{mol}]$ & 70,13 \\
Viscosidade $[\mathrm{mPa} . \mathrm{s}]$ a $20^{\circ} \mathrm{C}$ & 0,44 \\
\hline
\end{tabular}

\section{2.}

\section{Equipamentos e Acessórios}

Para que os trabalhos descritos nessa dissertação fossem executados, foram utilizados os seguintes equipamentos:

- Agitador magnético com placa de aquecimento - FISATOM, modelo 754A;

- Balança FA2104N - Bioprecisa - GEHAKA (balança analítica com 4 casas decimais de precisão);

- Balança BG4400 - GEHAKA (semi-analítica, com duas casas decimais de precisão);

- Ultra - Turrax® - IKA Modelo T25;

- Béquer de 25, 50, 100, 250 e 500 mL;

- Frasco de Vidro de 100 e $250 \mathrm{~mL}$;

- Pipetas Pasteur;

- Bastão de vidro; 
- Vidro de relógio;

- Reômetro Physica MCR301, Anton Paar;

- Geometria Couette CC27 12013;

- Microscópio óptico Nikon, Eclipse LV100N POL;

- Lâminas para microscopia.

3.3.

Métodos

\subsection{1.}

\section{Adição do ciclopentano à emulsão}

A adição do CP à emulsão é uma das etapas mais importantes da preparação desta. As primeiras tentativas foram adicionando o CP antes de fazer uma pré mistura das fases oleosa e aquosa no Turrax. Esse método se mostrou ineficaz, principalmente, graças ao aquecimento da amostra acima da temperatura de ebulição do $\mathrm{CP}$, aumentando, então, a perda por evaporação deste.

Stender (2015) confirma que a adição do CP antes de homogeneizar as fases oleosa e aquosa traz uma desvantagem com a perda de parte do componente devido à temperatura de mistura.

Outro fator importante é a quantidade de CP a ser utilizada na emulsão. Para que haja conversão completa de hidrato, há a necessidade de obedecer a razão estequiométrica entre o CP e a água, de 1:17 (Lo et al.,2004). As primeiras emulsões produzidas obedeceram a essa razão molar, mas a fim de obter um resultado com maior acurácia, passou-se a produzir emulsões com o triplo desta proporção, para minimizar a influência da perda durante o processo de mistura.

Com a finalidade de estabelecer a quantidade exata para essa proporção, após um dia da emulsão ter ficado pronta, calculou-se a quantidade da fase aquosa (em massa). Conhecendo as massas molares da água e do CP e suas respectivas densidades, foi possível calcular a quantidade necessária de $\mathrm{CP}$ a ser adicionada. 


\subsection{2.}

\section{Preparo das emulsões}

O preparo das emulsões foram evoluindo conforme verificações de suas estabilidades. A princípio, foi utilizado como óleo mineral a vaselina e como surfactante o $A R Q U A D \AA$, mas essa composição não atingiu a estabilidade desejada. Por isso, houve uma alteração para o Primol 352 e Span 80.

Um dos principais desafios, no tocante ao preparo das emulsões, é o preparo de emulsões estáveis e idênticas. Para avaliar a estabilidade dessas emulsões, foi necessário fazer uma avaliação visual da separação de fases e o tempo que levou para que elas se separassem. De modo geral, após as mudanças iniciais, foi atingido um grau de estabilidade satisfatório. Essas comparações e resultados serão discutidos no próximo capítulo.

As emulsões foram preparadas seguindo os seguintes passos:

- Todos os componentes foram devidamente pesados, utilizando as balanças FA2104N e BG4400, conforme as Tabela 7 e 8, distinguindo o tensoativo e suas porcentagens, além das porcentagens (em peso) do CP. Tanto a fase aquosa, quando a fase oleosa foram pesadas utilizando-se um Becker de $100 \mathrm{~mL}$ e os tensoativos no vidro de relógio na balança FA2104N;

- Após a pesagem, foi adicionado em um Becker de $100 \mathrm{~mL}$ primeiramente o surfactante e o óleo. Depois de adicionados ao mesmo recipiente, uma nova pesagem foi feita para conferir se não havia perdas no processo. Uma mistura inicial com o bastão de vidro foi feita;

- $\quad$ Após a mistura inicial, foi feita uma nova homogeneização entre o tensoativo e o Primol no agitador magnético com uma velocidade de 1000 rpm por 5 minutos;

- A água deionizada foi, então, adicionada ao recipiente e feita uma nova pesagem, para garantir que não houve perdas no processo. 
- $\quad$ Após a pesagem final, o dispersor de alto desempenho - Turrax IKA modelo T25 foi utilizado para a preparação da emulsão A/O. Durante 5 minutos o fluido foi misturado a uma velocidade de $10000 \mathrm{rpm}$. Nessa primeira fase, o CP ainda não havia sido adicionado, para evitar perdas por evaporação;

- Ao fim dos 5 minutos, novamente foi feito pesagem da mistura obtida e repousada por aproximadamente 15 minutos para que a temperatura fosse reduzida à temperatura ambiente. Então, foi adicionado o CP (que foi previamente pesado) à mistura;

- Novamente o Turrax foi utilizado, agora com uma redução na velocidade, para evitar que a mistura atingisse o ponto de ebulição do $\mathrm{CP}$ (aproximadamente $50^{\circ} \mathrm{C}$ ). Foi utilizada uma velocidade de $6000 \mathrm{rpm}$, por apenas 3 minutos;

- Ao fim da última etapa, a mistura foi colocada em repouso por aproximadamente 30 minutos, a fim de observar se havia uma separação de fases inicial. A emulsão formada tem um aspecto físico cremoso, esbranquiçada e com aparência espumosa.

Tabela 7 - Composição das Emulsões utilizando Vaselina e ARQUAD®.

\begin{tabular}{ccccc} 
Componentes: & Peso $(\mathrm{g})$ & $\%$ & Peso $(\mathrm{g})$ & $\%$ \\
\hline Fase Aquosa & 21 & 30 & 21 & 30 \\
Fase Oleosa (Vaselina) & 42,7 & 61 & 42,42 & 60,6 \\
ARQUAD® & 0,7 & 1 & 0,98 & 1,4 \\
CP & 5,6 & 8 & 5,6 & 8 \\
Total & 70 & 100 & 70 & 100 \\
\hline
\end{tabular}


Tabela 8 - Composição das Emulsões utilizando Primol 352 e Span80

\begin{tabular}{ccccc} 
Componentes: & Peso (g) & $\%$ & Peso (g) & $\%$ \\
\hline Fase Aquosa & 21 & 30 & 21 & 30 \\
Fase Oleosa (Primol 352) & 42,42 & 60,6 & 42,42 & 45,6 \\
Span 80 & 0,98 & 1,4 & 0,98 & 1,4 \\
CP & 5,6 & 8 & 16,1 & 23 \\
Total & 70 & 100 & 70 & 100 \\
\hline
\end{tabular}

\subsection{3.}

\section{Caracterização das emulsões}

\subsubsection{1.}

Teste de estabilidade

A separação das fases foi monitorada por inspeção visual à temperatura ambiente, induzida pela gravidade. Para tal fim, uma pequena amostra da emulsão foi depositada em um tubo fino graduado. As amostras foram monitoradas periodicamente.

\subsubsection{2.}

\section{Análise microscópica}

Para realizar uma análise microscópica do tamanho de gotas das emulsões pré e pós-formação de hidratos, foi colocada uma gota da amostra sobre uma lâmina, a qual foi sobreposta por uma lamínula, de tal forma a diminuir a quantidade de camadas do fluido a ser analisado e facilitar a inspeção visual. A sobreposição da lamínula tem que ser realizada cuidadosamente, a fim de evitar tanto que a gota seja deformada/achatada, quanto a imagem final seja distorcida.

Para um resultado com maior acurácia, as amostras foram analisadas logo quando foram produzidas. No caso das amostras pós-formação de hidrato, assim que os testes foram finalizados, a pasta de hidrato produzida foi preparada e analisada no microscópio, pois os hidratos quando estão 
fora da temperatura de formação, tendem a se dissociar rapidamente, o que pode causar uma imprecisão na análise.

\subsubsection{2.}

\section{Caracterização reológica da emulsão}

O reômetro de tensão controlada Anton Paar Physica MCR301 foi utilizado para a execução dos testes e medição das propriedades reológicas das emulsões. A geometria utilizada foi a de cilindros concêntricos ranhurados (tanto o corpo, quanto o rotor). Essa geometria consiste em um par de cilindros coaxiais, sendo o fluido posicionado no espaço anular entre os dois cilindros. O rotor gira com velocidade ou torque controlado.

A quantidade de amostra a ser adicionada no espaço anular é de 18 $\mathrm{mL}$ e os raios do rotor e do copo são iguais a 14,460 e 13,332 mm, respectivamente, com altura de 40,017 $\mathrm{mm}$. A temperatura da amostra é controlada através de uma placa Peltier com precisão de $0,03^{\circ} \mathrm{C}$.

Tal geometria foi escolhida segundo as características da fase oleosa, baixa viscosidade. Além disso, não foi considerado o problema de evaporação da água no sistema, uma vez que as emulsões são do tipo $\mathrm{A} / \mathrm{O}$ e que os testes com maior duração sempre foram executados a temperaturas mais baixas.

Foram feitos os seguintes testes para a caracterização reológica das emulsões com CP:

i. Constant Shear Rate (Taxa de Cisalhamento Constante): testes rotacionais que foram programados para durar, no máximo, 15 minutos. Foi aplicada uma taxa de cisalhamento mínima e uma máxima para determinar o tempo necessário para que essas emulsões entrassem em regime permanente. As taxas de cisalhamento utilizadas foram $0,001 \mathrm{~s}^{-1}$ e $100 \mathrm{~s}^{-1}$. Os testes foram realizados à uma temperatura de $20^{\circ} \mathrm{C}$;

ii. Flow Curve (Curva de Escoamento): Esses testes foram utilizados para analisar o comportamento viscoso dos fluidos. Os testes rotacionais 
foram feitos a $20^{\circ} \mathrm{C}$, com a taxa de deformação variando de 0,001 a $100 \mathrm{~s}$ ${ }^{1}$ e o tempo de marcação de cada ponto foi definido a partir do teste de taxa de cisalhamento constante, definido anteriormente;

iii. Time Sweep (Teste de Varredura): Esse teste foi realizado para identificar o comportamento da emulsão à uma temperatura de $20^{\circ} \mathrm{C}$ e uma frequência de $1 \mathrm{~Hz}$, como sendo elástico ou viscoso. Através da análise das curvas de $G^{\prime}$ e $G^{\prime \prime}$ é possível identificar a região viscoelástica linear, quando essas curvas se apresentam paralelas;

iv. Rampa de temperatura com cisalhamento constante: A fim de identificar a formação de hidratos no reômetro, foi executado esse teste rotacional, com uma taxa de cisalhamento constante (foram utilizadas as taxas $0,25,0,5,1,10,50$ e $100 \mathrm{~s}^{-1}$ ). Conforme mostra a Fig.40, a amostra foi submetida a diferentes estágios e temperaturas. Primeiramente, a amostra foi colocada em repouso a $20^{\circ} \mathrm{C}$ e resfriada (sem cisalhamento) até $1^{\circ} \mathrm{C}(2)$. Posteriormente, essa amostra foi submetida a uma taxa de cisalhamento $\dot{\gamma}$ por, aproximadamente, 10 minutos. Então, a amostra foi resfriada até a temperatura de $-12^{\circ} \mathrm{C}$ e permaneceu em repouso por 40 minutos (5). Foi aquecida, então, até a temperatura de $1^{\circ} \mathrm{C}$ e submetida novamente à taxa de cisalhamento $\dot{\gamma}$ para que pudesse ser feita uma análise da viscosidade em função do tempo. 


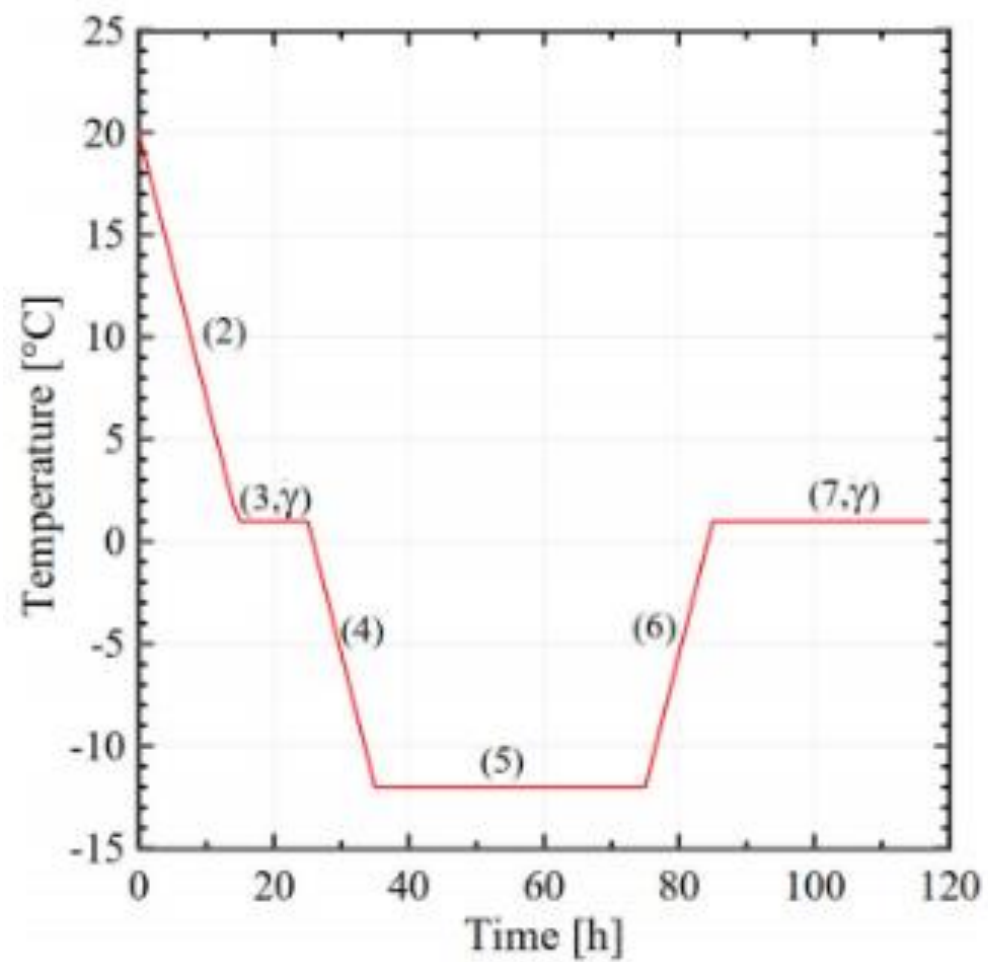

Figura 29 - Tratamento térmico da amostra para os testes de formação de hidrato. Os números entre parênteses indicam as etapas explicadas no texto. As etapas 3 e 7 são executadas com cisalhamento. 


\section{4}

\section{Resultados e Discussão}

Nesse capítulo são apresentados e discutidos os resultados referentes à estabilidade das emulsões estudadas, à caracterização reológica da emulsão modelo utilizada durante os experimentos subsequentes e aos testes reológicos, os quais objetivam analisar as condições necessárias para a formação de hidratos em emulsões $\mathrm{A} / \mathrm{O}$, com a presença do agente formador $\mathrm{CP}$.

\section{1.}

\section{Estabilidade das emulsões}

Para que os resultados dos experimentos tenham validade e acurácia é de suma importância que as emulsões utilizadas nos testes tenham uma estabilidade de, no mínimo, a duração do teste.

No caso do presente trabalho, a maioria dos testes que avaliam a formação de hidratos em emulsões $\mathrm{A} / \mathrm{O}$ demandam um tempo relativamente alto para ser performado, chegando, em algumas vezes, a passar de 24 horas.

Para que a emulsão tivesse uma estabilidade adequada, foram feitas algumas combinações diferentes de surfactante e óleo mineral, a fim de determinar a melhor opção para prosseguir com os experimentos. A seguir, serão apresentadas as 4 tipos diferentes de emulsão que foram analisadas, suas respectivas composições e o tempo de duração da estabilidade destas.

\subsection{1.}

\section{Emulsão 1}

A princípio, a composição escolhida para a emulsão $\mathrm{A} / \mathrm{O}$ foram: Vaselina líquida, $30 \%$ de $\mathrm{H}_{2} \mathrm{O}, 1 \%$ do tensoativo Arquad® e $8 \%$ de $\mathrm{CP}$. O 
processo utilizado foi explicado no capítulo anterior, com as principais diferenças:

- O CP foi adicionado logo após ser adicionada a água deionizada, antes de fazer a agitação da mistura;

- A velocidade de agitação foi de 10000 rpm por 10 minutos.

Ao fim da agitação, uma inspeção visual foi feita, para avaliar a estabilidade da emulsão. No caso da emulsão 1, poucos minutos após o fim da agitação, começou a ser observada uma separação de fases, indicando que o processo realizado não produziu uma emulsão estável. A Fig.30 mostra a emulsão 5 minutos após a sua produção. Pode-se observar que a fase oleosa (Primol + CP) se separou quase que instantaneamente. Duas hipóteses foram levantadas para explicar essa separação de fases:

i) a quantidade de tensoativo pode não ter sido suficiente;

ii) a necessidade de adicionar o CP somente após uma primeira mistura entre o óleo, água e surfactante.

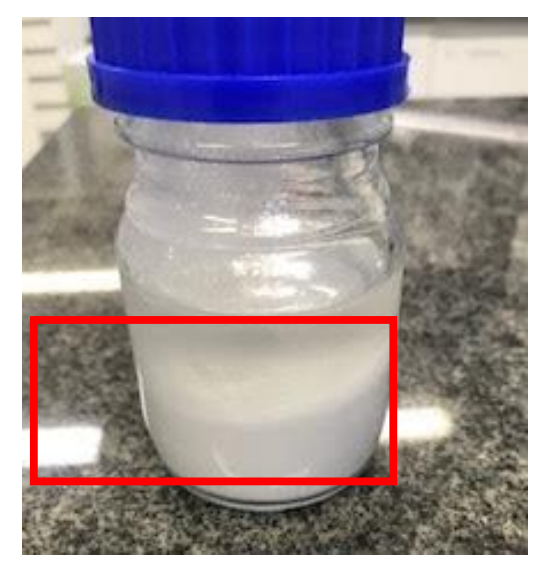

Figura 30 - Emulsão A/O 1: composta por 1\% de ARQUAD® e 8\% de CP.

\subsection{2.}

\section{Emulsão 2}

Depois de não obter sucesso com a emulsão 1, resolveu-se modificar a quantidade de tensoativo de $1 \%$ para $1.4 \%$ e, também, 
modificar uma etapa do processo, a qual o $\mathrm{CP}$ era adicionado à mistura antes da agitação. Nesse processo novo, o CP foi adicionado após uma primeira mistura entre as fases oleosa e aquosa. E, a fim de reduzir a perda por evaporação do mesmo, optou-se por diminuir a velocidade de agitação, para $4000 \mathrm{rpm}$.

Quando comparado com a Emulsão 1, essa nova emulsão obteve uma estabilidade um pouco maior. Esta apresentou uma estabilidade de até 3 horas quando, então, as fases começaram a se separar. Apesar de ser uma estabilidade superior à anterior, ainda não supriu a necessidade para os experimentos realizados.

Conforme visto na Fig.31, pode-se observar a separação de fases. Nesse caso, acredita-se que o primeiro componente a se separar foi o CP, visto que este foi adicionado por último e por apresentar a menor massa específica. Para tanto, levantou-se as hipóteses do porquê esta emulsão não ter atingido a estabilidade desejada:

i) o tensoativo usado, $A R Q U A D \AA$, não seria o ideal para esse tipo de emulsão;

ii) a velocidade de agitação/mistura dos componentes com o CP foi demasiadamente reduzida, impedindo que este último se incorporasse por completo à emulsão.

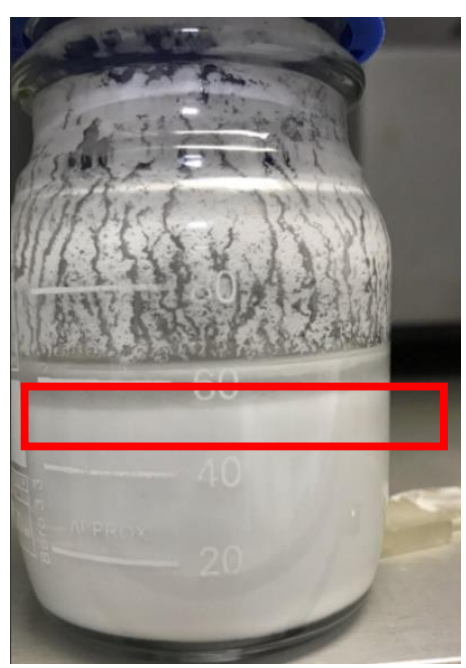

Figura 31 - Emulsão A/O 2: composta por 1.4\% de ARQUAD® e $8 \%$ de CP. 


\subsection{3.}

\section{Emulsão 3}

Para resolver os problemas encontrados nas duas emulsões testadas anteriormente, decidiu-se mudar o tensoativo para Span80, pois este é comumente utilizado na literatura em emulsões $A / O$, cuja finalidade é formar hidratos.

Além disso, alterou-se também a velocidade de agitação da mistura água/óleo com CP para 6000 rpm, por 3 minutos, com a finalidade de aumentar a agregação e reduzir a separação de fases da mistura, para que esta não prejudicasse os resultados dos testes a serem realizados.

Através de inspeção visual, pôde-se observar que a estabilidade da emulsão em questão se tornou bastante satisfatória, atingindo até 2 semanas sem que houvesse separação de fases visível. Entretanto, conforme será visto e discutido no item 4.3, essa emulsão, não apresentou nenhuma formação de hidrato. A Fig.32 mostra a emulsão após 2 semanas de ser preparada.

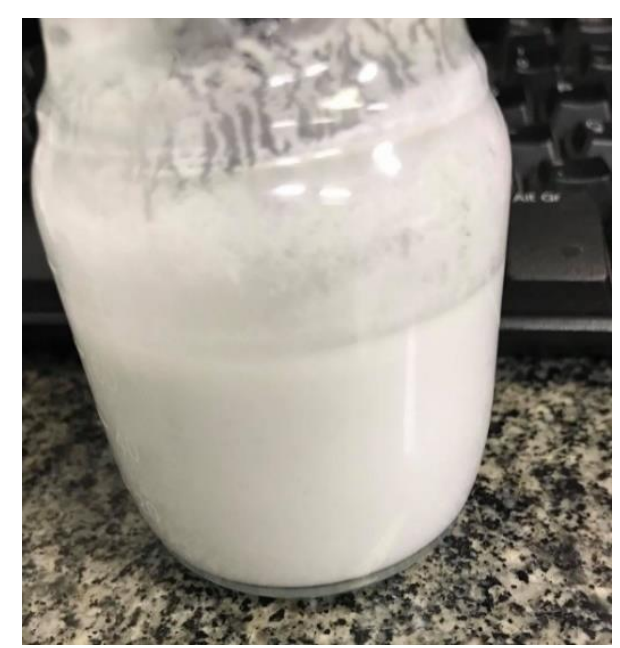

Figura 32 - Emulsão A/O 3: composta por 1.4\% de Span80 e 8\% de CP.

\subsection{4.}

\section{Emulsão 4}

Por fim, a última emulsão testada foi aplicando uma mudança na concentração de CP. Inicialmente, foi usado $8 \%$ do total da massa da 
emulsão, respeitando a quantidade estequiométrica mínima de água/CP para que seja possível a formação de hidrato. Entretanto, essa concentração mínima apresenta um problema: caso haja perda de qualquer quantidade de CP durante o processo de preparação da emulsão, provavelmente essa perda prejudicará a formação futura de hidratos nos testes subsequentes.

Portanto, optou-se por aumentar consideravelmente a concentração do CP (aproximadamente 3 vezes mais que o utilizado na emulsão anterior), para que não houvesse riscos de influência direta na produção de hidratos graças a qualquer perda mínima do componente.

A emulsão em questão apresentou estabilidade satisfatória, sendo quase 3 semanas sem que houvesse qualquer separação de fases. A Fig.33a mostra uma amostra logo após o seu preparo. Dessa mesma amostra foi retirada uma quantidade pequena de emulsão para marcar o dia em que ela começaria a separação de fases. A Fig.33b mostra que, após 18 dias de preparada, começou a exibir uma separação aparente (a água no fundo do recipiente).

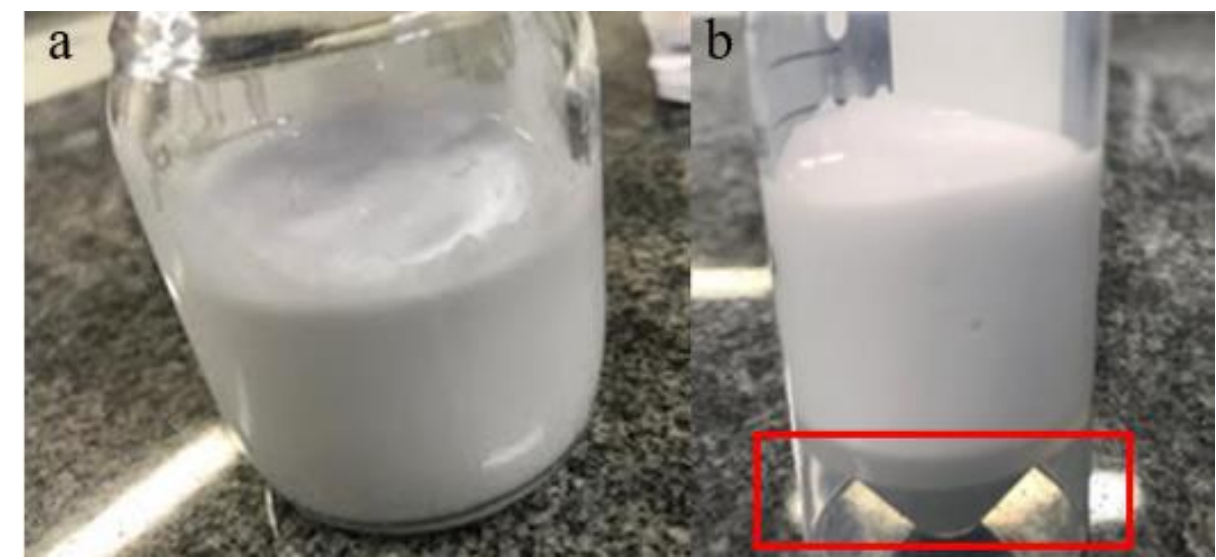

Figura 33 - Emulsão A/O 4: composta por 1.4\% de Span80 e 23\% de CP. A: Após o preparo. B: 3 semanas após o preparo.

\section{2.}

\section{Caracterização reológica da emulsão 4}

Para uma melhor compreensão de como a emulsão se comporta, antes de submetê-la a testes de formação de hidratos, uma caracterização 
reológica foi feita. Todos os testes foram feitos a temperatura de $1^{\circ} \mathrm{C}$, ou seja, a temperatura de trabalho dos testes de hidrato, para fins de comparação.

Primeiramente, há a necessidade de estabelecer a faixa de taxa de cisalhamento de trabalho para os testes de curva de escoamento, assim como o tempo necessário para garantir que o escoamento esteja dentro da faixa de regime permanente. Para tal, foram feitos dois testes nos quais foram impostas taxas de cisalhamento constantes: $0.001 \mathrm{~s}^{-1}$ e $100 \mathrm{~s}^{-1}$.

É considerado que o escoamento esteja no regime permanente, quando a viscosidade não varia com o tempo, ou seja, quando a curva é representada por uma reta paralela ao eixo x. Na Fig.34 pode-se observar que a amostra leva aproximadamente 100 segundos para entrar em regime permanente, quando aplicada uma taxa de 0.001 , enquanto para uma taxa de 100 (Fig.35), após o tempo de condicionamento, a amostra já se encontra em regime permanente instantaneamente. Por isso, o tempo escolhido para ser usado na medição de cada ponto na curva de escoamento, com uma margem de segurança, foi de 100 segundos.

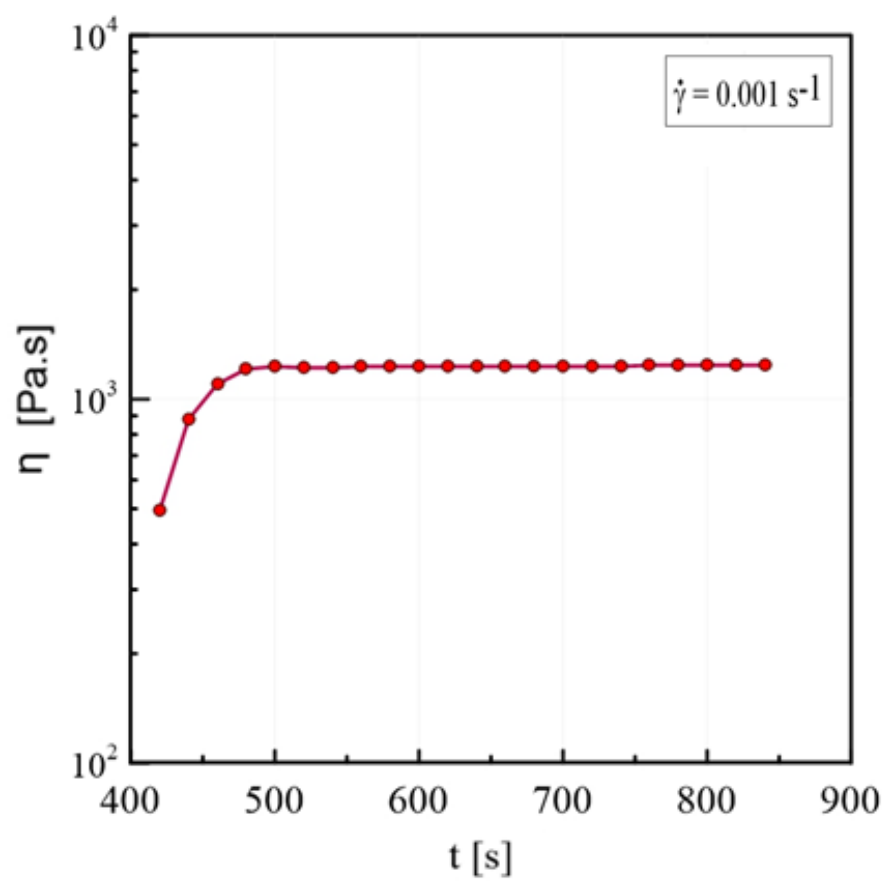

Figura 34 - Teste de taxa de cisalhamento constante de 0.001 1/s. 
Determinado o tempo para atingir o regime permanente, a curva de escoamento foi programada para apresentar um intervalo de taxa de cisalhamento entre $0.001 \mathrm{~s}^{-1}$ e $100 \mathrm{~s}^{-1}$, com cada ponto sendo medido a cada 100 segundos.

A Fig.36 mostra a curva de escoamento da emulsão 4 , a $1^{\circ} \mathrm{C}$, onde a viscosidade diminui com a taxa de cisalhamento, ou seja, o fluido tem comportamento pseudoplástico (ou shear-thinning), e a tensão de cisalhamento aumenta com a taxa. A partir de formulação utilizada no matlab, o modelo que melhor se ajuda a este fluido é o de Herschel-Bulkley, conforme Fig.37, e os parâmetros reológicos como tensão limite de escoamento, índice de consistência e índice de potência estão representados na Tab.8.

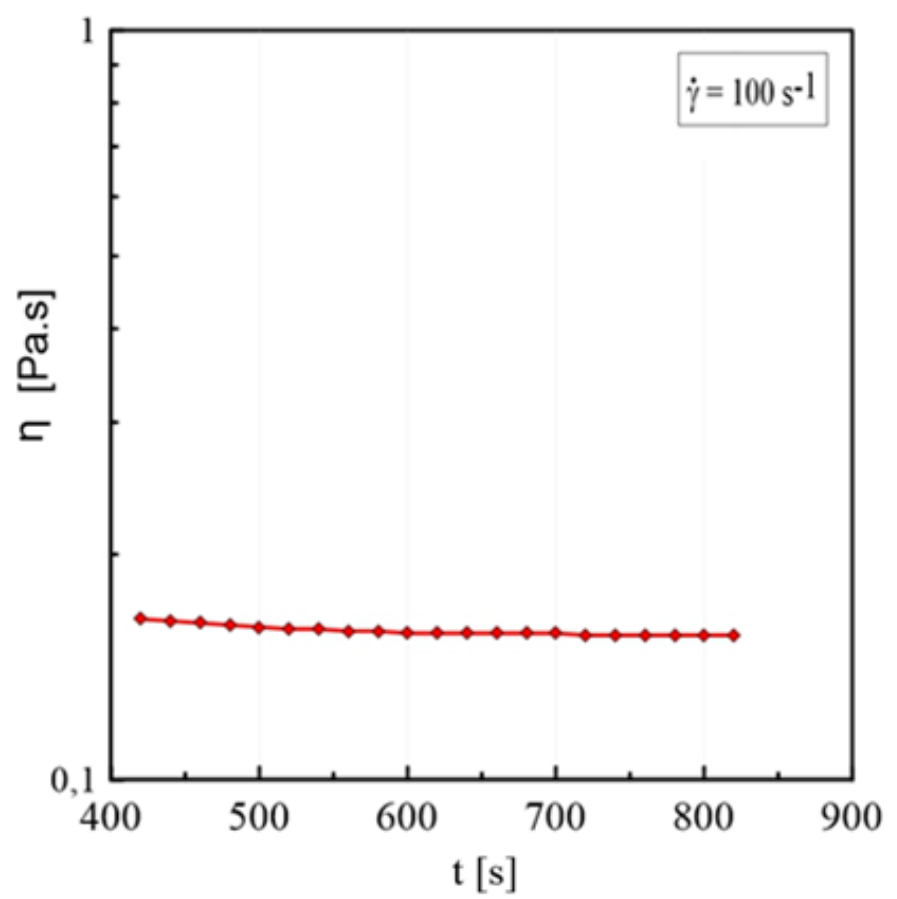

Figura 35 - Teste de taxa de cisalhamento constante de 100 1/s.

Como o índice de potência (n) é inferior a 1, a emulsão 4 tem características pseudoplásticas, assim como a tensão limite de escoamento é igual a $1.169 \mathrm{~Pa}$, valor que será importante para efeitos comparativos com os testes com formação de hidrato, mais adiante nesse capítulo. 
Tabela 9 - Parâmetros Reológicos da Emulsão 4.

\begin{tabular}{|c|c|}
\hline \multicolumn{2}{|c|}{ Parâmetros Reológicos calculados para o Modelo de Herschel-Bulkley } \\
\hline Tensão limite de escoamento $\left(\boldsymbol{\tau}_{\bullet}\right)$ & $1.169 \mathrm{~Pa}$ \\
\hline Índice de consistência (K) & $2.906 \mathrm{~Pa} . \mathrm{s}^{\star}$ \\
\hline Índice de potência (n) & 0.366 \\
\hline
\end{tabular}

Um teste de varredura de tensão foi aplicado à emulsão, a fim de analisar os módulos elástico e viscoso ( $G^{\prime}$ e $\left.G^{\prime \prime}\right)$, na Fig.37. A faixa de tensão analisada foi de $10^{-4}$ a $100 \mathrm{~Pa}$, com frequência constante de $1 \mathrm{~Hz}$. A partir deste, foi possível identificar a região viscoelástica linear, ou seja, quando as curvas destes módulos são paralelas e independem da tensão, encontrada aproximadamente entre os valores de 0,02 e 0,06 Pa.

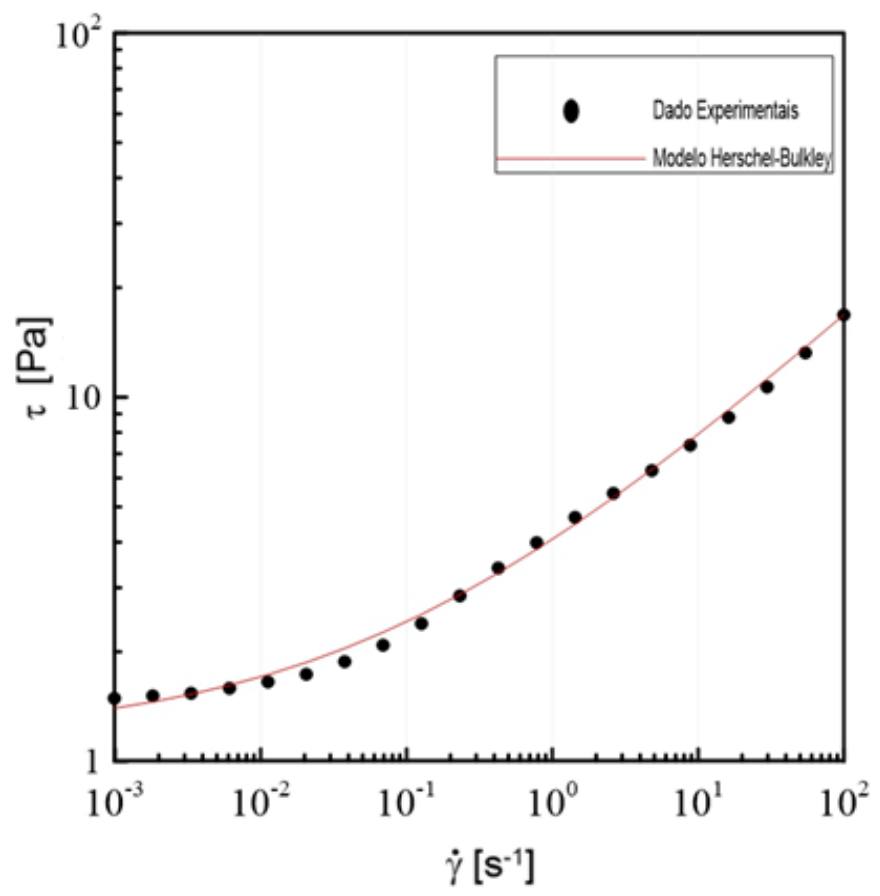

Figura 36 - Curve de escoamento da Emulsão 4 (Pontos experimentais e modelo mais adequado).

O fluido possui um comportamento predominantemente elástico, $G^{\prime}$ $>\mathrm{G}^{\prime \prime}$, até uma tensão de cerca de $2 \mathrm{~Pa}$. Quando submetidos a tensões superiores a esta, o fluido passa a desempenhar um comportamento 
predominantemente viscoso, ou seja, $G^{\prime \prime}>G^{\prime}$. O ponto de cruzamento entre as duas curvas ocorre em torno do valor da tensão limite de escoamento, quando a estrutura do fluido se quebra, permitindo que este escoe.

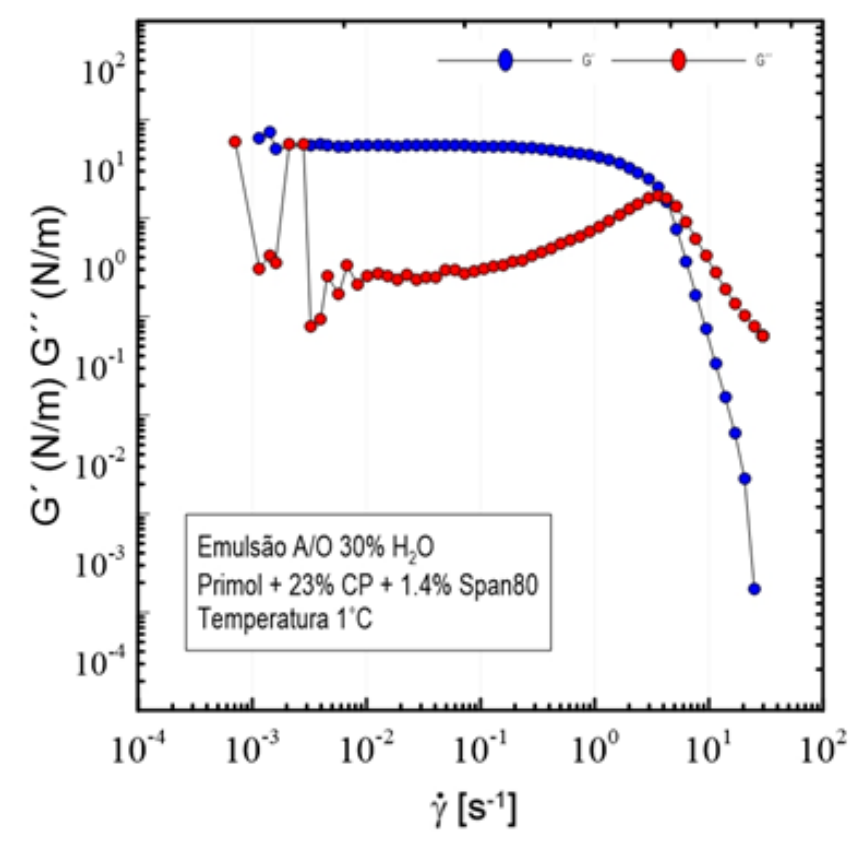

Figura 37 - Teste de varredura de tensão na emulsão 4.

\section{3. \\ Resultados - emulsão 3}

Tendo em vista a estabilidade satisfatória da emulsão 3, foram feitos testes com o objetivo de analisar a formação de hidratos, quando esta é submetida à perturbações de temperaturas negativas. A concentração de $\mathrm{CP}$, de $8 \%$, respeita o limite estequiométrico (1:17) de quantidade de moles de água e CP.

Para estimular a nucleação, a amostra foi levada a temperaturas de $-12^{\circ} \mathrm{C}$ por 40 minutos e, então, esta foi aumentada até $1^{\circ} \mathrm{C}$, quando uma taxa de cisalhamento foi aplicada e a respectiva variação de viscosidade analisada. As figuras 38 e 39 mostram testes para duas taxas distintas de 10 e $1 \mathrm{~s}^{-1}$, respectivamente.

Quando a temperatura positiva foi atingida, a viscosidade apresentou uma queda instantânea, para ambos os casos, indicando que 
não houve qualquer formação de hidratos. Essa redução de viscosidade foi mais brusca para taxas maiores, evidenciando o comportamento shearthinning já observado anteriormente na caracterização reológica destas emulsões $\mathrm{A} / \mathrm{O}$.

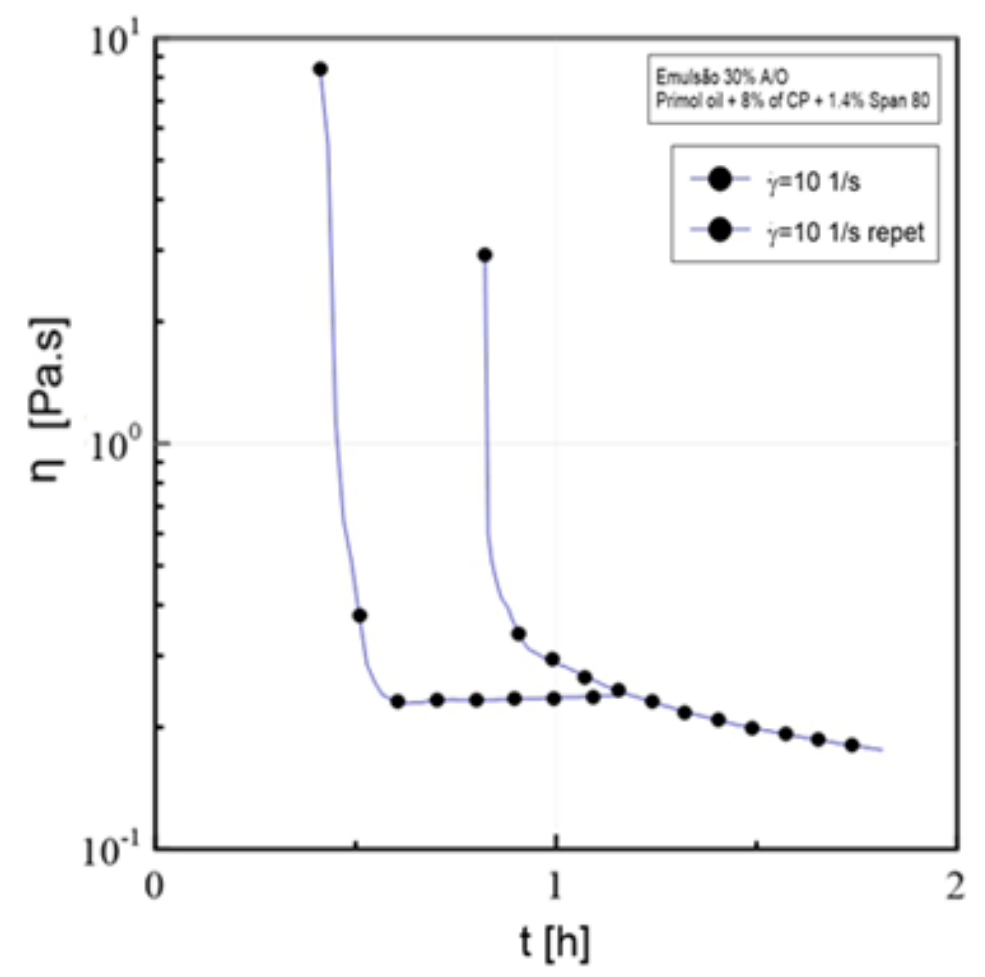

Figura 38 - Viscosidade $\mathrm{x}$ tempo para amostra submetida a taxa de cisalhamento de 10 $(1 / \mathrm{s})$.

Esse comportamento foi verificado em diversos outros testes, com diferentes taxas, estabelecendo esse padrão para a emulsão 3. Ou seja, com essas concentrações, a formação de hidratos não foi possível. Acredita-se que o principal motivo é que a porcentagem de CP fica exatamente no limite estequiométrico permitido e, na preparação da emulsão, alguma massa de CP é perdida por evaporação, impossibilitando que a quantidade utilizada seja capaz de promover a formação de cristais de hidrato. 


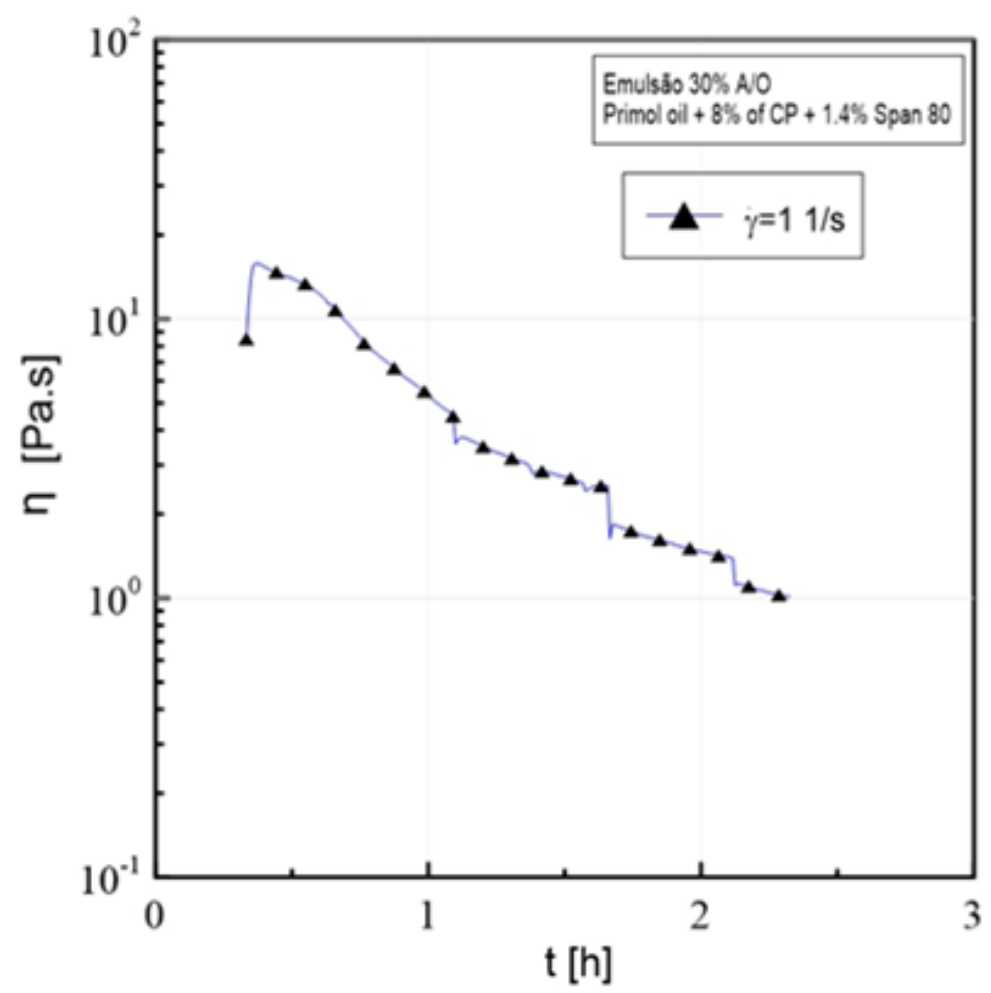

Figura 39 - Viscosidade $\mathrm{x}$ tempo para amostra submetida a taxa de cisalhamento de 1 $(1 / s)$.

\section{4.}

\section{Resultados - emulsão 4}

\subsection{1.}

\section{Análise da viscosidade durante a formação de hidratos}

A formação de hidratos, com utilização do CP como agente formador, necessita de uma perturbação inicial para que haja a nucleação em tempo razoável. Diferentes formas de perturbação são utilizadas na literatura, tais como: temperaturas negativas e adição de pequenos cristais de hidratos pré-formados.

No presente trabalho, dá-se um maior foco no tratamento térmico, como mostrado no capítulo anterior. Para um melhor desempenho dessa perturbação, alguns testes foram realizados, a fim de identificar qual 0 tempo ideal a que a emulsão deve ser submetida a temperaturas negativas, para que as pastas de hidrato possam ser estudadas devidamente. 


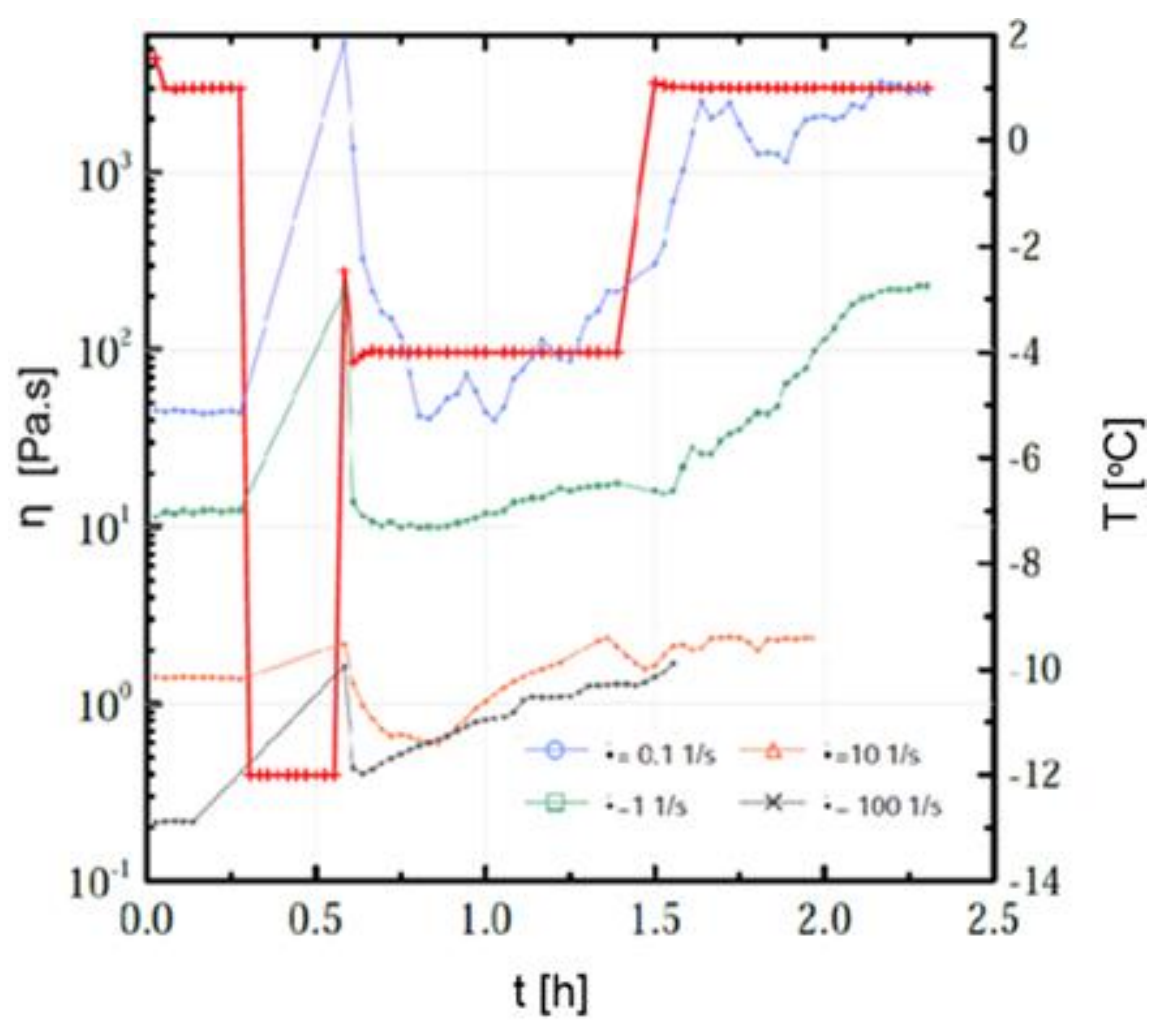

Figura 40 - Formação de hidratos utilizando duas temperaturas negativas diferentes.

A Fig.40 mostra a análise da viscosidade em função do tempo, quando a amostra foi submetida a uma rampa de temperaturas negativas $\left(-12^{\circ} \mathrm{C}\right.$ e $\left.-4^{\circ} \mathrm{C}\right)$, por 15 minutos e 1 hora, respectivamente. Após esse tempo, a temperatura de $1^{\circ} \mathrm{C}$ foi alcançada e foi possível observar a formação de hidratos. Entretanto, esse aumento na viscosidade em temperaturas positivas foi consideravelmente pequeno, sendo necessário que essa metodologia fosse reconsiderada.

Então, foi realizado um teste na temperatura de $-4^{\circ} \mathrm{C}$, tanto para uma emulsão com CP, quanto para uma emulsão sem. Conforme mostrado na Fig.41, a emulsão com CP atinge o patamar de viscosidade máxima entre 30 e 45 minutos, enquanto a emulsão sem $\mathrm{CP}$, leva aproximadamente 1 hora e meia para atingir o mesmo patamar. Para tanto, o valor de 40 minutos em temperaturas negativas se mostra aceitável para assegurar que a influência do gelo será mínima ou nula quando a emulsão for submetida à temperatura positiva, após o tratamento térmico. 


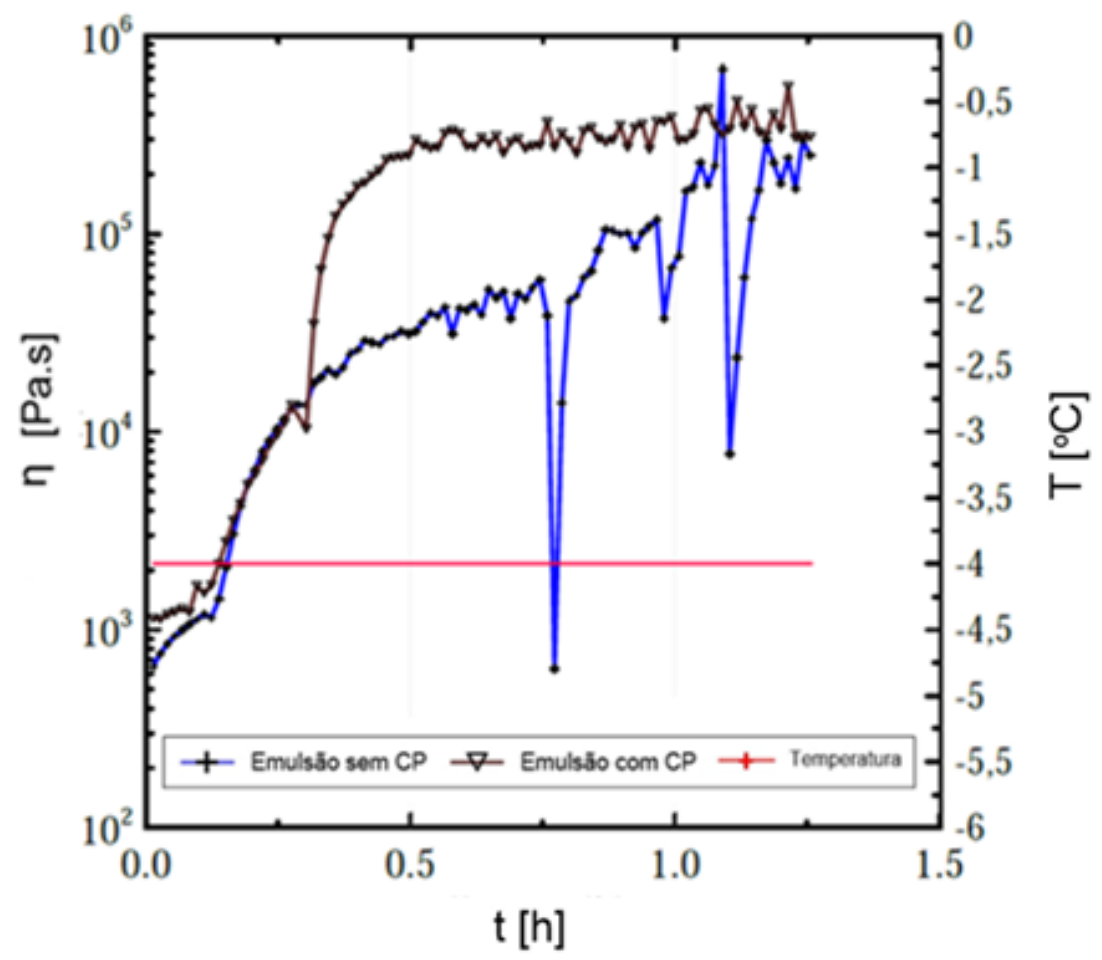

Figura 41 - Análise da viscosidade a -4ㄷ para emulsão sem e com CP.

Então, todos os testes passaram a seguir o tratamento térmico da Fig.29, com 7 etapas, sendo a última aquela na qual a viscosidade passa a ser medida por tempo, com a aplicação de uma taxa de cisalhamento definida. Além disso, para garantir a confiabilidade dos resultados, testes de repetitividade são realizados.

A Fig.42 apresenta o comportamento típico da viscosidade quando há a formação de hidratos, um crescimento abrupto desta em um pequeno espaço de tempo. É importante notar que dois testes foram realizados para amostras diferentes, mas com mesma composição, e a repetitividade é satisfatória. Esse fator, em testes de hidratos, são avaliados pela flutuação da viscosidade final em torno de um mesmo valor, porque o comportamento de cada cristal, mesmo quando submetidos a mesmas condições, não será exatamente igual.

O valor de viscosidade inicialmente fica em um valor mínimo, por aproximadamente 10 minutos, chamado tempo de indução, para, então, apresentar um aumento significativo até atingir o nível máximo. Esse 
aumento abrupto de viscosidade (de 2 para 3000 Pa.s) é associado diretamente à formação e agregação dos cristais de hidratos.

O período entre o valor mínimo e o valor máximo de viscosidade é conhecido como tempo de crescimento. Neste caso, o tempo é consideravelmente rápido, em torno de 30 minutos. Após atingir o valor máximo, a viscosidade começa a variar em torno de um valor, caracterizando a busca pelo equilíbrio entre as forças de cisalhamento geradas pela geometria de cilindros concêntricos e as forças de reconstrução dos cristais de hidratos.

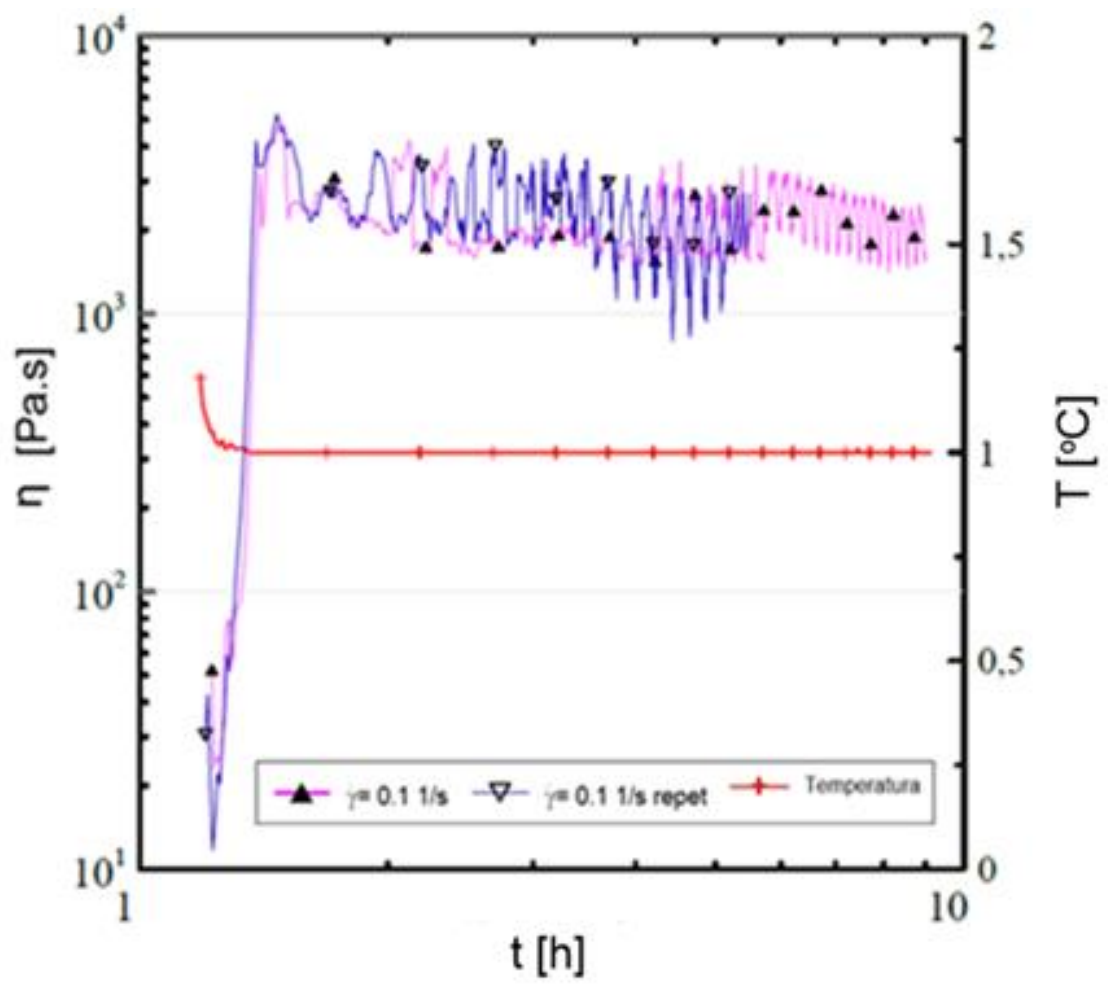

Figura 42 - Comportamento da viscosidade por tempo da emulsão 4. Curva de repetitividade.

\subsubsection{1.}

\section{Variação da taxa de cisalhamento}

A partir do resultado anterior, para melhor entender o comportamento da pasta de hidrato, esta foi submetida a diferentes taxas de cisalhamento, conforme Fig.43. Tais testes foram conduzidos mantendo todos os parâmetros constantes, exceto a taxa de cisalhamento, a qual foi variada em 4 ordens de grandeza (de 0.1 a $100 \mathrm{~s}^{-1}$ ). Conforme mostrado, 
as etapas onde houve aplicação de taxa de cisalhamento foram as etapas 3 e 7 , ambas em temperatura de $1^{\circ} \mathrm{C}$.

Os resultados mostram que conforme a taxa de cisalhamento aumenta, a viscosidade final atingida é menor, indicando um comportamento shear-thinning, assim como já era observado na emulsão a $1^{\circ} \mathrm{C}$, quando não foi feito tratamento térmico. A principal explicação para tal fenômeno é a competição entre as forças de coesão da estrutura cristalina e as forças de cisalhamento aplicadas na amostra, induzidas pela geometria de medição utilizada nos testes.

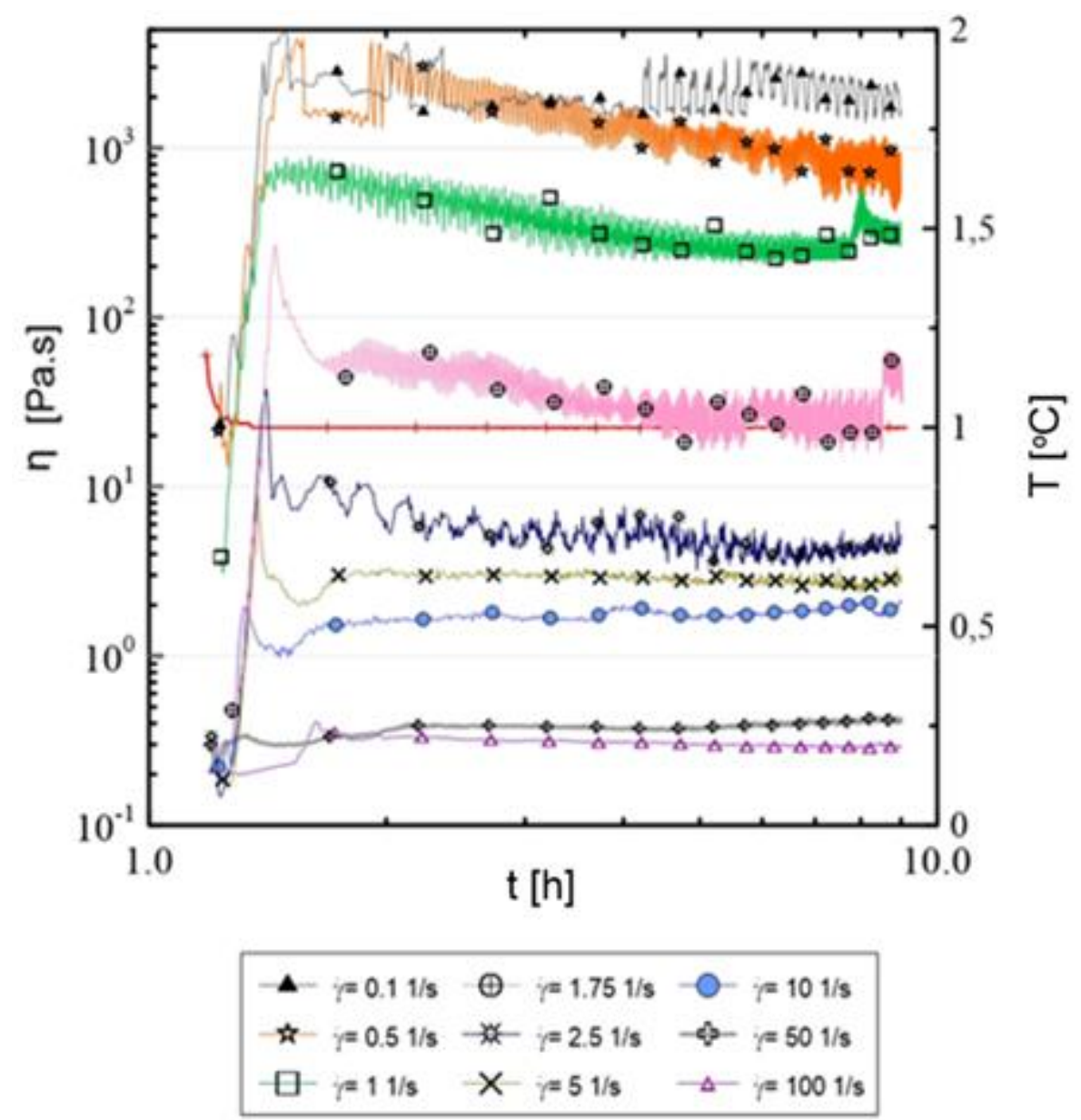

Figura 43 - Comportamento da viscosidade por tempo para diferentes taxas de cisalhamento.

Um fato observado é que essa competição entre forças é mais evidente para taxas de cisalhamento menores, tais como 0,1 e $0,5 \mathrm{~s}^{-1}$, quando é possível observar uma maior flutuação do valor da viscosidade, 
indicando que os agregados de hidratos estão sofrendo quebra e reconstrução constantemente. Para taxas maiores, como 50 e $100 \mathrm{~s}^{-1}$, essa flutuação é quase imperceptível, indicando que as forças conseguem atingir um valor em que não ocorre mais quebra e reconstrução, levando a uma viscosidade final mais próxima do constante.

Um parâmetro que deve ser analisado é a taxa de crescimento dos hidratos, GR, a qual é definida como:

$$
\left(G R=\frac{\eta_{f}-\eta_{i}}{t_{f}-t_{i}}\right)
$$

Onde:

$\eta_{f} \rightarrow$ Viscosidade final;

$\eta_{i} \rightarrow$ Viscosidade inicial;

$t_{f} \rightarrow$ Tempo final;

$t_{i} \rightarrow$ Tempo inicial;

Tabela 10 - GR das pastas de hidrato para diferentes taxas de cisalhamento.

\begin{tabular}{|c|c|}
\hline Taxa de Cisalhamento & GR \\
\hline 0,1 & 5,12 \\
\hline 0,5 & 2,28 \\
\hline 1 & 0,69 \\
\hline 1,75 & 0,034 \\
\hline 2,5 & 0,014 \\
\hline 5 & 0,0011 \\
\hline 10 & 0,00077 \\
\hline 50 & 0,00013 \\
\hline 100 & 0,00011 \\
\hline
\end{tabular}

Pode-se inferir que o GR diminui com a taxa de cisalhamento aplicada à amostra (Tabela 10), ou seja, os cristais de hidrato tendem a aglomerar mais rapidamente para menores taxas. Esse comportamento pode ser explicado pelas forças de coesão, que tendem a ser mais fortes que as forças cisalhantes para taxas menores.

Um fator que tem que ser considerado na formação de hidratos é o tempo de indução. Esse tempo é associado às forças condutoras de 
formação, as quais estão diretamente relacionadas à taxa de formação dos núcleos dos hidratos. Segundo a literatura, ele é reduzido com o aumento da taxa aplicada à amostra, pois esta estimula uma maior área de contato entre os componentes que formam o hidrato. Apesar do tempo de indução apresentado nos testes explicitados na Fig.43 serem muito pequenos, é possível confirmar que para taxas de cisalhamento maiores, esse tempo é ainda menor.

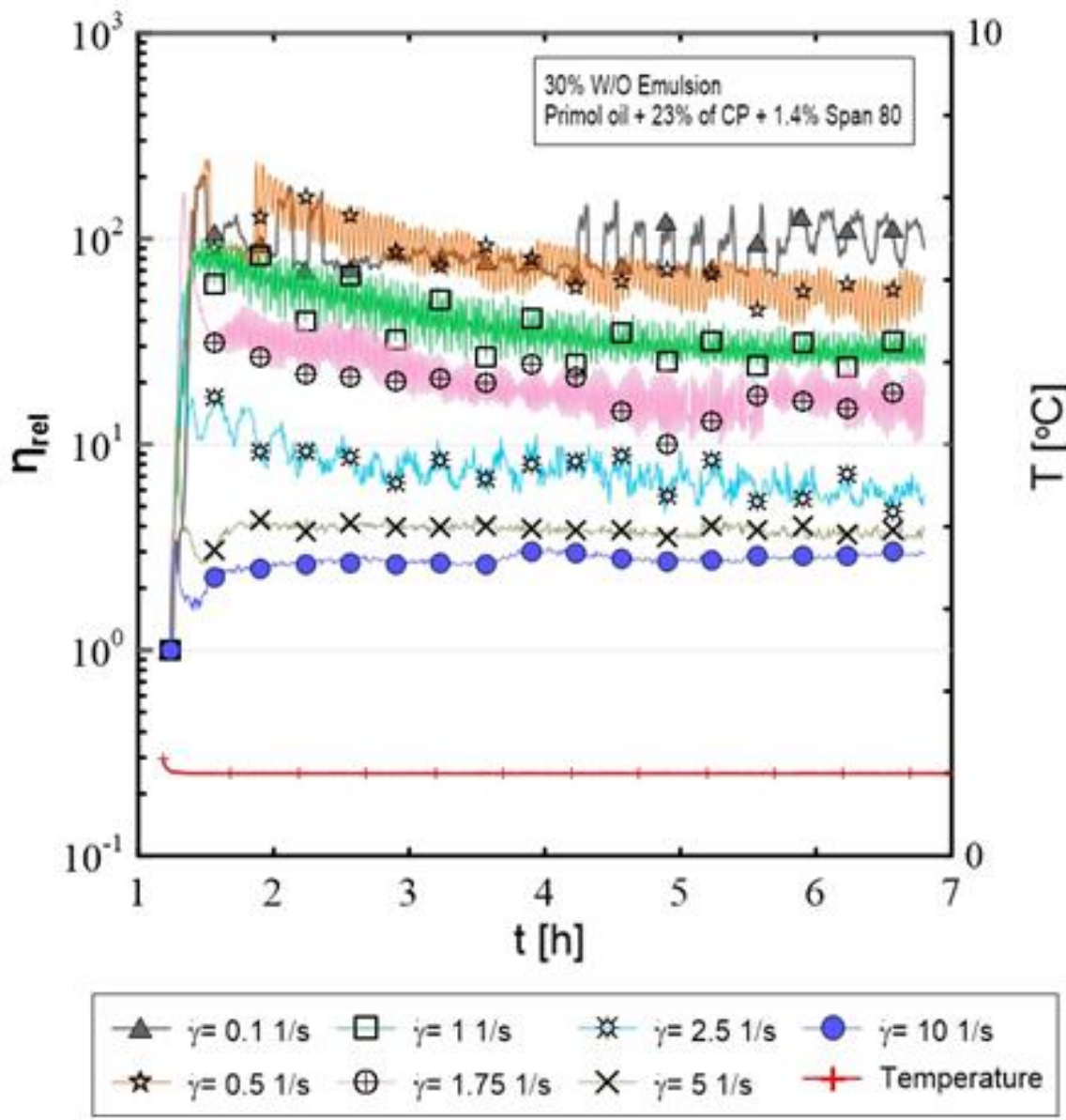

Figura 44 - Comportamento da viscosidade relativa para diferentes taxas de cisalhamento.

Para uma análise mais aprofundada, uma análise da viscosidade relativa das diferentes taxas de cisalhamento aplicadas foi necessária. A viscosidade relativa foi medida a partir do valor de viscosidade inicial, antes da formação das pastas de hidrato. Com isso, conforme Fig.44, todas as curvas partem de um mesmo valor unitário, possibilitando uma comparação com maior acurácia entre todos os testes. 
A partir deste resultado, foi possível confirmar que as pastas de hidrato tem um comportamento shear-thinning, ou seja, um aumento na taxa de cisalhamento, indica uma menor viscosidade final e, portanto, uma menor quantidade de hidratos formados, conforme esperado.

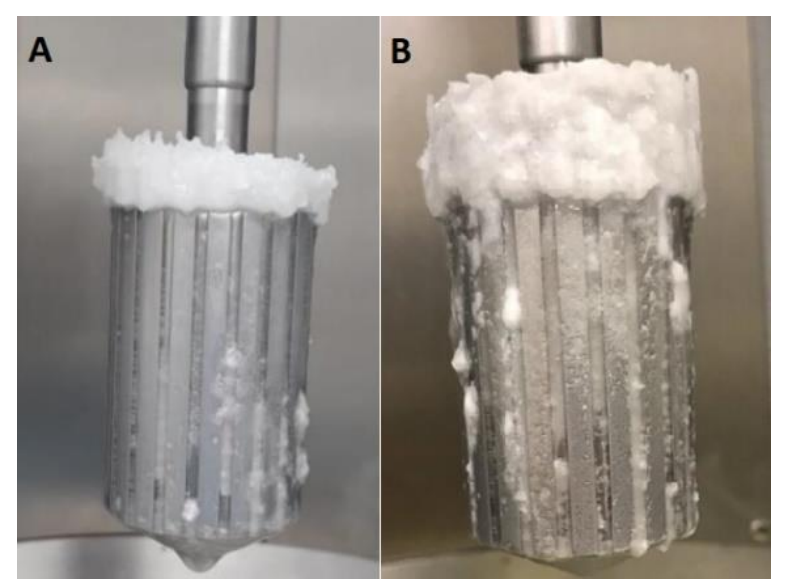

Figura 45 - Acúmulo de hidratos na parte superior do rotor para taxas de cisalhamento de (A) $50 \mathrm{~s}^{-1} \mathrm{e}$ (B) $100 \mathrm{~s}^{-1}$.

Para as taxas maiores, 50 e $100 \mathrm{~s}^{-1}$, o aumento na viscosidade é muito pequeno, quase irrelevante. Entretanto, a formação de hidrato foi observada na parte superior do rotor, ao final dos experimentos, conforme Fig.45. Para explicar tal fato, algumas hipóteses podem ser consideradas: a) Como as amostras estão sendo submetidas a elevadas taxas de cisalhamento, quando o cristal de hidrato se aglomera, ele logo é quebrado, se acumulando somente na parte superior do rotor, onde tais forças tendem a zero; b) A existência de deslizamento próximo à parede da geometria, resultando, então, em valores mais baixos de viscosidade.

Karanjkar et al (2016) identificou que hidratos formados a partir de emulsões utilizando Span80 como surfactante, tem uma morfologia específica que pode induzir o bloqueio ou o deslizamento na parede da geometria. Tal morfologia é caracterizada por uma microestrutura porosa e com aspecto de cabelos, os quais podem ser identificados pelos círculos vermelhos na Fig.46. É possível que tal característica forme pastas de hidrato mais leves, facilitando, então, que a microestrutura cristalina se mova para o topo da geometria. 


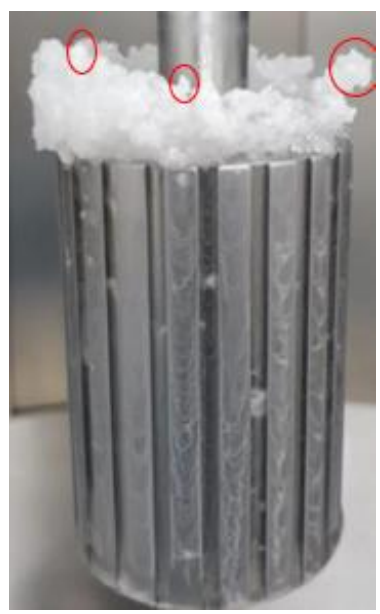

Figura 46 - Hidratos de CP com morfologia porosa e com aspecto de pelos.

Após uma análise detalhada do comportamento das pastas de hidrato formadas para diferentes taxas de cisalhamento, utilizando diferentes amostras, foi realizado um teste no qual a mesma amostra foi submetida a todo o tratamento térmico e, então, a uma rampa de taxa de cisalhamento.

Quando atingida a temperatura de $1^{\circ} \mathrm{C}$, a amostra começou a ser submetida a uma taxa de cisalhamento de $0.1 \mathrm{~s}^{-1}$, por 4 horas, e então essa taxa foi sendo aumentada, até $10 \mathrm{~s}^{-1}$. Quando comparados os resultados obtidos nas Fig.43 e Fig.47 pode-se observar que a diferença entre os valores da viscosidade é menor quando diferentes taxas são aplicadas a uma mesma amostra.

Esse comportamento pode ser atribuído, principalmente, a dois fatores: a) como a amostra começou sendo submetida a uma taxa de cisalhamento menor, $0.1 \mathrm{~s}^{-1}$, as forças de coesão foram predominantes, contribuindo para uma aglomeração dos cristais maior e mais rápida e, então, quando taxas maiores começaram a ser aplicadas, a quebra desses aglomerados se tornou mais lenta, resultando numa maior viscosidade; b) o tempo de exposição a cada taxa de cisalhamento, 4 horas, foi significantemente menor, quando comparado aos testes com amostras diferentes. 


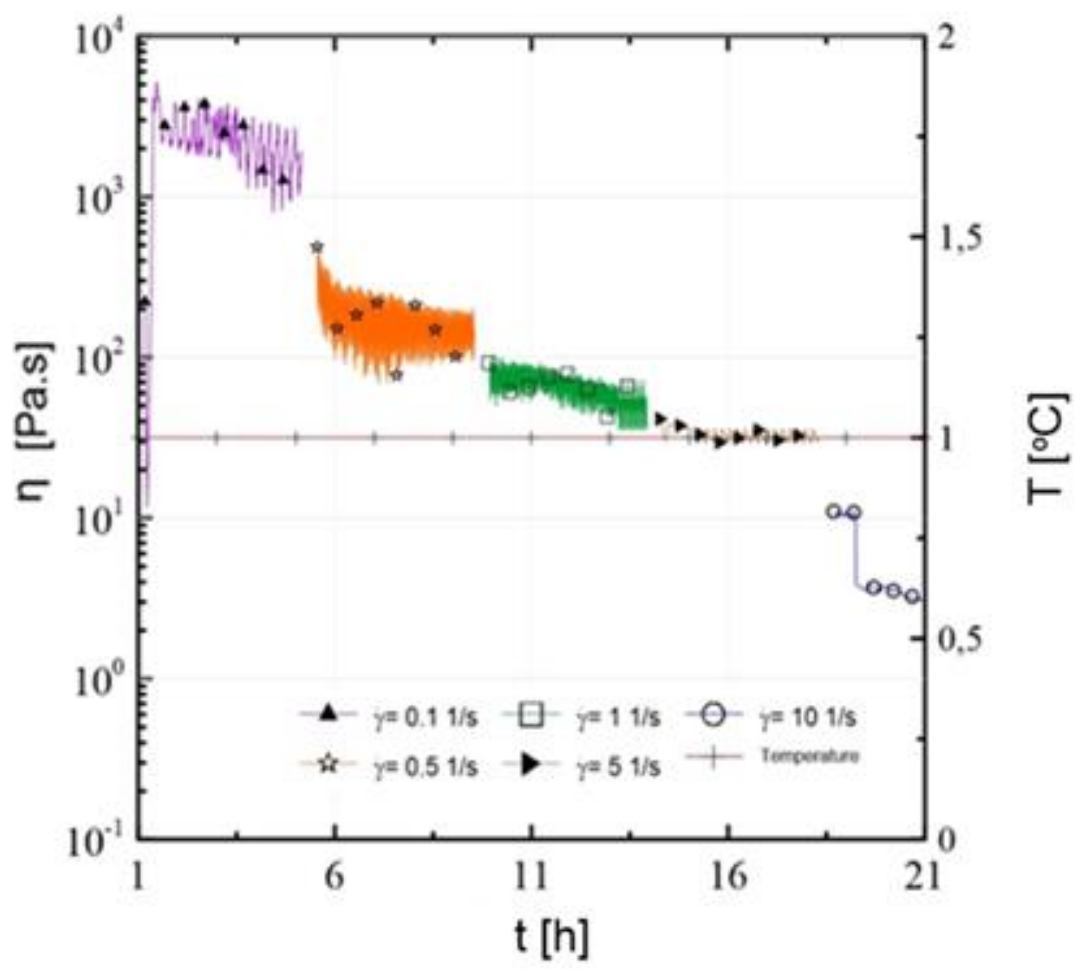

Figura 47 - Comportamento da viscosidade pelo tempo em uma mesma amostra submetida a diferentes taxas de cisalhamento.

A Fig.47 mostra a curva de escoamento referente a este teste realizado com uma mesma amostra. Para melhor entender 0 comportamento da pasta de hidrato, foi plotado o valor médio de viscosidade obtido para cada taxa de cisalhamento aplicada, assim como a tensão de cisalhamento.

Como visto em outros testes realizados em amostras separadas, a pasta de hidrato tem um comportamento shear-thinning com o aumento da tensão de cisalhamento, enquanto a taxa de cisalhamento aumenta. $\mathrm{O}$ modelo mais adequado para este comportamento foi o de Herschel-Bulkley e, dentre os parâmetros reológicos, a tensão limite de escoamento encontrada foi de 88,57 Pa. Quando comparada com a encontrada para a emulsão sem formação de hidratos (Fig.36), nota-se um aumento de aproximadamente 76 vezes, evidenciando um comportamento viscoplástico bem mais acentuado que resulta na maior dificuldade de quebra da estrutura para que o início de escoamento da pasta. 


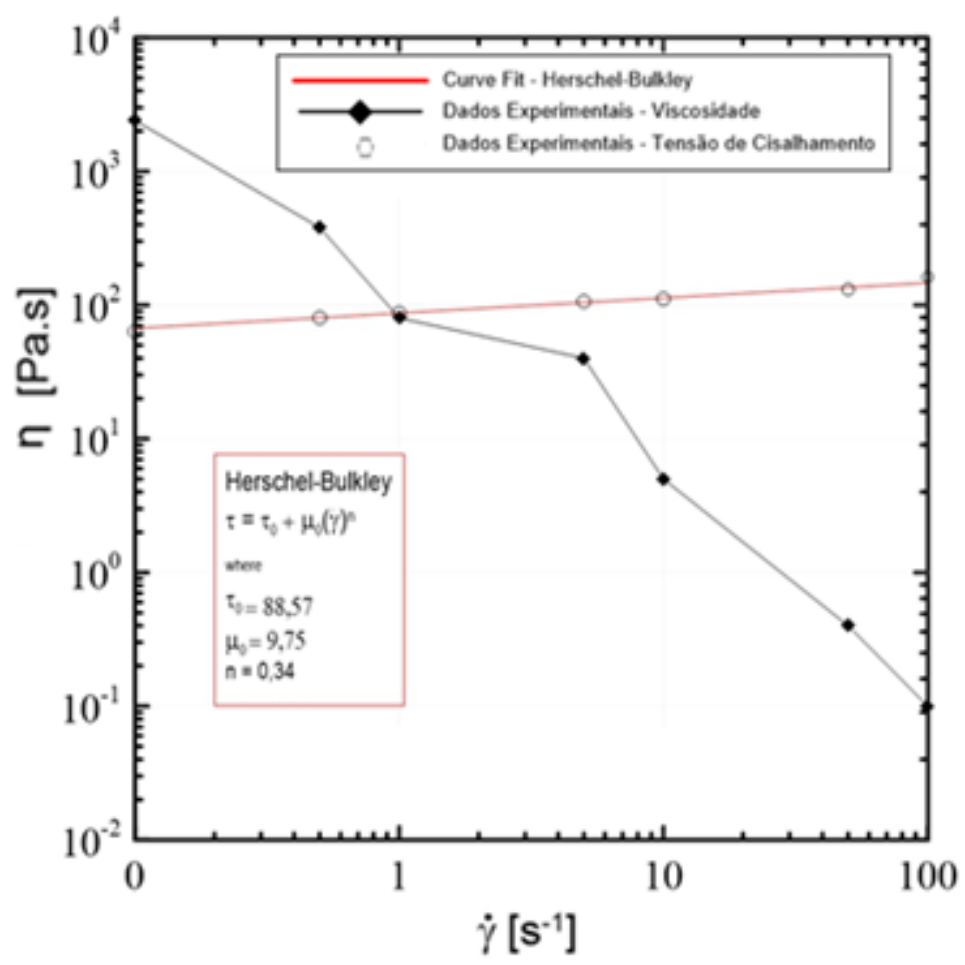

Figura 48 - Curva de escoamento para amostra submetida a diferentes taxas de cisalhamento.

\subsubsection{2.}

\section{Variação da temperatura de indução}

Uma das etapas mais importantes nos experimentos é quando a amostra é submetida a uma temperatura negativa para estimular a nucleação dos cristais de hidratos, temperatura esta chamada de temperatura de sedimentação. Para um melhor entendimento dessa influência, foram realizados testes variando tal parâmetro, conforme Fig.49.

A curva vermelha, na qual usou-se a temperatura de $-12^{\circ} \mathrm{C}$ é a mesma representada na Fig.43, para efeitos comparativos. Inicialmente, foi realizado um teste utilizando a temperatura de $-4^{\circ} \mathrm{C}$, mantendo todas as etapas do tratamento térmico e aplicando uma taxa de cisalhamento de 0.1 $\mathrm{S}^{-1}$ quando a temperatura de $1^{\circ} \mathrm{C}$ foi atingida. Ao atingi-la, a viscosidade não apresentou uma variação significativa, indicando que esta temperatura não foi suficiente para estimular a formação de hidratos.

Então, diminuiu-se a temperatura para $-6^{\circ} \mathrm{C}$ e, novamente, a viscosidade final não sofreu alterações significativas, mas observou-se um 
aumento pequeno da viscosidade, quando comparada ao teste de $-4^{\circ} \mathrm{C}$. Finalmente, ao ter a temperatura diminuída para $-8^{\circ} \mathrm{C}$, pôde-se observar um aumento significativo da viscosidade, indicando que foi formado hidrato no tempo considerado, assim como para as temperaturas de sedimentação de $-10^{\circ} \mathrm{C}$ e $-12^{\circ} \mathrm{C}$.

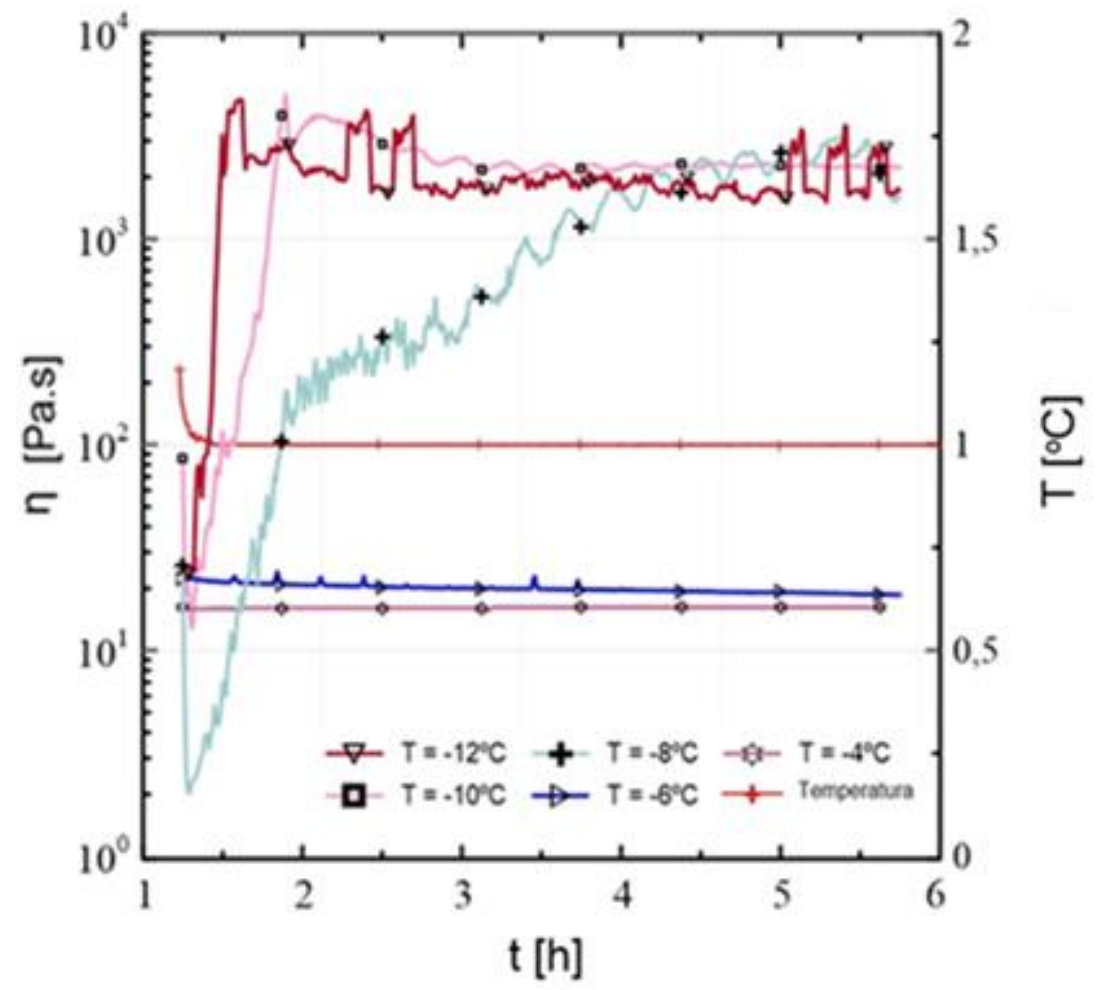

Figura 49 - Comportamento da viscosidade dos hidratos de CP com o tempo sobre diferentes temperaturas de indução.

A principal diferença entre as três temperaturas que formaram hidratos foi no tempo de crescimento. No caso da curva verde $\left(-8^{\circ} \mathrm{C}\right)$, a amostra levou aproximadamente 5 horas para atingir o patamar de viscosidade máximo encontrado nos outros dois testes (aproximadamente 2000 Pa.s). Já para o caso da curva rosa $\left(-10^{\circ} \mathrm{C}\right)$, esse tempo foi 40 minutos maior do que quando uma temperatura de $-12^{\circ} \mathrm{C}$ foi utilizada. Ou seja, quando submetidos a uma temperatura de sedimentação menor, em um mesmo tempo, a pasta de hidrato se forma mais rapidamente e, consequentemente, atinge o patamar máximo de viscosidade mais rapidamente. 


\subsubsection{3.}

\section{Análise da viscosidade em sistemas não emulsificados}

Um questionamento que normalmente é levantado na literatura é se sistemas não emulsificados são capazes de formar hidratos em determinadas condições de trabalho. Para tal, dois testes foram realizados,

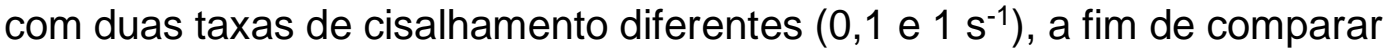
com os resultados obtidos anteriormente na Fig.43.

A Fig.50 mostra uma comparação entre os testes utilizando amostras com a emulsão 4 e os testes com sistemas não emulsificados. Para produzir esses sistemas, na hora da mistura entre o óleo Primol, Span80 e água deionizada, a velocidade de rotação e o tempo de mistura foram reduzidos em 50\%, assim como a adição do CP foi realizada previamente, sem a necessidade de uma segunda mistura, causando uma separação de fases imediata.

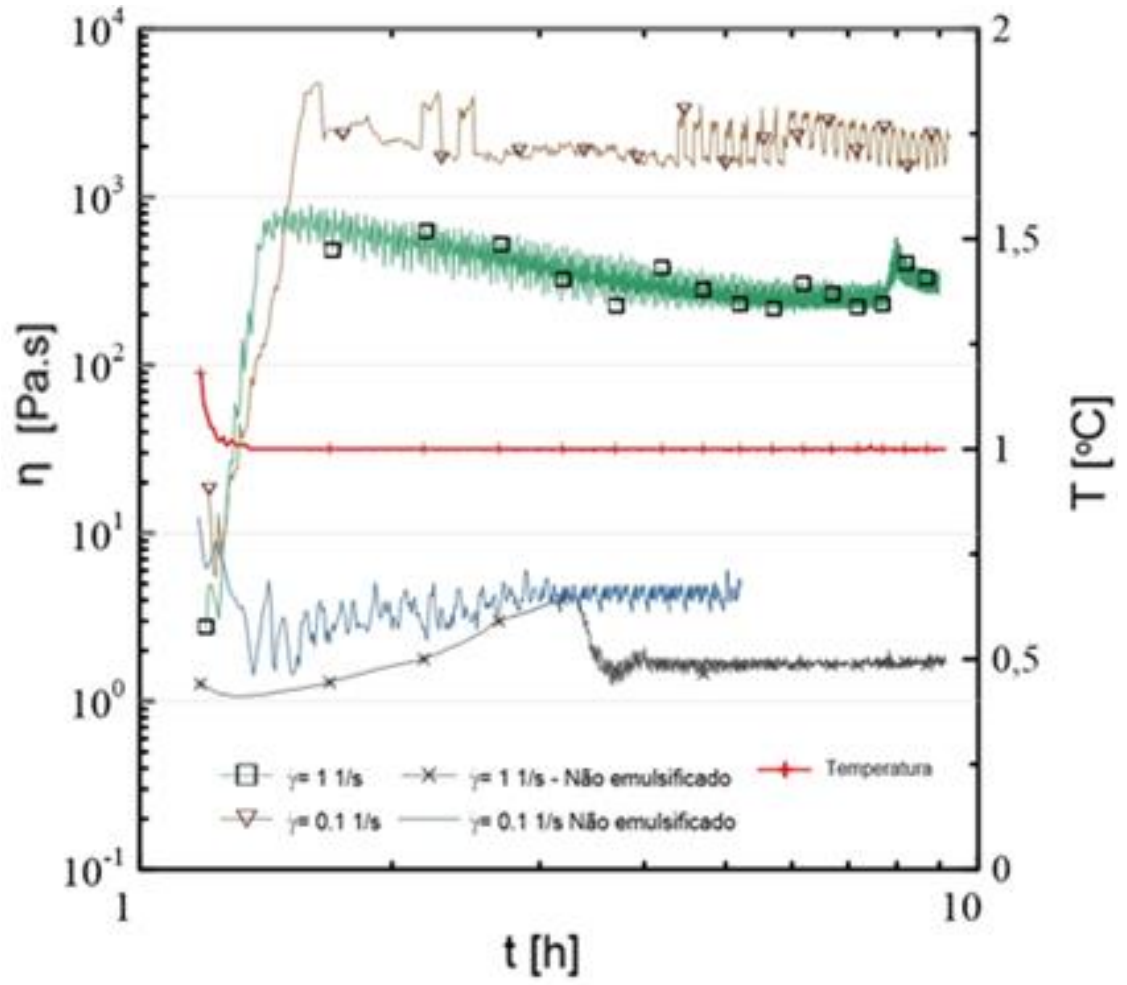

Figura 50 - Comportamento da viscosidade com o tempo para sistemas emulsificados e não emulsificados. 
Todos os outros parâmetros e rampa de temperatura foram mantidos constantes. Pode se observar que os sistemas não emulsificados não apresentam um aumento considerável da viscosidade, indicando que não houve formação de hidratos. Assim que a temperatura de $1^{\circ} \mathrm{C}$ foi atingida, as viscosidades para ambos os sistemas foram semelhantes, mas o valor da viscosidade foi muito discrepante, assim como a análise visual ao fim do teste, a qual não indicou presença de cristais de hidrato.

Acredita-se que o fator determinante para a formação ou não de hidratos em sistemas não emulsificados seja o tipo de geometria utilizada nos testes. No caso da geometria couette, utilizada nos testes em questão, não há uma mistura entre os componentes durante o teste, dificultando a interação entre as moléculas de água e $\mathrm{CP}$, as quais apresentam densidades consideravelmente diferentes. Uma hipótese é que, caso seja usada uma geometria vane, por exemplo, essa interação entre moléculas é facilitada e, portanto, aumenta a possibilidade de formação de hidratos, mesmo em sistemas não emulsificados.

\subsubsection{4. \\ Influência do gelo na temperatura de formação de hidratos}

Como os testes utilizam temperaturas de sedimentação muito baixas e negativas, é importante garantir que todo a análise pós rampa de temperatura é baseada principalmente na formação de hidratos. O teste mostrado na Fig.41 indica que, quando em temperaturas negativas, um tempo de 40 minutos garante que a influência do gelo é mínima, quando comparada com os cristais de hidrato.

Por isso foram realizados testes com e sem a adição de CP, conforme mostrado na Fig.51. A curva roxa indica o teste sem a utilização de $\mathrm{CP}$ na composição da emulsão $\mathrm{e}$, ao atingir a temperatura de $1^{\circ} \mathrm{C}$, uma diminuição na viscosidade foi observada, confirmando, então, que não houve formação de hidrato. As curvas verde e cinza indicam o comportamento da viscosidade sem o tratamento térmico, para fins de comparação com as viscosidades finais dos testes com tratamento (tanto com e sem CP). Esse resultado já era esperado, já que o CP é a substância 
que promove diretamente a formação de hidratos a pressão atmosférica, porém, esse resultado é importante para definir que não havia gelo na amostra ou que este não contribui diretamente para o aumento na viscosidade.

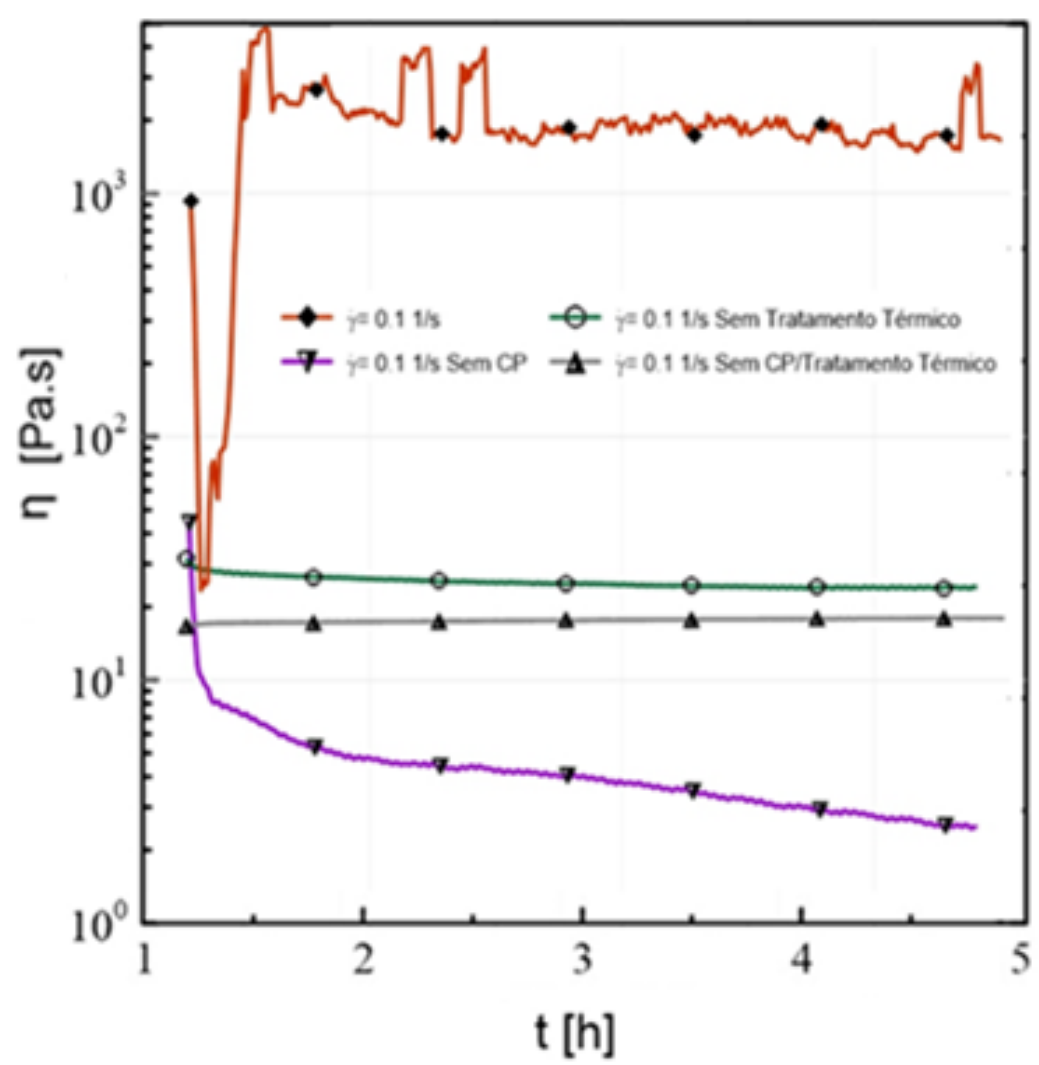

Figura 51 - Comportamento da viscosidade com o tempo para emulsões com e sem CP.

\subsubsection{5.}

Influência da taxa de resfriamento na formação de hidratos

Um outro parâmetro importante de ser analisado é a taxa de resfriamento $(\mathrm{CR})$, pois esta pode influenciar diretamente no tempo de indução e na taxa de crescimento dos cristais de hidratos. A Fig.52 ilustra os resultados obtidos a partir destes experimentos, nos quais as velocidades de resfriamento (etapas 2, 4 e 6 da Fig.29) foram variadas de $1.3^{\circ} \mathrm{C} / \mathrm{min}$ até uma taxa mínima de $0.1625^{\circ} \mathrm{C} / \mathrm{min}$.

Assim como os testes anteriores, os resultados são mostrados a partir do momento em que se atinge a temperatura de formação dos cristais 
de hidratos, ou seja, $1^{\circ} \mathrm{C}$. Pode-se observar uma defasagem entre as curvas, diretamente ligada às taxas de resfriamento e ao tempo que estas necessitam para atingir a temperatura de formação, ou seja, quanto menor a taxa de resfriamento, maior esse tempo.

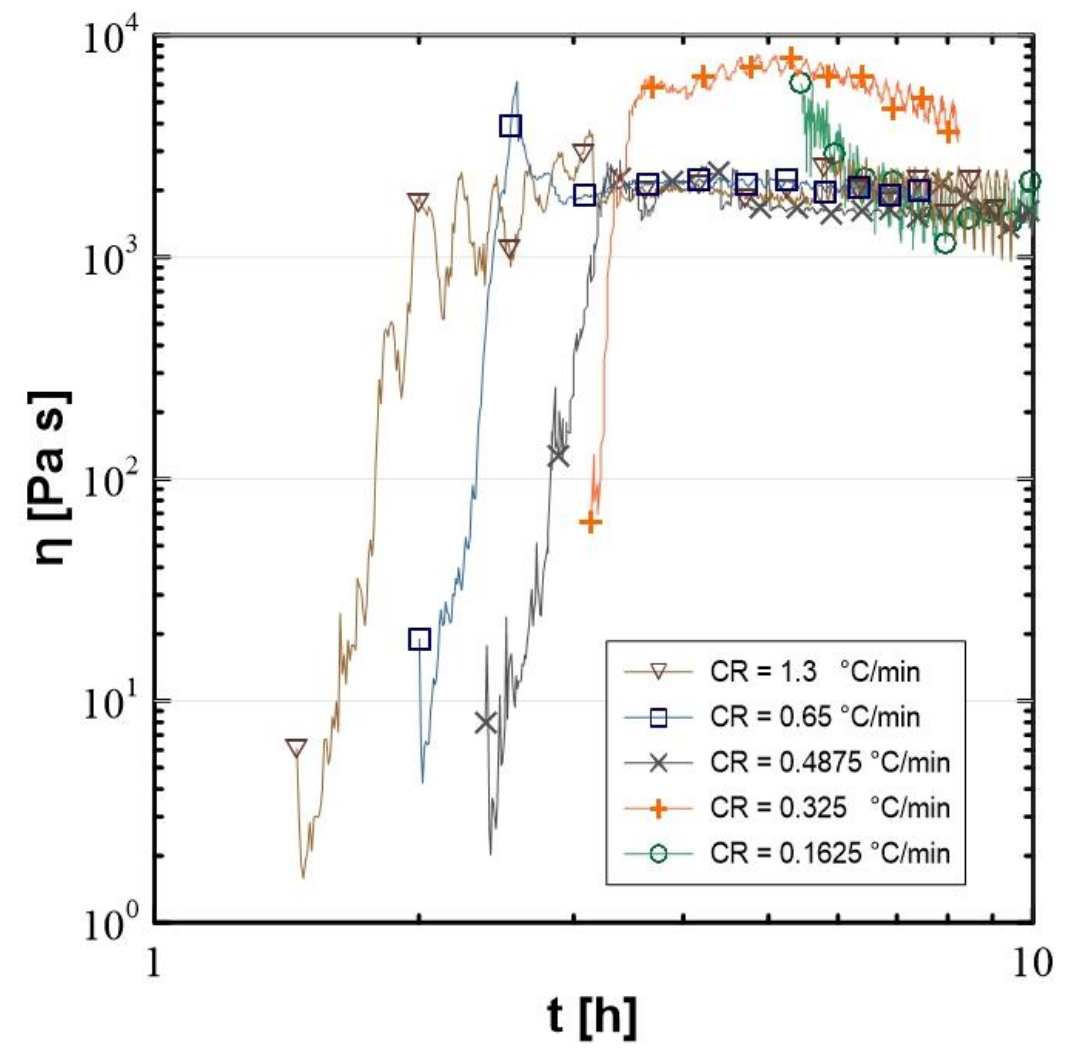

Figura 52 - Comportamento da viscosidade com o tempo para diferentes taxas de resfriamento.

Para melhor entendimento e para uma melhor comparação, as curvas foram deslocadas no tempo, para um mesmo instante, mostrado na Fig.53. É possível observar que as taxas 1,3, 0,65 e 0,4875으/min (curvas marrom, azul e roxa) atingem o mesmo patamar de viscosidade final e tem tempos de indução e crescimento muito parecidos, indicando que essa variação na taxa não influencia diretamente na formação e aglomeração dos cristais de hidrato.

Entretanto, quando o $\mathrm{CR}$ é reduzido para $0,325^{\circ} \mathrm{C} / \mathrm{min}$ (curva laranja), o valor de viscosidade inicialmente atinge um crescimento 10 vezes maior, quando comparado com as taxas maiores de resfriamento. 
Este valor de viscosidade continua aumentando por aproximadamente 1 hora, quando começa a reduzir progressivamente, tendendo ao patamar encontrado nas taxas maiores.

Quando reduzimos essa taxa pela metade, $0,1625^{\circ} \mathrm{C} / \mathrm{min}$ (curva verde), o valor da viscosidade é de aproximadamente 4000 Pa.s. Este valor começa a sofrer uma redução progressiva com o acionamento do rotor, até alcançar um patamar estável e semelhante do encontrado para as taxas maiores (aproximadamente 2000 Pa.s). Tais resultados indicam que a velocidade com que os hidratos se formam está diretamente ligada à taxa de resfriamento, e que esta formação é acelerada a partir de um certo valor de CR.

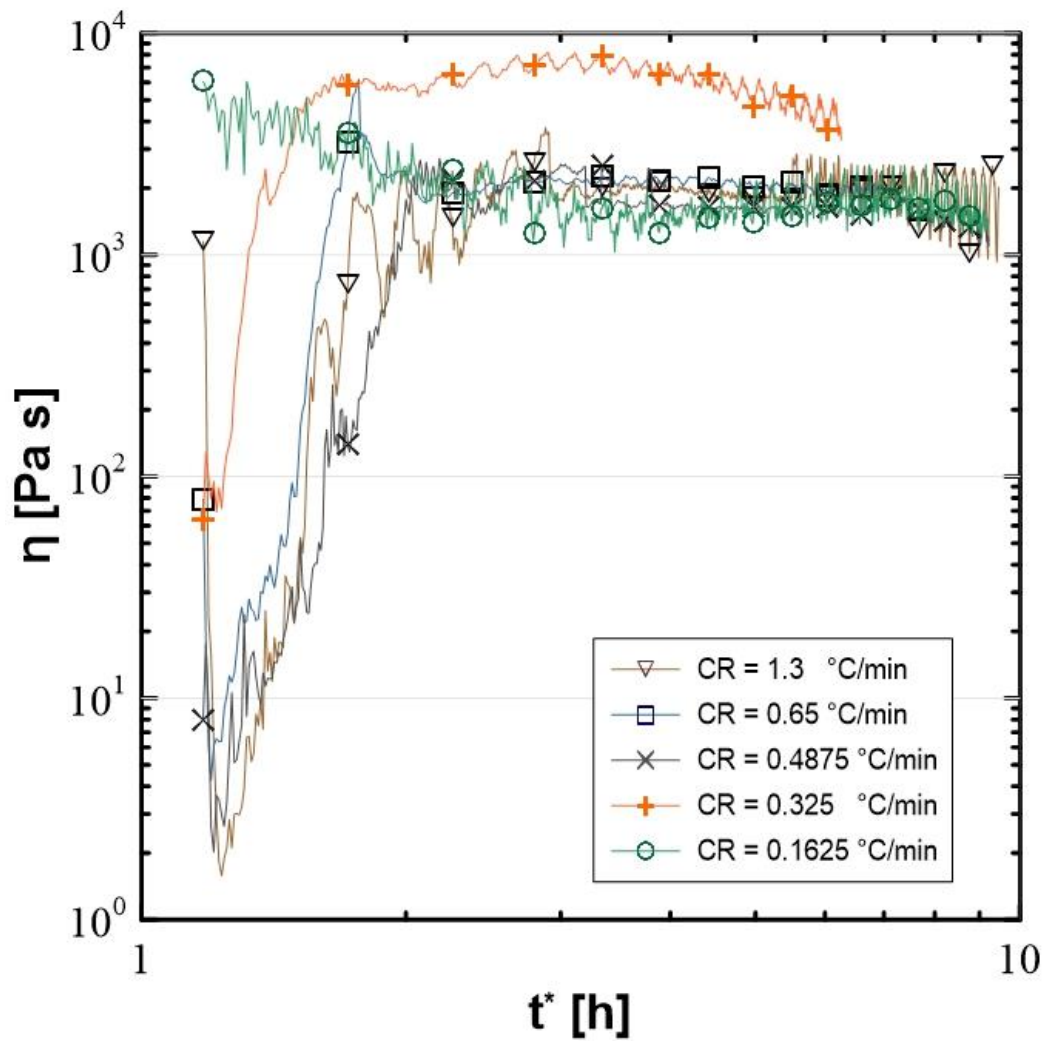

Figura 53 - Comportamento da viscosidade com o tempo para diferentes taxas de resfriamento. Curvas deslocadas.

Para analisar uma possível formação de hidratos sem que haja necessidade das etapas de tratamento térmico, uma amostra foi submetida a uma taxa de resfriamento de $0,08125^{\circ} \mathrm{C} / \mathrm{min}$. Somente a etapa de redução de temperatura de $20^{\circ} \mathrm{C}$ a $1^{\circ} \mathrm{C}$ foi mantida e, ao atingir a 
temperatura de formação, a amostra começou a ser submetida a uma taxa de cisalhamento de $1 \mathrm{~s}^{-1}$.

A Fig.54 mostra que quando reduzimos o CR a níveis ainda menores, mas sem utilizar as etapas de tratamento térmico para estimular a nucleação dos cristais de hidrato, a viscosidade não apresenta uma variação significativa, indicando que não houve formação de hidratos. Acredita-se que mesmo o CP sendo um agente formador de hidratos capaz de formá-los nessa temperatura e a pressão atmosférica, o tempo de indução para formação dos hidratos sem que haja uma perturbação no sistema é consideravelmente grande, o que tornaria os experimentos sem tratamento térmico ou qualquer outra perturbação, inviáveis.

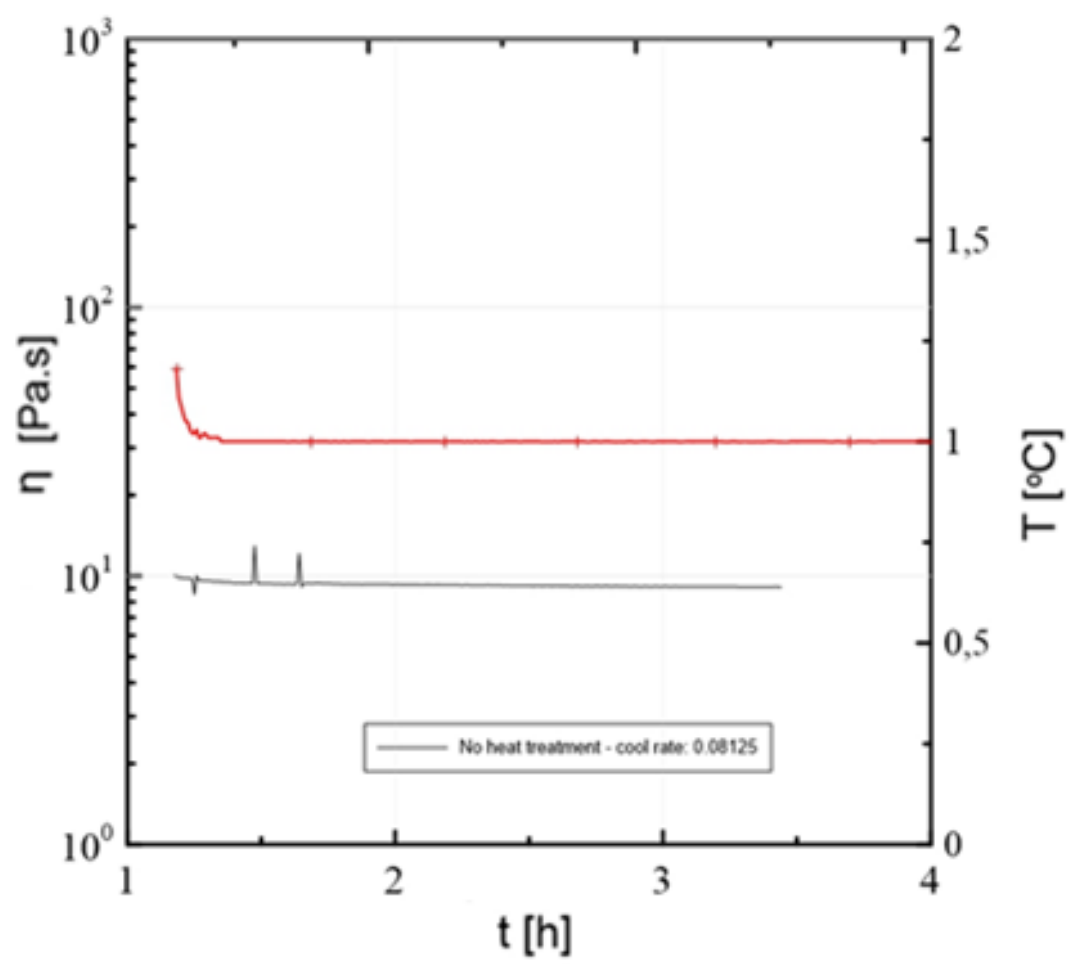

Figura 54 - Análise da viscosidade com o tempo para uma taxa de resfriamento baixa, sem tratamento térmico.

\subsubsection{6.}

\section{Influência da fração volumétrica de água na formação de hidratos}

Com a finalidade de entender melhor a influência da fração volumétrica de água, foram preparadas 4 emulsões com valores diferentes: 
$20 \%, 30 \%, 40 \%$ e $50 \%$. A partir daí, todas as amostras foram submetidas ao mesmo tratamento térmico mostrado na Fig.29 e, quando atingida a temperatura de formação, uma taxa de cisalhamento de $0,1 \mathrm{~s}^{-1}$ foi aplicada.

Conforme mostrado na Fig.55, para uma fração volumétrica de 40\% (curva marrom), houve uma extrapolação do valor da viscosidade (elipse vermelha) e o torque máximo do reômetro foi atingido instantaneamente, pois a quantidade de hidrato formado foi muito elevada. Já para a fração volumétrica de $20 \%$, não houve formação de hidratos, mas com o decorrer do teste, houve uma oscilação considerável da viscosidade. Ao fim deste teste, pôde-se observar, na parte inferior do copo da geometria, um pequeno bloco de gelo, explicando, então, os picos de viscosidade.

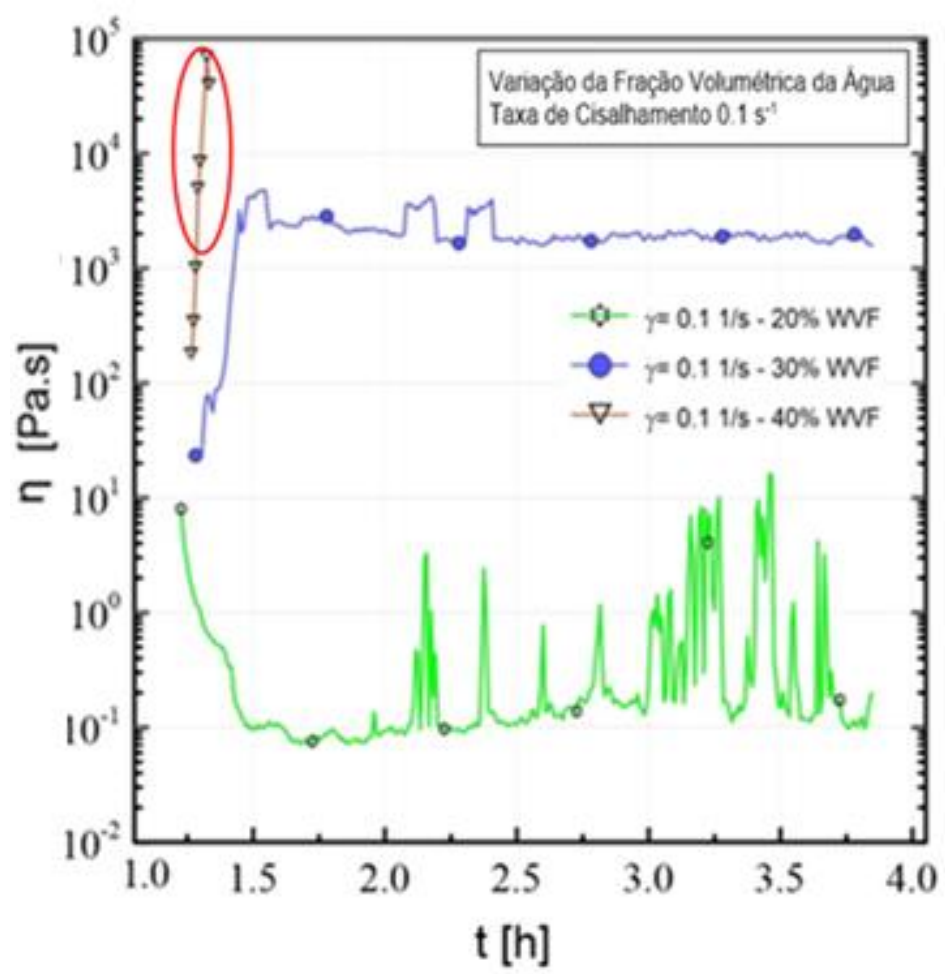

Figura 55 - Comportamento da viscosidade com o tempo para diferentes frações volumétricas de água. Taxa de cisalhamento de $0.1 \mathrm{~s}^{-1}$.

Já que os resultados apresentados na Fig.55 não favoreceram uma comparação com a fração volumétrica testada anteriormente (30\%), optouse por fazer uma análise com uma taxa maior, de $10 \mathrm{~s}^{-1}$, mostrada na Fig.56. Nesse caso, quando utilizada uma fração volumétrica de $40 \%$, o torque máximo não foi atingido e foi possível observar formação de 
hidratos, o mesmo ocorrendo para o corte de água de $20 \%$, enquanto para fração de $50 \%$, a quantidade de hidratos formados foi muito elevada, levando à extrapolação da viscosidade (elipse vermelha).

Quando analisado o tempo de crescimento, pode-se notar que, para frações volumétricas maiores, este é menor. A curva verde (20\%) leva aproximadamente 30 minutos para atingir o valor máximo de viscosidade, enquanto a curva marrom (40\%) leva menos de 10 minutos. Além disso, a viscosidade final aumenta, com o aumento da fração volumétrica, visto que uma quantidade maior de moléculas de água fica disponível para interagir com o CP, possibilitando uma maior formação de cristais de hidratos e, consequentemente, uma maior aglomeração destes.

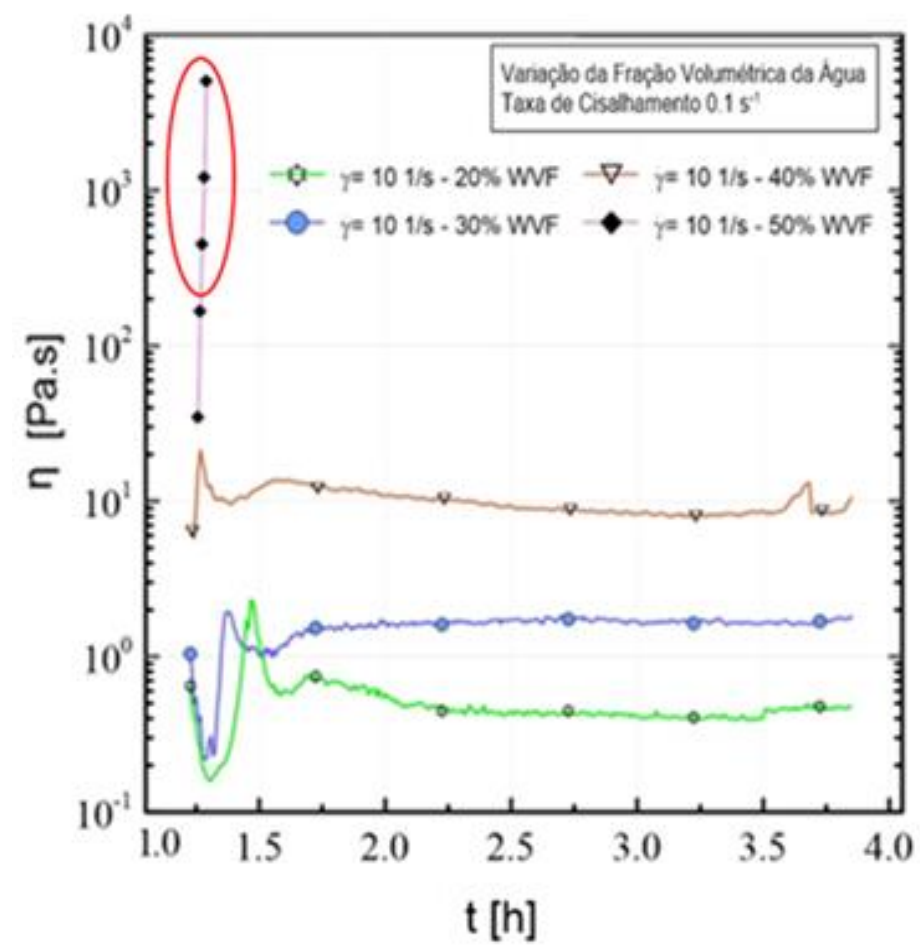

Figura 56 - Comportamento da viscosidade com o tempo para diferentes frações volumétricas de água. Taxa de cisalhamento de $0.1 \mathrm{~s}^{-1}$.

\subsubsection{1.}

Curvas de escoamento para as diferentes frações volumétricas

Para melhor entender o comportamento das diferentes emulsões com diferentes frações volumétricas de água, ao fim dos testes 
apresentados na Fig.56, foram realizadas curvas de escoamento, mantendo a frequência constante e igual a $1 \mathrm{~Hz}$ e fazendo uma rampa de taxa de cisalhamento de 0,1 a $100 \mathrm{~s}^{-1}$, a 1ํㅡ. Para o caso da emulsão com $50 \%$ de água, como o torque máximo foi atingido e o teste teve que ser interrompido, essa análise não foi possível.

As Figuras 57, 58 e 59, representam os resultados obtidos para as frações volumétricas de 20, 30 e $40 \%$, respectivamente. Em todas as situações, foi possível observar um comportamento pseudoplástico da pasta de hidrato formada, pois a viscosidade aparente do fluido reduz com o aumento da taxa de cisalhamento.

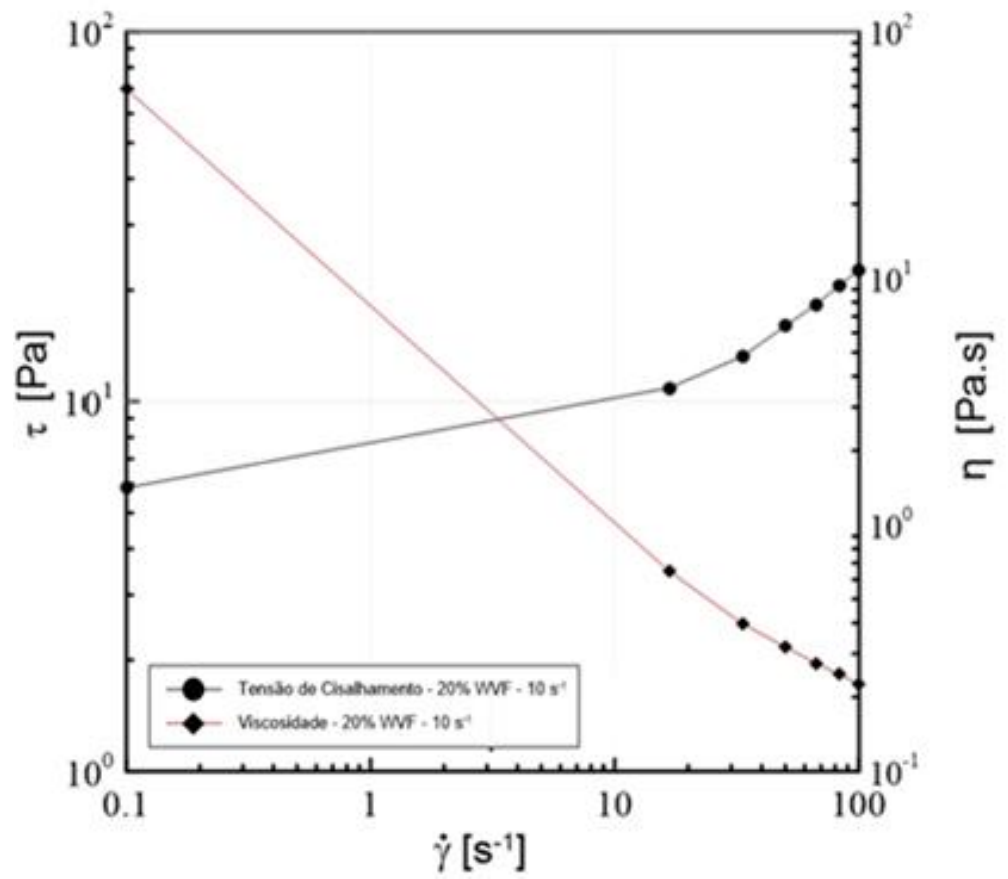

Figura 57 - Curva de escoamento após formação de hidrato para fração volumétrica de $20 \%$.

É importante observar que quanto maior a fração volumétrica de água na emulsão, maior a viscosidade para taxas pequenas, comportamento dentro do esperado, visto que mais moléculas de água são capazes de aprisionar as moléculas de CP disponíveis e, portanto, uma maior quantidade de hidratos é formada. Por exemplo, para fração de $20 \%$, a viscosidade quando uma taxa de $0,1 \mathrm{~s}^{-1}$ é aplicada é em torno de 70 Pa.s, 
enquanto que para uma fração de $30 \%$ é de 400 Pa.s e fração de $40 \%$ é de 3000 Pa.s.

Quando analisada a tensão de cisalhamento em função da taxa, nota-se que para os casos de $20 \%$, há um aumento mais evidente com o aumento da taxa de cisalhamento. Enquanto para $30 \%$, o aumento é mais suave e para $40 \%$, o valor praticamente se mantém constante. Esse comportamento também pode estar diretamente associado à quantidade final de hidratos formados no topo do rotor, aumentando o deslizamento na parede da geometria cilíndrica e comprometendo, então, os valores finais.

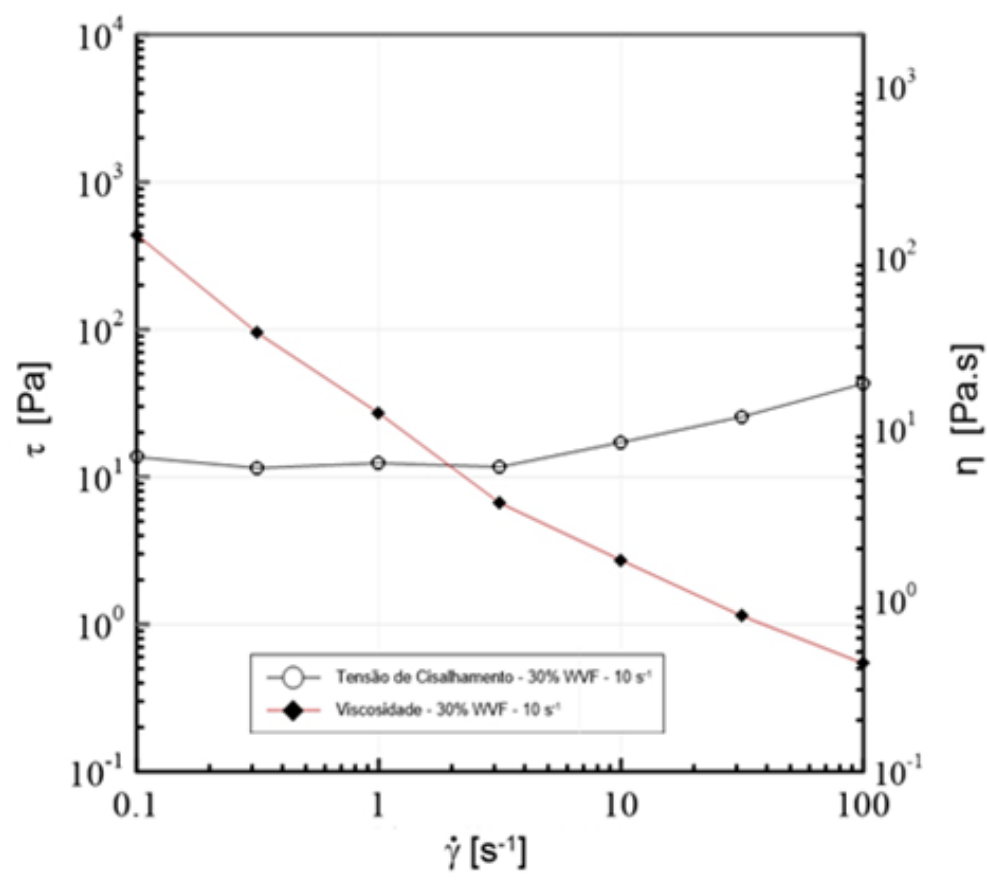

Figura 58 - Curva de escoamento após formação de hidrato para fração volumétrica de $30 \%$.

Por fim, quando analisadas as tensões limite de escoamento, ou seja, o valor no gráfico quando a taxa de cisalhamento tende a zero, para frações de $20 \%$ encontrou-se um valor em torno de $6 \mathrm{~Pa}$, para $30 \%$ um valor de $15 \mathrm{~Pa}$, enquanto para $40 \%$ um valor de $250 \mathrm{~Pa}$. Ou seja, frações volumétricas de água mais elevadas, tem a tendência de formar mais cristais de hidratos, aumentando a dificuldade e, consequentemente, a força necessária para quebrá-los. Enquanto frações volumétricas menores, 
tendem a formar pastas de hidratos, as quais são mais facilmente quebradas para, então, escoar.

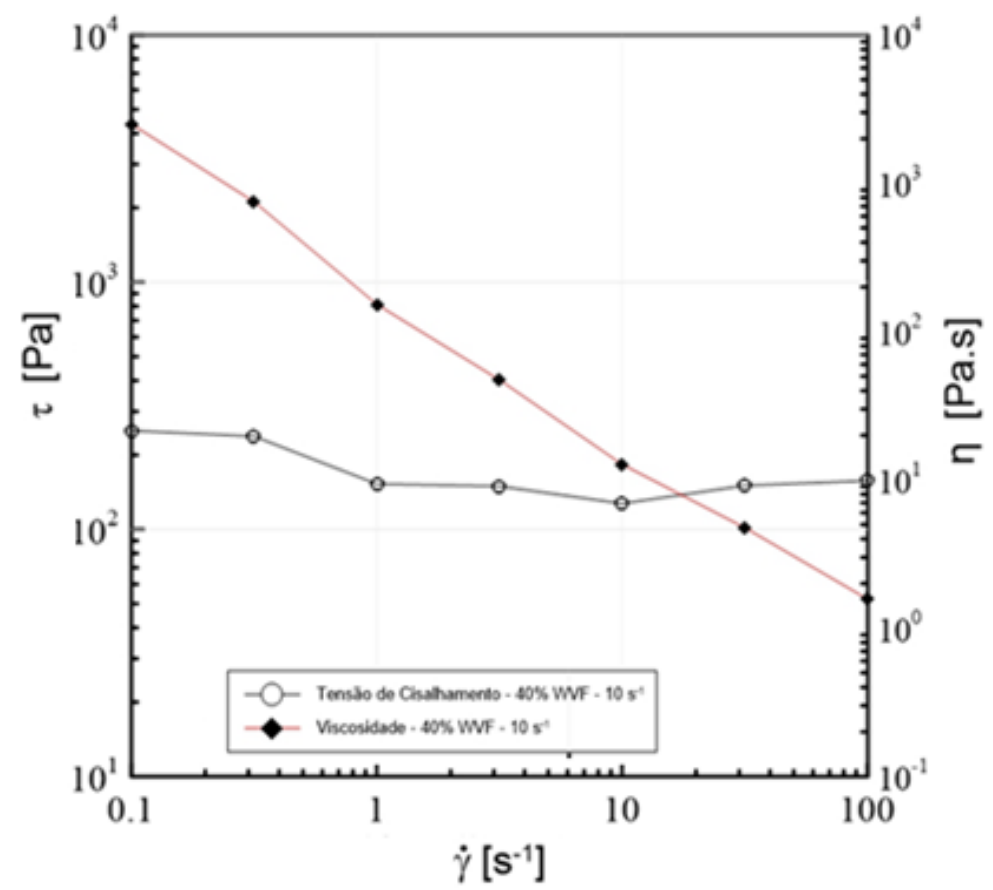

Figura 59 - Curva de escoamento após formação de hidrato para fração volumétrica de $40 \%$.

\subsubsection{2.}

\section{Análise microscópica para as diferente frações volumétricas}

Para melhor entender o comportamento de cada emulsão, tanto antes quanto depois do tratamento térmico e formação de hidratos, uma análise microscópica foi realizada em cada caso. As análises foram feitas imediatamente após a produção da emulsão e, posteriormente, após a formação dos cristais de hidrato.

As figuras 60 e 61 ilustram a microscopia realizada na emulsão com $50 \%$ de fração volumétrica de água e a distribuição de gotas desta, respectivamente. Essa emulsão tem uma estabilidade reduzida, em torno de 1 hora, quando a separação de fases começa a ser observada. Tal fato é confirmado com o tamanho médio das gotas sendo, em sua maioria, acima de $30 \mu \mathrm{m}$. A distribuição de gotas teve uma variação de $10 \mu \mathrm{m}$ a 70 $\mu \mathrm{m}$. 


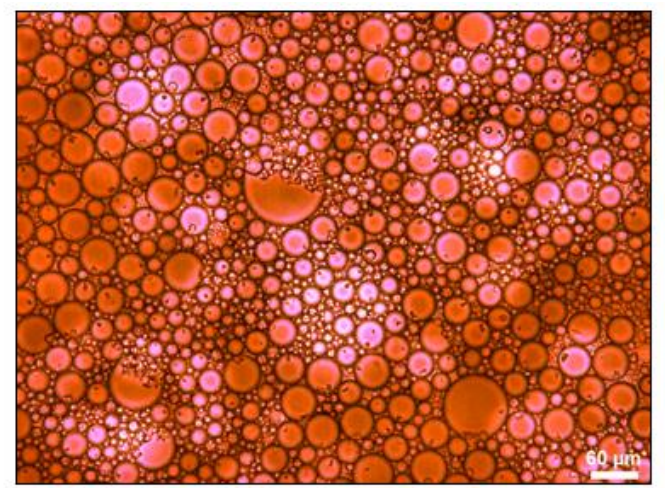

Figura 60 - Microscopia da emulsão com 50\% de fração volumétrica de água.

Diferente das outras frações volumétricas, não foi possível realizar uma análise pós-formação de hidrato, pois, conforme visto anteriormente, a quantidade de hidratos formada foi muito elevada, formando somente um grande bloco de hidratos, o qual causou o bloqueio imediato do reômetro.

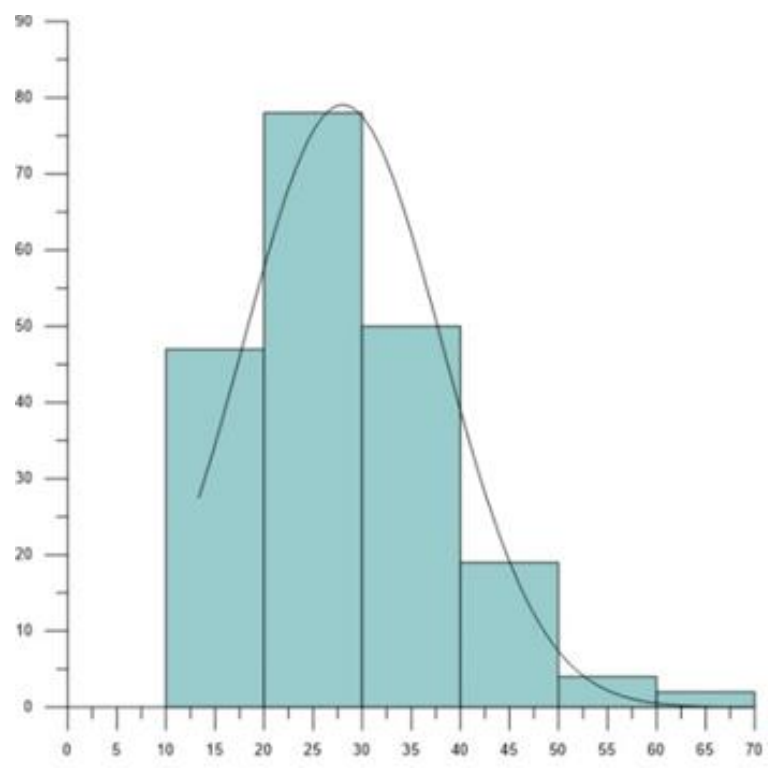

Figura 61 - Distribuição de gotas da emulsão com $50 \%$ de fração volumétrica de água pré-formação de hidratos.

Para as emulsões com $40 \%$ de fração volumétrica, foi possível fazer ambas as análises, assim como para $30 \%$ e $20 \%$. A Fig.62a mostra a microscopia realizada pré-tratamento térmico e, a partir da distribuição de gotas (Fig.63), é possível observar uma distribuição entre $2 \mu \mathrm{m}$ e $36 \mu \mathrm{m}$, sendo a maior concentração de tamanho de gotas em torno de 8 e $10 \mu \mathrm{m}$, confirmando a análise visual de uma estabilidade superior a 3 dias. 


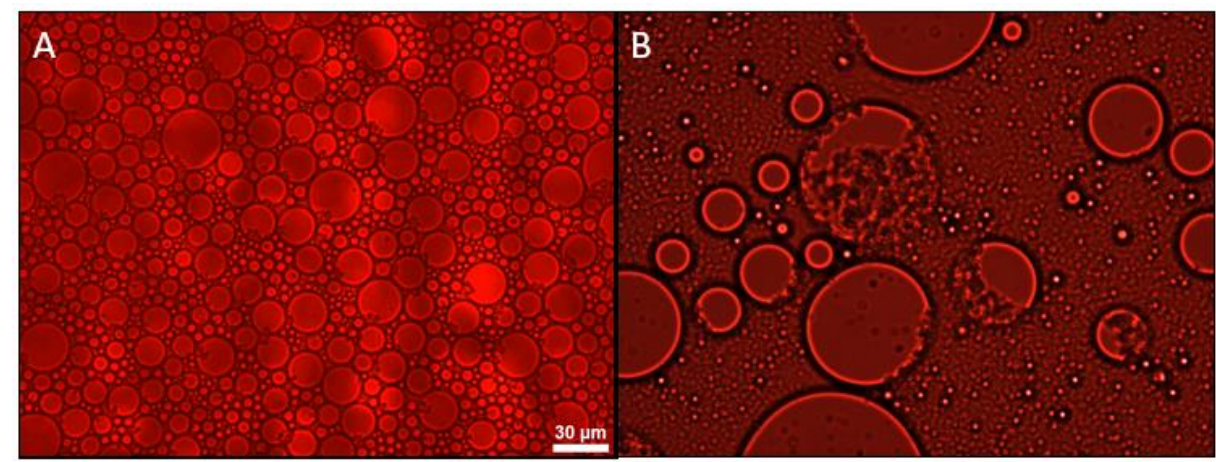

Figura 62 - Microscopia da emulsão com $40 \%$ de fração volumétrica de água. A: Préformação de hidratos. B: Pós-formação de hidratos.

Assim que o teste de formação de hidrato foi finalizado, separou-se o bloco de hidrato formado, da emulsão que sobrou no fundo da geometria. Esta parte líquida continha pequenos cristais de hidratos visíveis e tinha um aspecto pastoso. A Fig.62b mostra uma emulsão desestabilizada, com gotas de água maiores que $40 \mu \mathrm{m}$ e bem espaçadas.

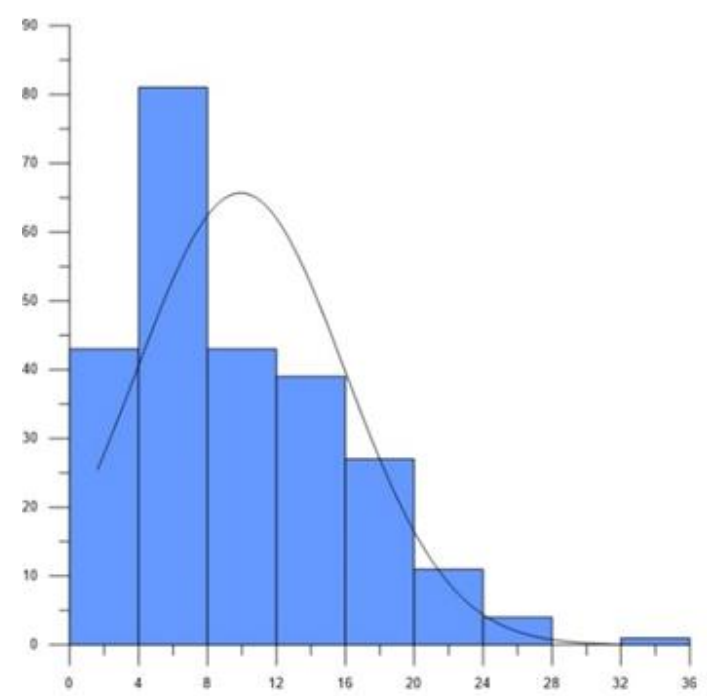

Figura 63 - Distribuição de gotas da emulsão com 40\% de fração volumétrica de água pré-formação de hidratos.

É possível observar que algumas gotas, principalmente as maiores, tem um preenchimento parcial ou próximo do total, diferente das demais gotas, o que pode ser indicativo de um estado intermediário entre os estados líquido e sólido, possivelmente graças à ao efeito de cristalização conferido às moléculas de água e CP. 
Para emulsões com $30 \%$ de fração volumétrica de água, é possível observar, tanto através de análise microscópica (Fig.64a), quando através da análise da distribuição do tamanho das gotas (Fig.65) que a emulsão é mais estável, confirmando a análise visual, que constatou que tal emulsão fica estável por mais de 1 semana. A distribuição do tamanho de gotas variou de $4 \mu \mathrm{m}$ a $28 \mu \mathrm{m}$, sendo que $92 \%$ das gotas analisadas eram menores que $20 \mu \mathrm{m}$.

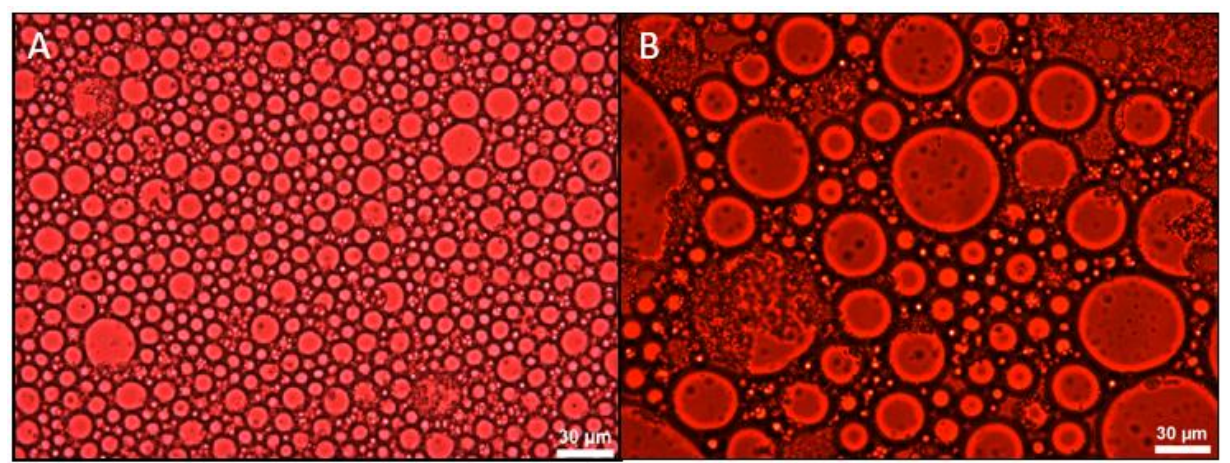

Figura 64 - Microscopia da emulsão com 30\% de fração volumétrica de água. A: Préformação de hidratos. B: Pós-formação de hidratos.

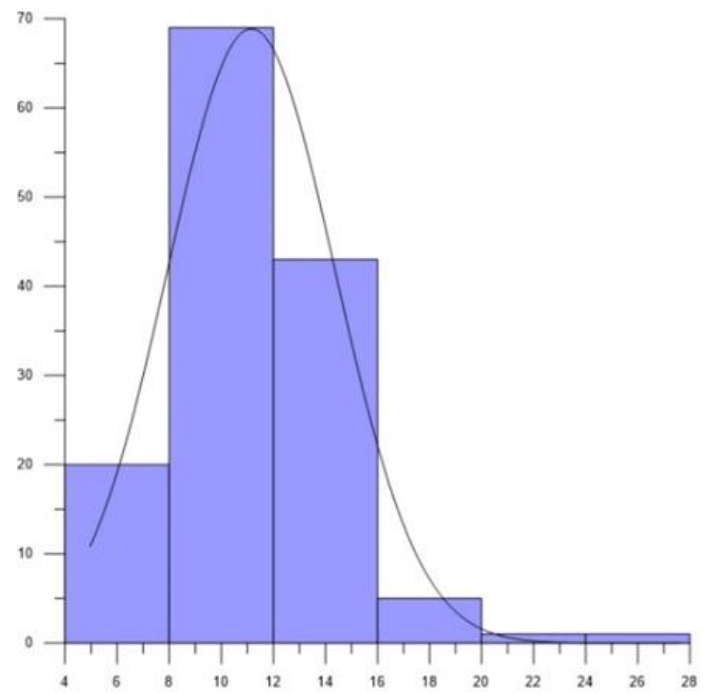

Figura 65 - Distribuição de gotas da emulsão com 30\% de fração volumétrica de água pré-formação de hidratos.

A partir da análise pós-formação de hidratos, também foi possível observar gotas com preenchimento parcial, do que se acredita ser um estado transitório cristal/líquido. Além disso, é possível observar que as 
gotas pós-formação estão menos espaçadas, indicando que, apesar de ter havido desestabilização da emulsão, ela foi menos evidente do que para emulsões com $40 \%$ de fração volumétrica.

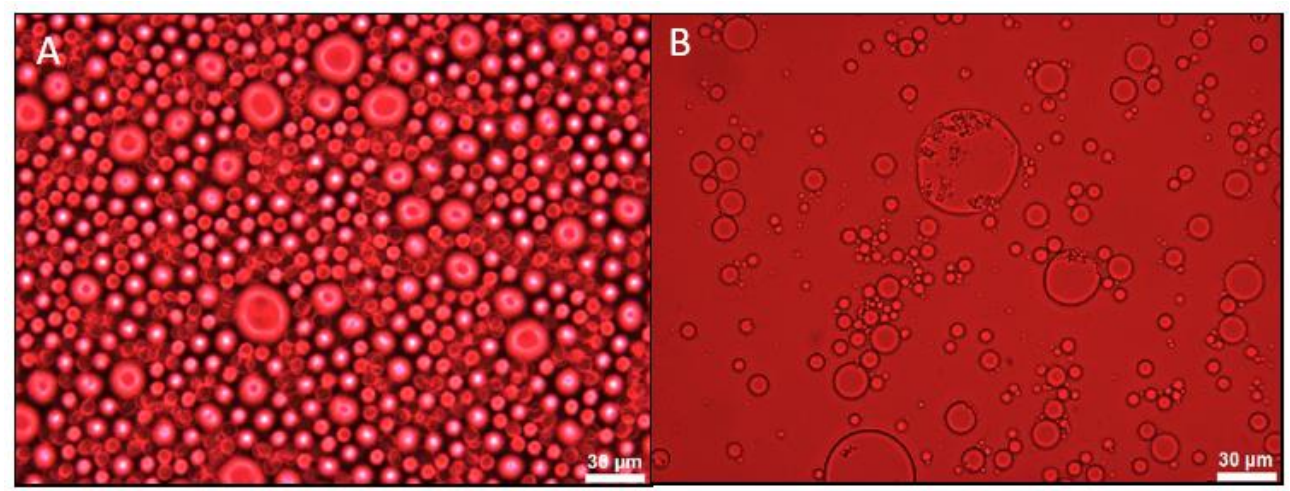

Figura 66 - Microscopia da emulsão com 20\% de fração volumétrica de água. A: Préformação de hidratos. B: Pós-formação de hidratos.

Por último, fez-se a análise microscópica de emulsões com $20 \%$ de fração volumétrica (Fig.66a). Estas emulsões têm uma estabilidade visual de quase 4 semanas e apresentam um aspecto mais pastoso, quando comparadas com as demais. Foi possível inferir que o tamanho de gotas variou entre $1,5 \mu \mathrm{m}$ e $24 \mu \mathrm{m}$ e que $88 \%$ das gotas analisadas apresentavam um valor inferior a $16 \mu \mathrm{m}$.

Por apresentar uma porcentagem de água mais baixa e muito próxima do limite mínimo estequiométrico de água para $\mathrm{CP}$, necessário para formar hidratos, a quantidade final de cristais formados foi menor, como também mostrado anteriormente. Por isso, a análise microscópica pós formação de hidratos (Fig.66 b) apresentou uma menor incidência de bolhas com aspecto semelhante aos casos de $30 \%$ e $40 \%$.

A partir de emulsões $\mathrm{A} / \mathrm{O}$ utilizando $\mathrm{CP}$, foi possível observar em diversas amostras esse aspecto intermediário sólido/líquido que poderia indicar a cristalização das moléculas de água que aprisionaram moléculas de CP no processo de formação de hidratos. 


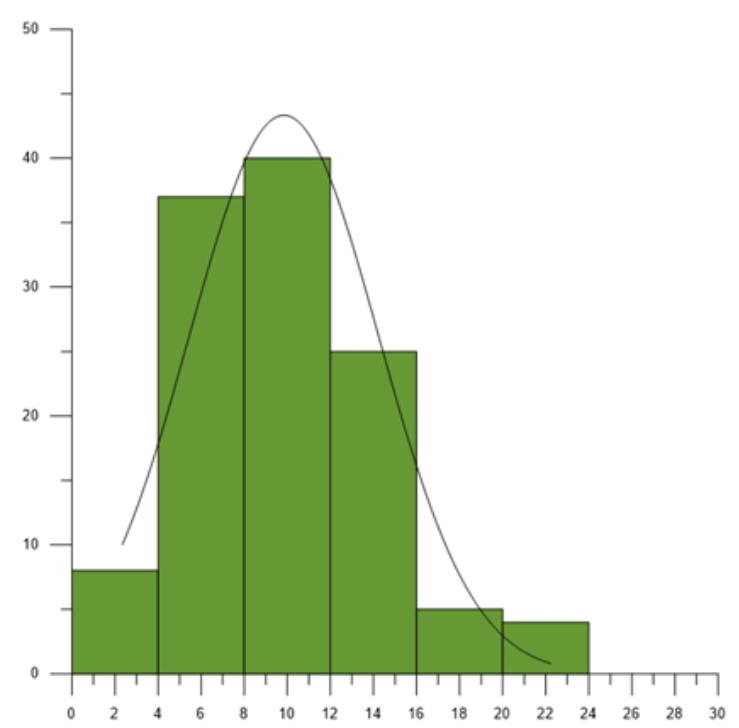

Figura 67 - Distribuição de gotas da emulsão com $20 \%$ de fração volumétrica de água pré-formação de hidratos.

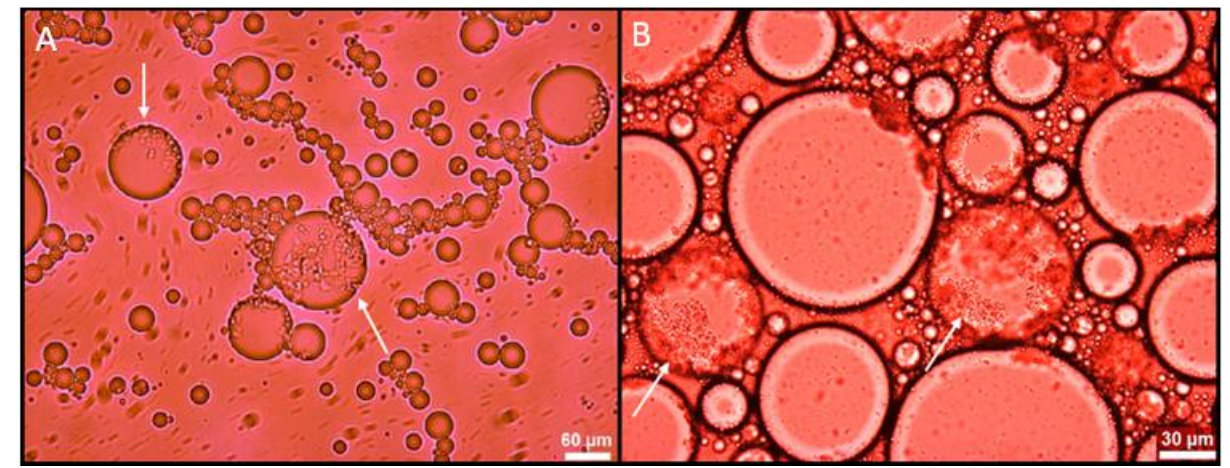

Figura 68 - Microscopia de emulsão utilizada para testes de repetitividade. A: Emulsão 30\% de água.

B: Emulsão $40 \%$ de água.

Nas Fig.68a e Fig68.b, é possível identificar mais de uma bolha com o aspecto mencionado, indicadas pelas setas brancas. Também é importante destacar que o processo individual de cristalização das moléculas é muito complexo e que a análise microscópica deste fenômeno precisa ser mais bem analisada para que uma compreensão mais ampla seja atingida.

\subsubsection{7.}

\section{Influência da temperatura de formação dos hidratos}

A Fig.69 mostra como a temperatura final pode influenciar a formação e aglomeração dos cristais de hidrato. Para tal, todas as etapas 
do tratamento térmico foram mantidas constante, exceto a etapa final, quando a temperatura foi alterada.

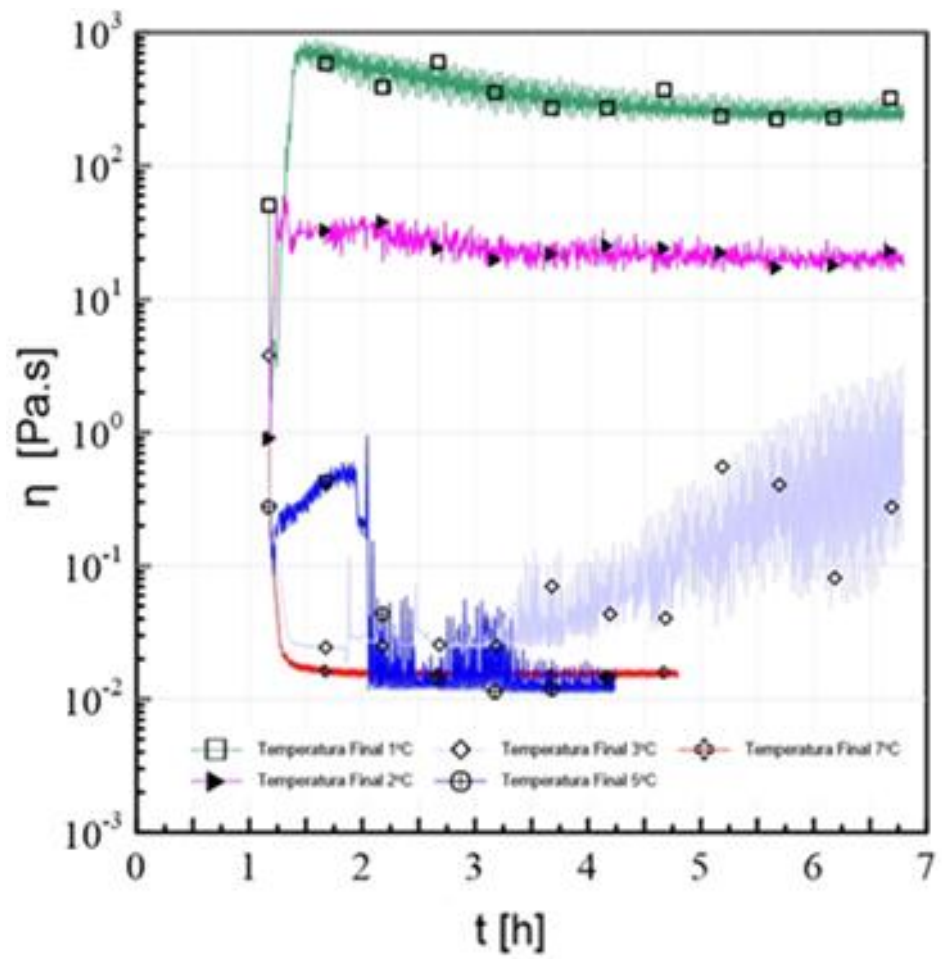

Figura 69 - Comportamento da viscosidade com o tempo para diferentes temperaturas finais.

A temperatura de formação de hidratos, a partir da utilização de $\mathrm{CP}$, tem um valor máximo de aproximadamente $6,4^{\circ} \mathrm{C}$, ou seja, acima desta, não há formação. A curva vermelha mostra a variação da viscosidade quando a temperatura final foi de $7^{\circ} \mathrm{C}$, fora do envelope de formação, e aplicação de uma taxa de cisalhamento igual a $1 \mathrm{~s}^{-1}$. Conforme esperado, a viscosidade teve uma diminuição inicial e, então, se manteve constante pelo resto do teste, indicando que não houve formação de hidratos.

A curva azul (temperatura final de $5^{\circ} \mathrm{C}$ ) mostra um comportamento um pouco diferente do anterior, pois quando atingida tal temperatura, houve um aumento de viscosidade por aproximadamente 1 hora, quando esta teve uma queda brusca, apresentando, então, uma grande flutuação. Possivelmente tal comportamento indica que essa temperatura, no tempo de teste estudado, não é suficiente para estimular uma agregação dos cristais, apesar de estarem presentes. 
Já para uma temperatura final de $3^{\circ} \mathrm{C}$ (curva lilás) é possível observar um tempo de indução de 3 horas, quando a viscosidade começou a aumentar. Quando comparado com as temperaturas de $2^{\circ} \mathrm{C}$ e $1^{\circ} \mathrm{C}$ (curvas rosa e verde), também pôde-se observar que o tempo de crescimento é muito mais longo, indicando uma maior dificuldade dos cristais de hidrato se agregarem, resultando em um valor final de viscosidade inferior e com maior flutuação.

Portanto, mesmo a temperatura final estando dentro do envelope de formação de hidratos, há uma influência direta na quantidade de hidratos formados, no tempo de indução e no tempo de crescimento destes, sendo um parâmetro importante na análise e compreensão do comportamento da pasta de hidrato formada.

\subsubsection{8.}

\section{Dependência temporal dos aglomerados de hidratos}

Uma análise importante para entender como a pasta de hidrato se comporta com o tempo foi feita, aplicando uma taxa inicial de $1 \mathrm{~s}^{-1}$ durante 2 horas, seguida por um tempo de descanso de 2 horas. Após esse período foi aplicada novamente a mesma taxa por mais 4 horas, seguida por um novo descanso de 4 horas. Por fim, aplicou-se novamente a taxa de $1 \mathrm{~s}^{-1}$ por 4 horas.

Pôde-se observar, na Fig.70, que após o primeiro descanso, a diferença entre os valores de viscosidade foi mínima, enquanto que para o segundo, um aumento de 300 Pa.s para $400 \mathrm{~Pa} . \mathrm{s}$ (33,3\%) foi verificado. Esse comportamento pode ser justificado pelo fato de que quanto mais tempo os cristais de hidrato ficam sem ser submetidos à taxa alguma, mais tempo estes conseguem se rearranjar de tal forma a favorecer uma maior aglomeração e, portanto, uma maior viscosidade final. 


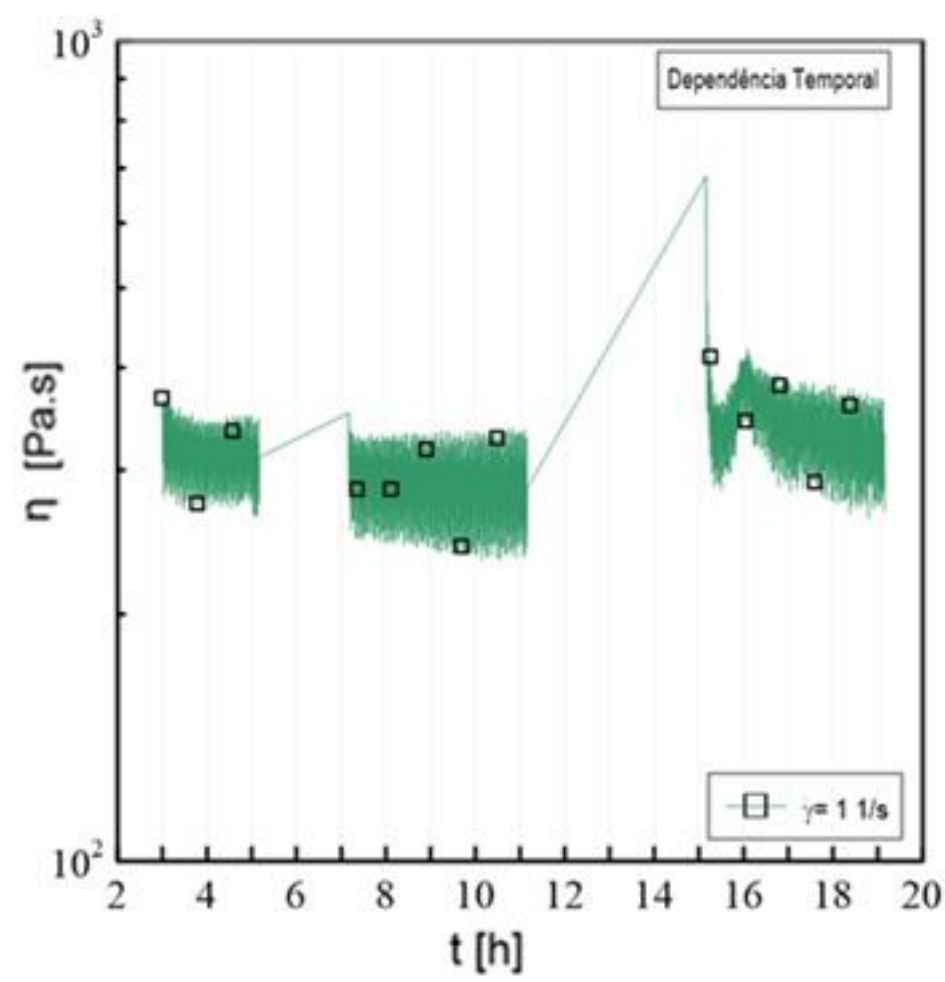

Figura 70 - Comportamento da viscosidade quando a amostra é submetida a diferentes tempos de descanso.

\subsubsection{9. \\ Influência do tempo de descanso a temperaturas acima da de formação}

Para analisar o efeito do tempo de descanso, foi realizado um teste em que a amostra foi submetida a todo o tratamento térmico (Fig.29) e, então, uma taxa de cisalhamento foi aplicada por 4 horas, seguida por um aquecimento da amostra de $1^{\circ} \mathrm{C}$ para $8^{\circ} \mathrm{C}$, a fim de estimular a dissociação dos hidratos, a partir do deslocamento desta amostra para uma temperatura fora do envelope de formação.

A Fig.71 mostra o comportamento da viscosidade, quando uma taxa de $1 \mathrm{~s}^{-1}$ foi aplicada. Conforme observado, após o tempo em que a amostra foi submetida a uma temperatura de $8^{\circ} \mathrm{C}$, por 8 horas, a viscosidade teve uma redução considerável, indicando que os aglomerados de hidrato previamente formados foram totalmente dissociados.

Então, pôde-se observar um tempo de indução de aproximadamente 1 hora, quando, então, começou a ser observado um aumento gradativo na 
viscosidade. Depois de 4 horas, a viscosidade conseguiu atingir o mesmo patamar de antes dessa dissociação.

O mesmo comportamento pode ser observado na Fig.72, onde uma taxa de cisalhamento de $10 \mathrm{~s}^{-1}$ foi aplicada. Apesar de ambos os casos atingirem, ao final, o mesmo patamar de viscosidade inicial, nota-se uma diferença quanto ao tempo de indução, pois para a taxa de $10 \mathrm{~s}^{-1}$, este foi de aproximadamente 5 horas.

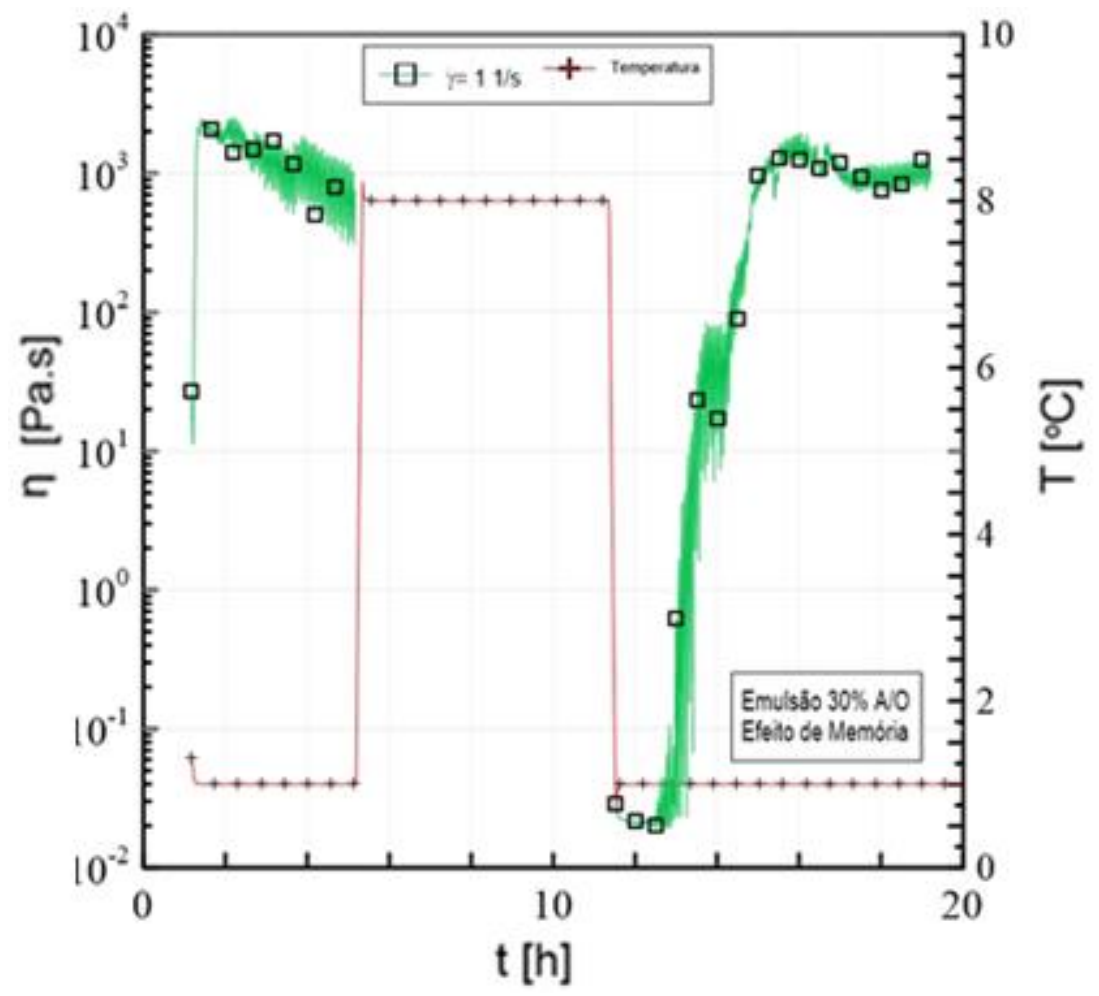

Figura 71 - Comportamento da viscosidade com o tempo após formação de hidrato e após tempo fora do envelope de formação. Taxa de $1 \mathrm{~s}^{-1}$.

Tal comportamento pode estar diretamente associado à quantidade de aglomerados formados para ambos os casos. Quanto maior a taxa de cisalhamento aplicada, menos cristais de hidratos se aglomeram, refletindo em uma viscosidade menor.

Quando essas amostras são levadas a uma temperatura fora do envelope de formação de hidrato, os aglomerados são quebrados e, visualmente, não é possível observá-los. Acredita-se que, a nível molecular, as estruturas dos cristais se mantenham, de tal forma que quando a amostra é novamente submetida à temperatura de $1^{\circ} \mathrm{C}$, haja uma 
rearranjo gradual e progressivo, até que, a nível micro e macroscópico, estes comecem novamente a formação e aglomeração dos cristais, atingindo os níveis alcançados anteriormente.

O aumento no tempo de indução se dá devido ao aumento da taxa de cisalhamento, visto que esta tem uma capacidade maior de quebra da estrutura cristalina e, consequentemente, o rearranjo posterior seja um processo mais lento.

Para associar este comportamento ao efeito de memória de hidratos, é necessário comparar o tempo de indução encontrado em ambos os gráficos, com o efeito de indução da mesma emulsão sem submetê-la a um tratamento térmico. Conforme dito anteriormente, quando não é aplicada uma perturbação no sistema, esse tempo de indução é muito elevado, tornando os testes inviáveis.

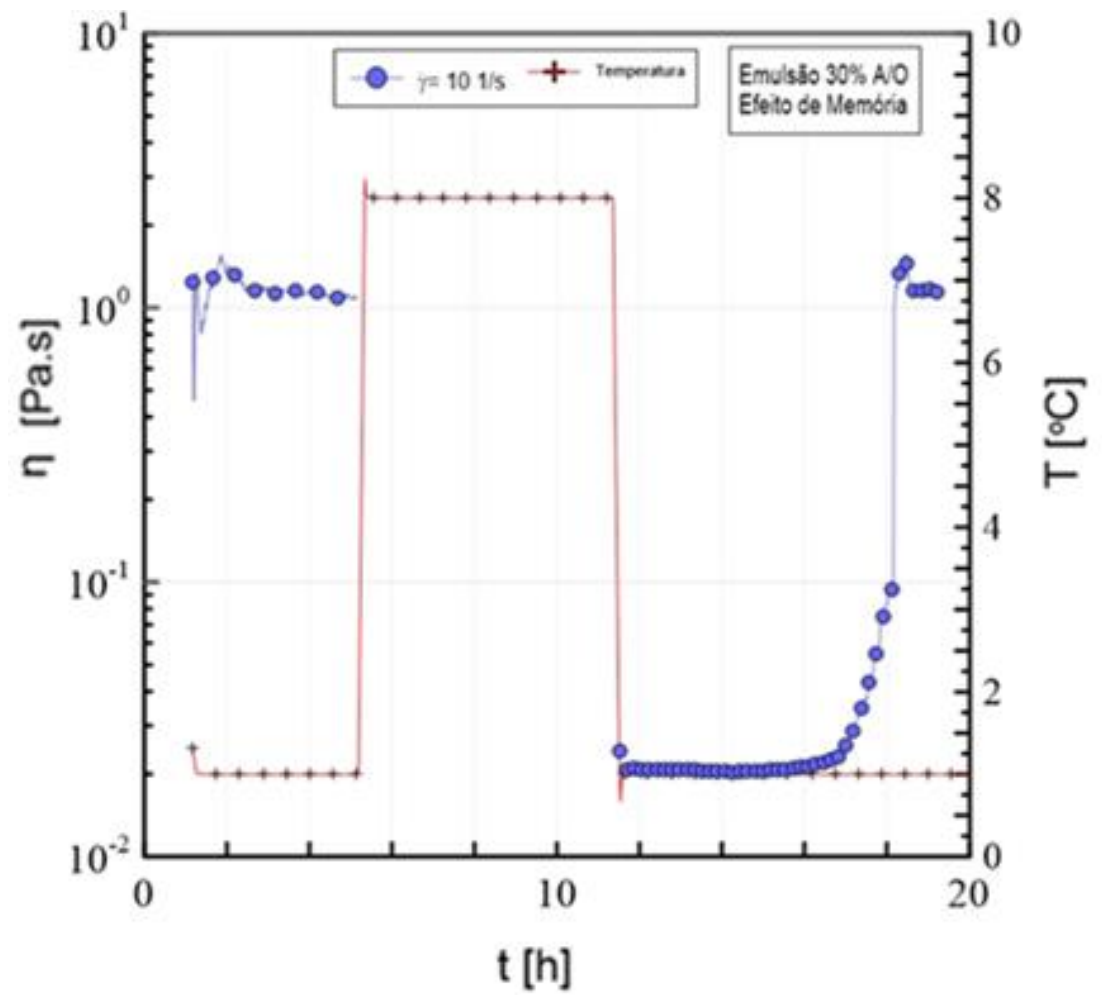

Figura 72 - Comportamento da viscosidade com o tempo após formação de hidrato e após tempo fora do envelope de formação. Taxa de $10 \mathrm{~s}-1$. 


\subsection{2.}

\section{Testes Oscilatórios}

\subsubsection{1.}

\section{Análise da varredura de tensão}

A varredura de tensão é um teste oscilatório, o qual necessita que a frequência seja mantida constante e haja uma variação da tensão de cisalhamento em uma faixa determinada. A partir deste, é possível fazer uma análise os módulos elástico ( $\left(G^{\prime}\right)$ e viscoso ( $\left.G^{\prime \prime}\right)$ em função da tensão.

Para realizar tais testes, as amostras foram primeiramente submetidas ao tratamento térmico (Fig. 29) e, ao atingir a temperatura de formação de hidrato $\left(1^{\circ} \mathrm{C}\right)$, uma taxa de cisalhamento foi aplicada por 3 horas, a fim de atingir um patamar estável de viscosidade e, então, aplicouse uma frequência constante de $1 \mathrm{~Hz}$ a uma faixa de tensão de 0,1 a 1000 Pa. Como já foi analisado a influência da taxa de cisalhamento na formação de hidratos, foram realizados diferentes varreduras de tensão, para diferentes pastas de hidratos formadas a partir da aplicação de diferentes taxas.

A Fig.73 mostra o comportamento dos módulos elástico e viscoso para uma pasta de hidrato formada a partir da taxa $1 \mathrm{~s}^{-1}$. Para valores menores que $10 \mathrm{~Pa}$, o torque foi menor do que o mínimo recomendado pelo reômetro, por isso tais valores foram desconsiderados.

Como pode ser observado, o módulo elástico começa se sobrepondo ao módulo viscoso e é possível determinar uma região viscoelástica linear entre os valores de 50 e $200 \mathrm{~Pa}$. O momento em que as curvas de G' e G" indica o exato momento em que há a quebra da estrutura elástica, permitindo, então, que o fluido escoe. A partir do valor dessa interseção, é possível estimar uma faixa em que ocorre a tensão limite de escoamento que, nesse caso, é em torno de $500 \mathrm{~Pa}$. 


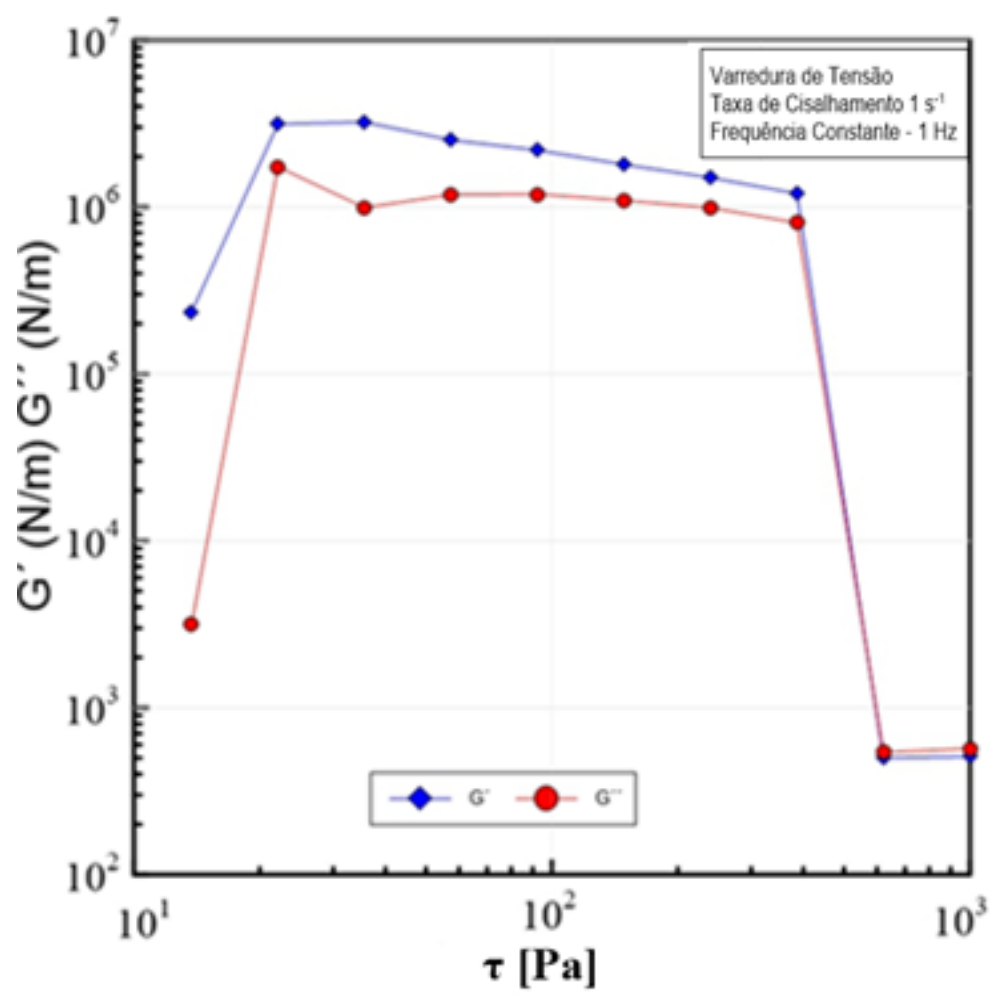

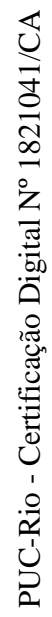

Figura 73 - Varredura de Tensão para pasta de hidrato formada a partir de uma taxa de cisalhamento de $1 \mathrm{~s}^{-1}$.

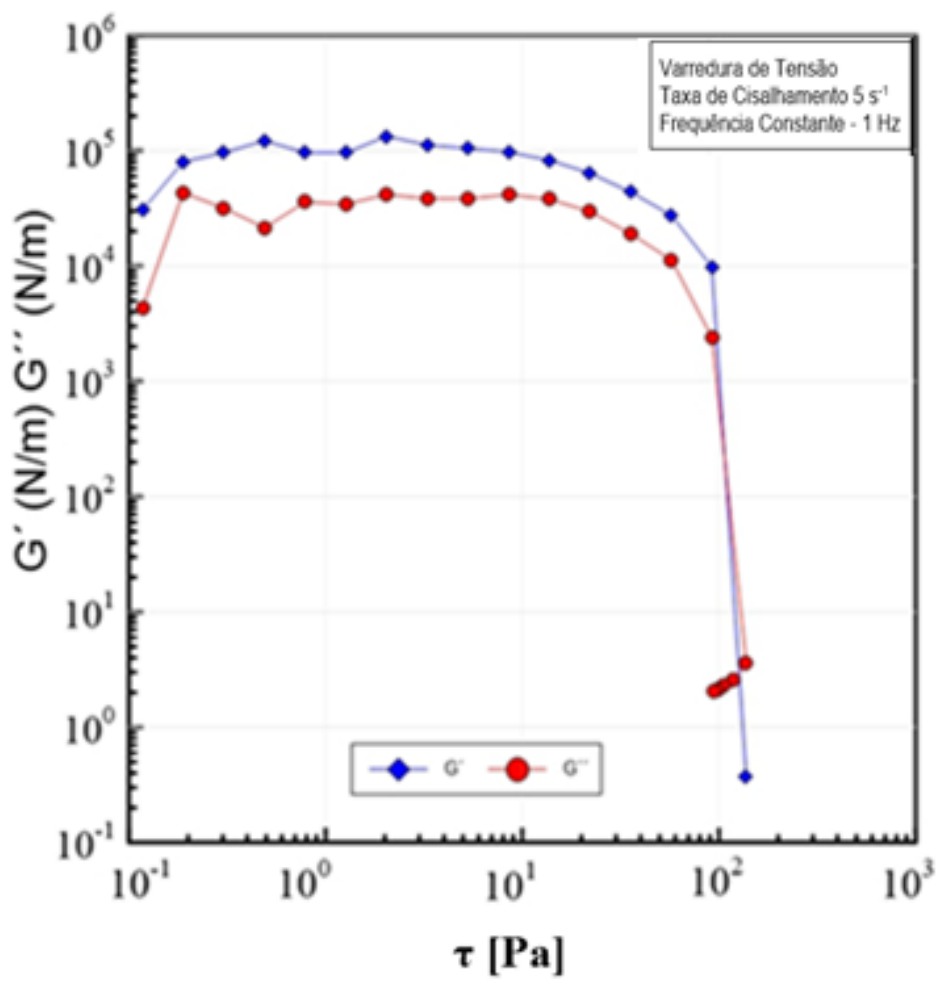

Figura 74 - Varredura de Tensão para pasta de hidrato formada a partir de uma taxa de cisalhamento de $5 \mathrm{~s}-1$. 
Para pastas de hidrato formadas a partir de uma taxa de $5 \mathrm{~s}^{-1}$ (Fig.74), nota-se que foi possível observar uma faixa de região viscoelástica linear entre $1 \mathrm{~Pa}$ e $10 \mathrm{~Pa}$ e o módulo elástico foi superior ao viscoso até um valor de $110 \mathrm{~Pa}$, quando houve a interseção entre as curvas e posterior predomínio do comportamento viscoso, devido à quebra da estrutura elástica.

Para uma taxa de $10 \mathrm{~s}^{-1}$ (Fig.75), a faixa viscoelástica linear também foi entre 1 e $10 \mathrm{~Pa}$, onde $\mathrm{G}^{\prime}$ era superior ao $\mathrm{G}^{\prime \prime}$, indicando um comportamento elástico, conforme esperado. Já o momento em que a estrutura elástica foi quebrada para dar espaço para o comportamento viscoso ocorreu em torno de $60 \mathrm{~Pa}$, valor que pode ser considerado uma estimativa da tensão limite de escoamento.

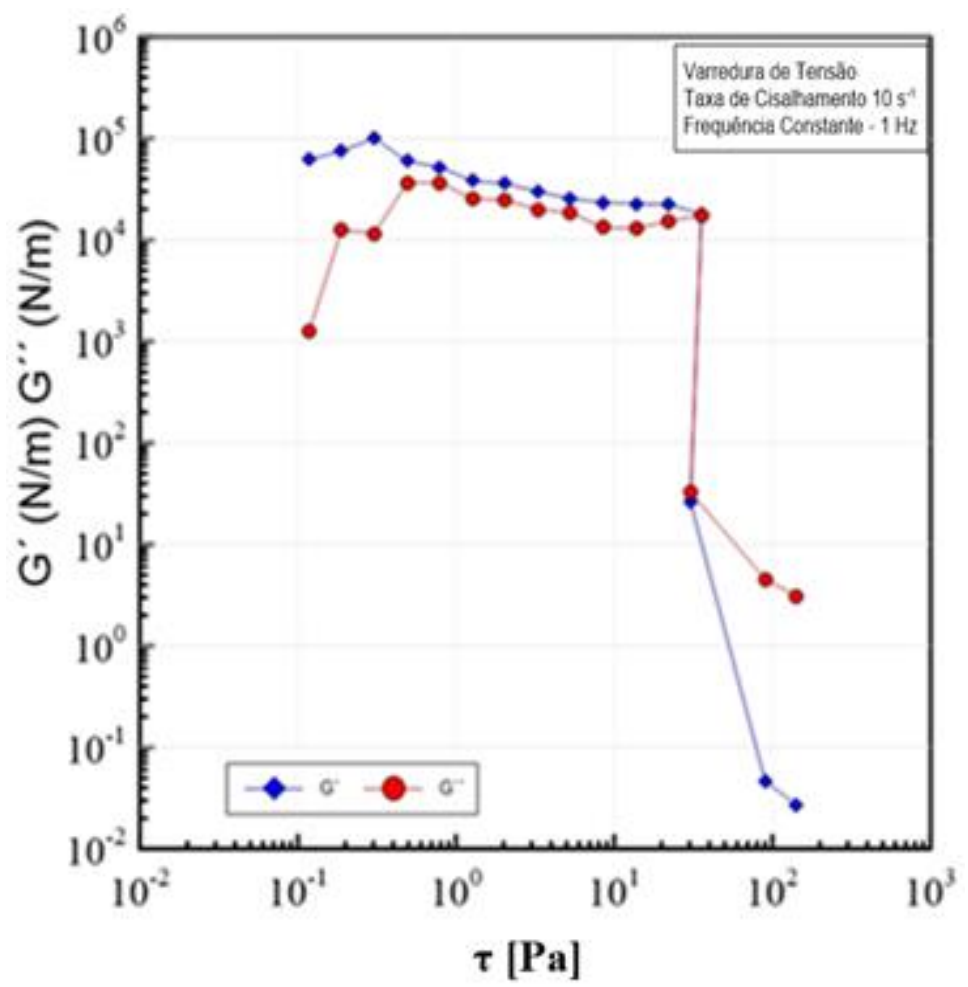

Figura 75 - Varredura de Tensão para pasta de hidrato formada a partir de uma taxa de cisalhamento de $10 \mathrm{~s}-1$.

A Fig.76 ilustra o comportamento destes módulos para uma pasta de hidrato formada a partir de uma taxa de $50 \mathrm{~s}^{-1}$. Assim como nos casos anteriores, o comportamento elástico começou se sobrepondo ao viscoso. 
Entretanto, a queda inicial apresentada por ambos os módulos, não é um comportamento esperado.

É possível que esse comportamento tenha ocorrido pois pastas formadas a partir de uma taxa de $50 \mathrm{~s}^{-1}$ tem uma estrutura cristalina mais instável, causando uma maior demora para atingir um regime permanente. Ainda é possível observar que as curvas se interceptam e ocorre uma inversão no comportamento, aproximadamente, para um valor de tensão de $1 \mathrm{~Pa}$.

Com a análise e comparação entre os resultados dos testes anteriores, é possível inferir que quanto menor a taxa de cisalhamento aplicada à emulsão para formar os cristais de hidrato, maior a quantidade de aglomerados e mais forte a sua ligação, resultando em estruturas elásticas mais difícil de ser quebradas e, consequentemente, uma maior tensão limite de escoamento estimada. Por exemplo, quando diminuimos a taxa aplicada para formação de $10 \mathrm{~s}^{-1}$ para $1 \mathrm{~s}^{-1}$, observa-se um aumento de aproximadamente 4,5 vezes.

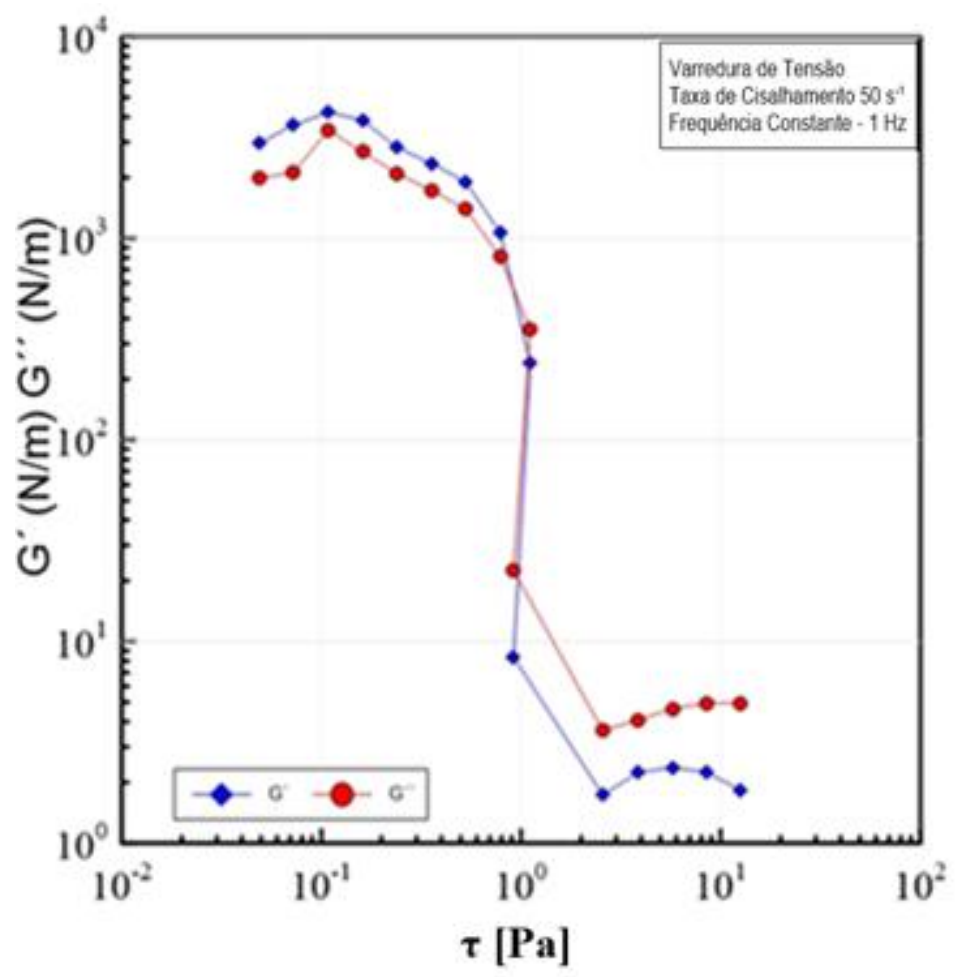

Figura 76 - Varredura de Tensão para pasta de hidrato formada a partir de uma taxa de cisalhamento de $50 \mathrm{~s}-1$. 


\subsubsection{2.}

\section{Análise da varredura de tempo}

Para analisar o comportamento dos módulos elástico e viscoso com o tempo, foi realizado um teste oscilatório, mantendo constante a frequência $(1 \mathrm{~Hz})$ e a tensão de cisalhamento (5 Pa e $10 \mathrm{~Pa})$, mostrados nas Fig.77 e Fig.78. Tais valores de tensão foram escolhidos, pois estes estão dentro do limite de torque utilizado pelo reômetro Physica MCR301.

A medição foi realizada durante todo o tratamento térmico, a fim de compreender o comportamento pré e pós-formação de hidrato. Para o caso em que a tensão de cisalhamento foi de $5 \mathrm{~Pa}$, nota-se que a amostra apresentou um comportamento predominantemente viscoso antes da temperatura ser reduzida até $-12^{\circ} \mathrm{C}$, quando começou a haver formação de gelo e nucleação do hidrato e, então, houve uma inversão no comportamento, a partir do qual $\mathrm{G}^{\prime}$ ficou superior a $\mathrm{G}^{\prime \prime}$.

Ao atingir a temperatura de $1^{\circ} \mathrm{C}$, observou-se uma queda brusca em ambos os módulos, devido à fusão do gelo e, então, o módulo elástico teve um aumento abrupto, enquanto o viscoso se manteve em patamares reduzidos, comprovando a presença de hidratos.

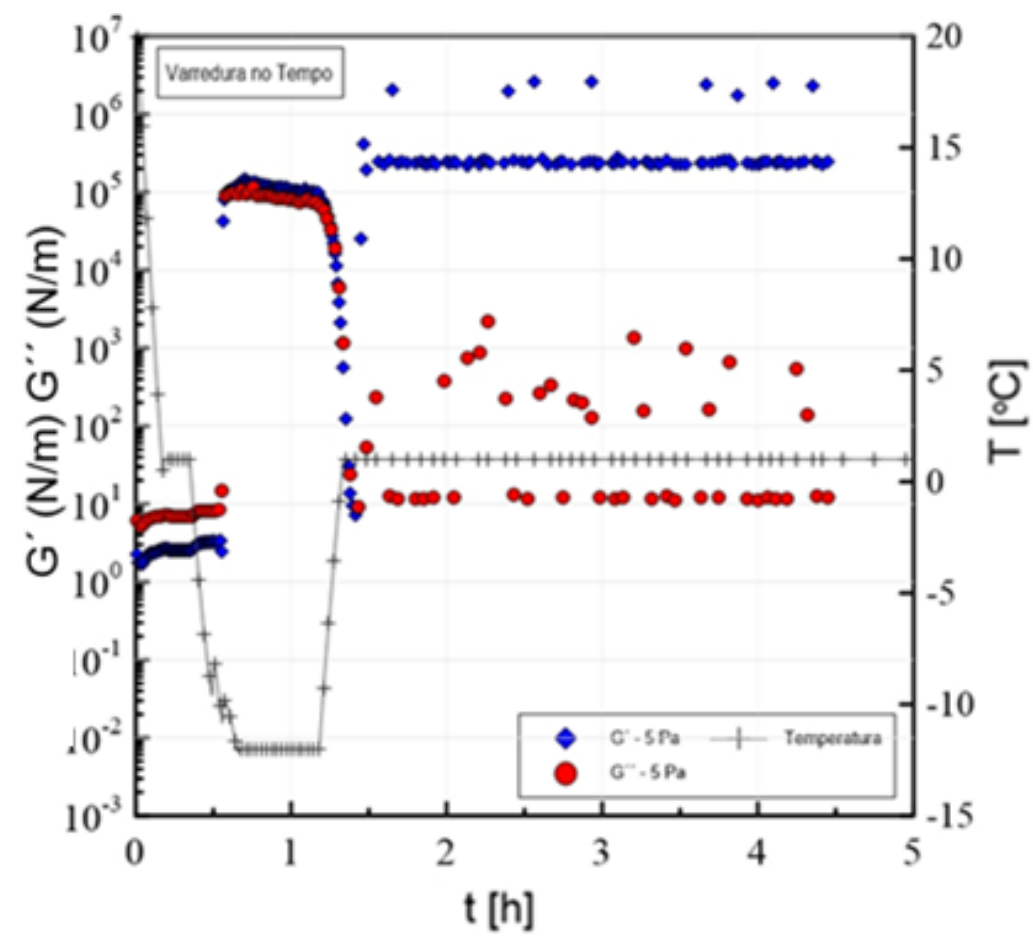

Figura 77 - Varredura no tempo para pasta de hidrato. Tensão de cisalhamento de $5 \mathrm{~Pa}$. 


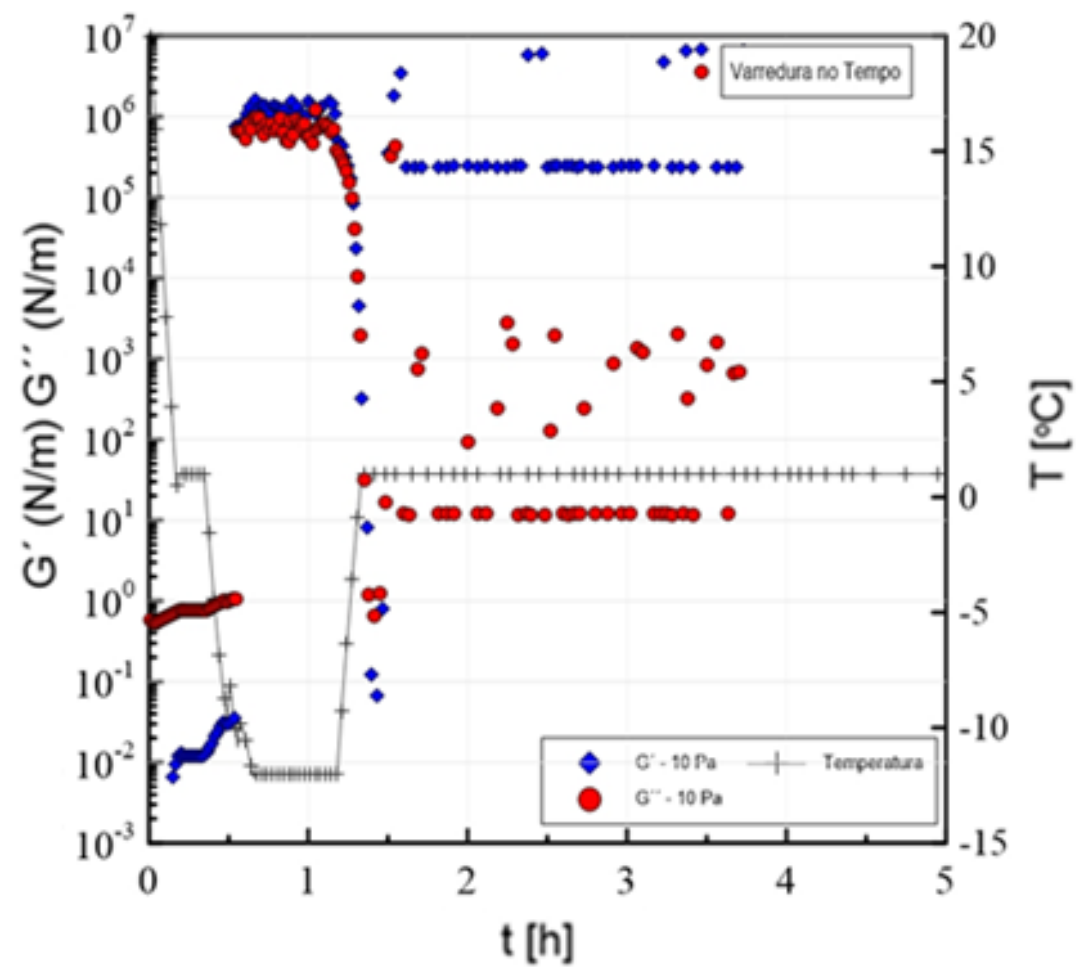

Figura 78 - Varredura no tempo para pasta de hidrato. Tensão de cisalhamento de 10 $\mathrm{Pa}$.

Quando comparado com a varredura de tempo para a tensão constante de $5 \mathrm{~Pa}$, observou-se que a principal diferença foram os valores dos módulos antes da amostra ser levada a temperaturas negativas. Devido a uma maior tensão, estes módulos tiveram valores reduzidos, porém o G" continuou se sobrepondo ao G'.

No momento em que a formação de hidratos começou, o comportamento foi o mesmo para ambas as tensões aplicadas nos testes diferentes. Nota-se que nos dois testes é possível observar valores flutuantes, tanto de $\mathrm{G}^{\prime}$ quanto e $\mathrm{G}^{\prime \prime}$, que podem ser explicados por um possível deslizamento na parede da geometria.

A Fig.79 tem a finalidade de comparar a varredura de tempo, aplicando tensão constante de $5 \mathrm{~Pa}$, mas com temperatura final de $8^{\circ} \mathrm{C}$. Conforme mostrado, os valores de $\mathrm{G}^{\prime}$ e $\mathrm{G}^{\prime \prime}$ são equivalentes aos mostrados na Fig.77 nas etapas 1-6 da rampa de temperatura. Entretanto, quando a temperatura final é atingida, fora do envelope de formação, o comportamento viscoso se sobrepõe ao elástico, confirmando que não há formação de cristais de hidratos, conforme esperado. 


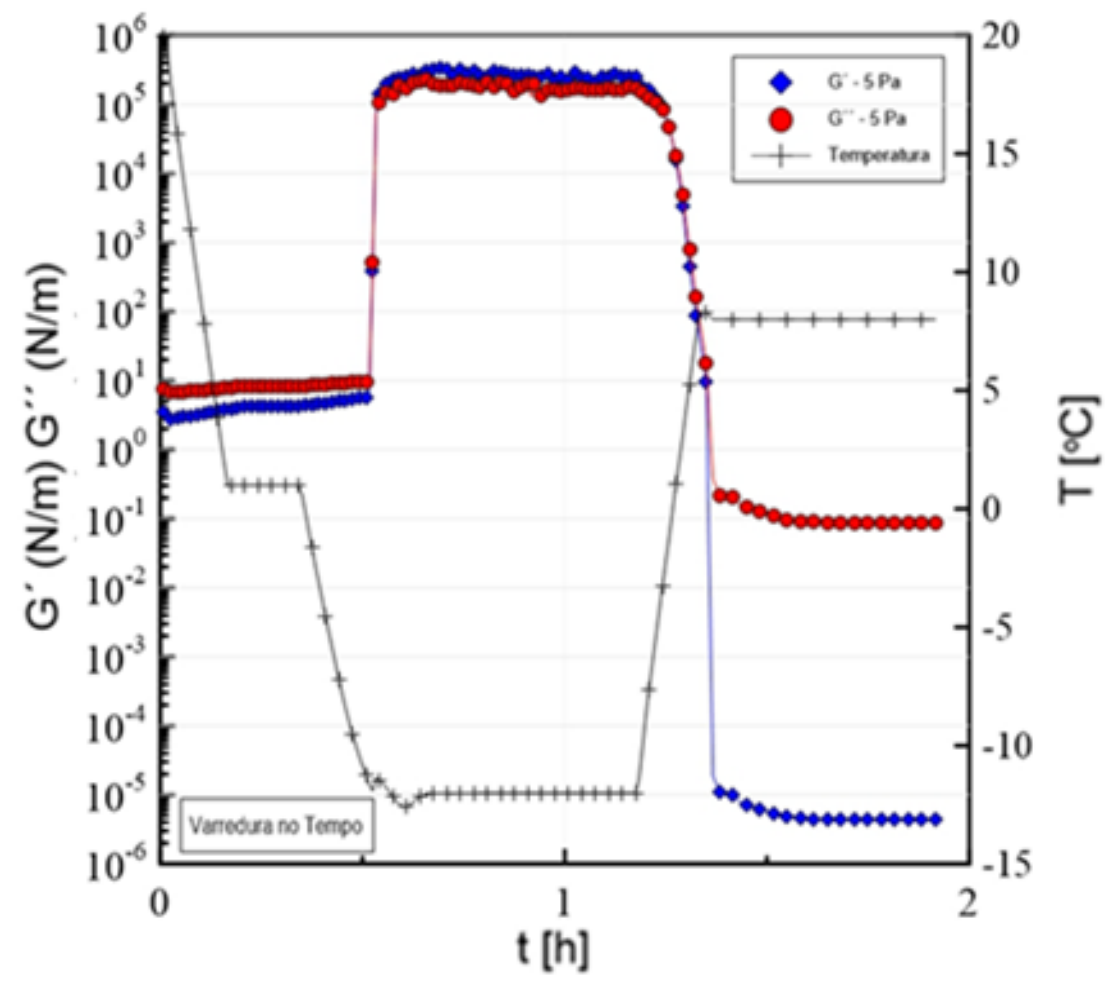

Figura 79 - Varredura no tempo para pasta de hidrato. Tensão de cisalhamento de $5 \mathrm{~Pa}$ e temperatura final de $8^{\circ}$.C. 


\section{5 \\ Conclusão e sugestões para trabalhos futuros}

\section{1. \\ Conclusão}

Foi analisada a estabilidade de 4 diferentes emulsões, com diferentes óleos minerais, surfactantes e concentrações de todos os componentes. A partir de uma análise visual, foi constatado que somente as emulsões 3 e 4 tiveram estabilidade acima de 1 dia, sendo que, para a emulsão 3 , diversos testes com rampa de temperatura foram realizados, sem haver produção de hidratos.

Definida a emulsão de trabalho, foi possível analisar diversos parâmetros que influenciam diretamente na produção e consequente aglomeração dos cristais de hidrato formados. A rampa de temperatura usada durante todos os testes foi o distúrbio necessário, no sistema, capaz de estimular a nucleação dos cristais, quando a temperatura de formação foi atingida.

Diferentes taxas de cisalhamento, temperaturas de indução, taxas de resfriamento, temperaturas finais de formação foram aplicadas após a nucleação, apresentando resultados significativos para melhor entender o comportamento os cristais de hidrato e sua posterior aglomeração.

Foi possível observar que, quando não há a presença de $\mathrm{CP}$, não há um aumento de viscosidade após a rampa de temperatura, indicando que há a fusão do gelo quando atingida a temperatura de formação do hidrato $\left(1^{\circ} \mathrm{C}\right)$. Outro ponto estudado foram os sistemas não-emulsificados, os quais não indicaram formação de hidratos, possivelmente pela geometria couette utilizada nos testes.

Quanto à fração volumétrica de água utilizada nas emulsões, testes com 20\%, 30\%, 40\% e 50\% foram realizados, além de uma análise microscópica pré e pós-formação de hidratos. Para emulsões com menores frações volumétricas, o tamanho de gotas era menor e a estabilidade maior. Quando analisadas as amostras pós-formação de hidratos, foi possível observar gotas com formatos e preenchimento diferentes do comum, 
levantando-se a hipótese de se tratas de gotas com um estágio intermediário entre o estado líquido e sólido, visto que essas amostras foram analisadas quando cristais de hidratos eram observados visualmente.

Por fim, foram feitos testes oscilatórios para analisar 0 comportamento dos módulos elástico e viscoso. Com esses testes foi possível estimar uma faixa para o valor de tensão limite de cisalhamento. Quanto menor a taxa utilizada para formar a pasta de hidratos, maior a tensão limite de cisalhamento, pois forma-se estruturas cristalinas mais bem desenvolvidas e em maior quantidade, dificultando a quebra destas e aumentando a tensão necessária para que estes fluidos escoem.

Os resultados obtidos são importantes para uma possível implementação, por analogia, em situações reais de produção de óleo e gás. Apesar do presente trabalho não utilizar as condições reais, de pressão e temperatura, a utilização de ciclopentano é capaz de formar estruturas cristalinas muito próximas às formadas na produção real de petróleo.

Entender como os cristais se comportam em situações de diferentes taxas de cisalhamento, a diferentes temperaturas de formação (dentro do envelope), com diferentes frações volumétrica, pode ajudar, principalmente, na melhoria das técnicas de mitigação já existentes.

Por exemplo, entender como os cristais de hidrato se comportam após tempos de descanso, pode ajudar a entender como os aglomerados se comportam, em situações reais, durante as paradas promovidas na produção de petróleo. Esse tipo de parada pode favorecer e acelerar a aglomeração de hidratos, levando, inclusive, a uma obstrução total destes tubos e, consequentemente, uma parada total da produção, a qual é indesejada pelas empresas, pois demanda tempo e dinheiro para reverter a situação.

Portanto, o estudo da reologia dos cristais de hidrato, de ciclopentano, formados a partir de emulsões água em óleo modelo, pode indicar caminhos de como melhor agir diante às situações adversas 
ocasionadas devido a formação e rápida aglomeração dos cristais de hidrato.

\section{2.}

\section{Sugestões para trabalhos futuros}

A partir dos resultados e análises obtidas no presente trabalho, algumas sugestões de trabalhos futuros são apresentadas:

1. Analisar e detalhar a influência de diferentes tensoativos e concentrações na formação/inibição de hidratos;

2. Ampliar o estudo de sistemas não-emulsificados, utilizando a geometria Vane, a fim de traçar uma comparação com os resultados obtidos pela geometria couette;

3. Fazer uma análise visual da formação de hidratos, a partir de uma geometria transparente e de acrílico, para melhor entender os estágios de formação dos cristais de hidrato;

4. Fazer uma análise mais profunda do estudo microscópico pré e pósformação de hidratos, com utilização da microscopia com luz polarizada, identificando a presença de cristais na interface fase dispersa-contínua;

5. Estimular a nucleação de hidratos a partir do efeito de seeds, identificando as principais diferenças com a utilização de rampa de temperatura;

6. Realizas testes oscilatórios para emulsões com diferentes frações volumétricas de água;

7. Realizar testes de tensão constante para pastas de hidrato já formadas, a fim de fazer uma análise mais minuciosa da tensão limite de escoamento; 


\section{6}

\section{Referências Bibliográficas}

ABAY, H. Kinetics of gas hydrate nucleation and growth. 2011. 126p. Pós-doutorado. Faculdade de Ciências e Tecnologia Departamento de Engenharia de Petróleo, University of Stavanger, Noruega.

Ahuja, Amit, Genti Zylyftari, and Jeffrey F. Morris. "Yield stress measurements of cyclopentane hydrate slurry." Journal of NonNewtonian Fluid Mechanics 220 (2015): 116-125.

ARANBERRI, I. et al. Elaboracion y caracterización de emulsiones estabilizadas por polimeros $y$ agentes tensioactivos. Revista Iberoamericana de Polímeros, vol 7(3). p. 211-231. 2006. Disponível em: $<$ http://www.ehu.eus/revi

berpol/pdf/AGO06/aranberri.pdf>. Acesso em: 22/05/2020

BAI, Y.; Bai, Q. Subsea Engineering Handbook, Elsevier Science Publishers B.V., 2010.

BAPTISTA, J.M.M. Análise da Formação de Hidratos em Atividades de Perfuração de Campos Petrolíferos. Monografia (Projeto Final), Departamento

Acadêmico de Mecânica, Universidade Tecnológica Federal do Paraná. Curitiba.167p. 2007.

BARNES, H. A. A Handbook of Elementary Rheology, Institute of NonNewtonian Fluid Mechanics, University of Wales, 2000.

BARNES, H. A.; HUTTON, J. F.; Walters, K. F. R. S. An Introduction to Rheology, Elsevier Science Publishers B.V., 1993, Third Edition.

BIRD, R. Byron; ARMSTRONG, Robert, C.; HASSAGER, Ole. Dynamics of Polymeric Liquids. vol. 1. 2. ed. New York: John Wiley \& Sons, 1987.

BISHNOI P. R.; Natarajan V. Formation and decomposition of gas hydrates. Fluid

Phase Equilibria, v. 117, p. 168-177, 1996.

CASTRO, A. G.; COVAS, J. A.; DIOGO, A. C. Reologia e Suas

Aplicações Industriais. 1.ed. Ciência e Técnica (Instituto Piaget). Lisboa, Portugal. 462 p. 2001.

CHHABRA, R. P. Non-Newtonian Fluids: An Introduction, Department of Chemical Engineering, Indian Institute of Technology Kanpur, 2010.

COUTINHO, R. C. C. Estudo da estabilidade de emulsões de água em petróleo. Dissertação de Mestrado, Departamento de Engenharia, COPPE/UFRJ. Rio de Janeiro. 112p. 2005. 
Del Aguila M. Escoamento de Emulsões Óleo em Água através de Microcapilares. Dissertação de Mestrado, DEM, PUC-Rio, 2008.

DALTIN, D. (2011). Tensoativos: química, propriedades e aplicações. São Paulo: Blucher.

FAERGESTAD, I. M. Rheology, Schlumberger, 2016.

FU, S. B. et al. A summary of successful field applications of a kinetic hydrate inhibitor. In: SPE international symposium on oilfield chemistry. Society of Petroleum Engineers, 2001.

GRIFFIN, William C. Classification of Surface-Active Agents by "HLB". Journal of The Society of Cosmetic Chemists. v. 1. p. 311-326. 1949. Disponível em: <journal.scconline.org/contents/cc1949/cc001n05.html>. Acesso em: 13/04/2020

IBP, 2019. Disponível em: <https://www.ibp.org.br/observatorio-dosetor/producao-nacional-de-og-e-pre-sal/> . Acesso em: 18/07/2020

JACQUES, Alain. Emulsions. In: Handbook of detergentes, part A: Properties. 1st. ed. Boca Raton, New York: CRC Press, 1999. p. 181-252. Disponível em: <https://books.google.com.br>.

Karanjkar, P. U., Ahuja, A., Zylyftari, G., Lee, J. W., \& Morris, J. F. (2016). Rheology of cyclopentane hydrate slurry in a model oil-continuous emulsion. Rheologica Acta, 55(3), 235-243.

Kelland, M. A., Svart_as, T. M., Andersen, L. D., 2009. Gas hydrate antiagglomerant

properties of polypropoxylates and some other demulsifiers. Journal of Petroleum Science

and Engineering 64 (1), $1\{10$.

KRONBERG, B.; HOLMBERG, K.; LINDMAN, B. (2014). Surface Chemistry of Surfactants and Polymers, 1st Edition, Wiley SANTOS, F. K. G.; ALVES, J. V. A.; DANTAS, T. N. C.; NETO, A. A. D.; DUTRA JR, T. V.; NETO, E. L. B. (2007). Determinação da Concentração Micelar Crítica de Tensoativos Obtidos a Partir de Óleos Vegetais para Uso na Recuperação Avançada de Petróleo. 4 PDPETRO, Campinas, São Paulo.

Kumar R., Linga P. (2018) Gas Hydrates. In: White W. (eds) Encyclopedia of Geochemistry. Encyclopedia of Earth Sciences Series. Springer, Cham

LIMA, C. M. (2013). Estudo da dispersão de nanodiamantes sobre nanotubos de carbono verticalmente alinhados como emissores de elétrons. Dissertação de Mestrado. Pós-Graduação em Engenharia e 
Tecnologia Espaciais/Ciência e Tecnologia de Materiais e Sensores, INPE, São José dos Campos.

L. L. Shcramm, Emulsions, Foams, and Suspensions - Fundamental and Applications, 2006.

LONG, J., Gas Hydrate Formation Mechanism and Its Kinetic Inhibition. Colorado. 1994. Ph.D. Thesis, Colorado School of Mines, Estados Unidos da América.

LUCASSEN-REYNDERS, E. H. Dynamic Interfacial Properties in Emulsification. In: Encyclopedia of Emulsion Technology. v. 4. New York: Marcel Dekker Inc. 1996. p. 63-91. Disponível em: <https://books.google.com.br>. Acesso em: 14/04/2020

MAJID, Ahmad AA; TANNER, Braeden; KOH, Carolyn A. Cyclopentane hydrate slurry viscosity measurements coupled with visualisation. Molecular Physics, p. 1-11, 2019.

MAKOGON, Y.F.; HOLDITCH, S.A; MAKOGON, T.Y. Natural GasHydrates: A Potential Energy Source for the 21st Century. Journal of Petroleum Science and Engineering 56, pp 14-31, Elsevier, 2007.

MULLIGAN, C.N. Environmental applications for biosurfactants. Environmental Pollution. v. 133. Oxford. p. 183-198. 2005.

NAKAJIMA, Masahiro; OHMURA, Ryo; MORI, Yasuhiko H. Clathrate hydrate formation from cyclopentane-in-water emulsions. Industrial \& engineering chemistry research, v. 47, n. 22, p. 8933-8939, 2008.

OHMURA, Ryo; OGAWA, Mikio; YASUOKA, Kenji; MORI, Yasuhiko H. Statistical Study of Clathrate-Hydrate Nucleation in a Water/Hydrochlorofluorocarbon System: Search for the Nature of the "Memory Effect". J. Phys. Chem. B. Estados Unidos. v. 107. p. 5289-5293. 2003.

PEIXINHO, Jorge; KARANJKAR, Prasad U.; LEE, Jae W.; MORRIS, Jeffrey F. Rheology of Hydrate Forming Emulsions. Langmuir. 26 (14). Estados Unidos. p.11699-11704. 2010.

PETRONOTICIAS, 2017.2 Disponível em: <https://petronoticias.com.br/archives/96912>. . Acesso em: 15/04/2020

RODGER, P. Mark. Methane hydrate: melting and memory. Annals of the New York Academy of Sciences, v. 912, n. 1, p. 474-482, 2000.

SALAS, M. K. S. (2014). Estudo da Injeção de Água na Recuperação Melhorada de Petróleo: Efeito da Salinidade e Surfactante. Dissertação de Mestrado. Engenharia Mecânica, PUC-Rio, Rio de Janeiro. 
SANDOVAL, Gustavo AB et al. Analysis of $\mathrm{CO} 2$ hydrates in crude oils from a rheological point of view. Energy \& Fuels, v. 32, n. 3, p. 2733-2741, 2018.

SCHRAMM, L. L. (2000). Surfactants: fundamentals and applications in the petroleum industry, Cambridge University Press, New York.

SCHRAMM, L. L.; STASIUKB, E. N.; MARANGONIC, D. G. Surfactants and their applications. Annual Reports Program Chemistry, Section. C: Phys.

Chem. v.99. p. 3-48. 2003.

SCHRAMM, Laurier L.; KUTAY, Susan M. Emulsions and Foams in the Petroleum Industry. In: Surfactants: Fundamentals and Applications in the Pe- troleum Industry. UK, Cambridge: Cambridge University Press, 2000. p. 79-117.

SHAW, Duncan James. Introdução à Química dos Colóides e de Superfícies. São Paulo: Edgard Blucher, Ed. da Universidade de São Paulo, 1975.

STEINBAKK, C. H. Hydrate Inhibition - and the environmental impact. NTNU - Trondheim: Norwegian University of Science and Technology, 2012.

SLOAN, E. D. Fundamental principles and applications of natural gas hydrates. Nature, v. 426, p. 353-362, 2003

SLOAN JR, E. Dendy; $\mathrm{KOH}$, Carolyn A. Clathrate hydrates of natural gases. CRC press, 2007.

SULLIVAN, A. P.; KILPATRICK, P. K. The Effects of Inorganic Solid Particles on Water and Crude Oil Emulsion Stability. Industrial Engineering Chemical Resource. American Chemical Society. v. 41. North Carolina. p. 3389-3404. 2002. Disponível em: <http://pubs.acs.org/doi/abs/10.1021/ie010927n>.

SUM, Amadeu K.; WU, David T.; YASUOKA, Kenji. Energy science of clathrate hydrates: Simulation-based advances. MRS bulletin, v. 36, n. 3, p. 205-210, 2011.

TADROS, Tharwat F. Emulsion Science and Technology: A General Introduction. In: Emulsion Science and Technology. Weinheim: WILEY$\mathrm{VCH}, 2009$. p. 1-55.

TANNER, R. I. Engineering Rheology. Ed. Rev. New York: Oxford University Press, 1988, 451p.

TURNER, D. J., 2006. Clathrate Hydrate Formation in Water-in-Oil Dispersions. Dissertação de pós-doutorado. Departamento de Engenharia Química, Colorado School of Mines, Golden, Colorado. 2006. 
VLIET, T. V.; LYKLEMA H. Rheology. In: LYKLEMA, J. (Editor), Fundamentals of interface and colloid science, v. 4, Elsevier, 2005, p. 6.1-6.88.

WEBB, Eric B.; RENSING, Patrick J.; KOH, Carolyn A.; SLOAN, E. Dendy; SUM, Amadeu K.; LIBERATORE, Matthew W. High-Pressure Rheology of Hydrate Slurries Formed from Water-in-Oil Emulsions. Energy \& Fuels. v. 26. Estados Unidos. p. 3504-3509. 2012.

WILSON, P. W.; LESTER, Daniel; HAYMET, A. D. J. Heterogeneous nucleation of clathrates from supercooled THF/water mixtures and the effect of an added catalyst. Chem. Eng. Sci.. v. 60. Estados Unidos. p. 2937-2941. 2005.

YAO, Hai-Yuan; LI, Qing-Ping; CHEN, Guang-Jin; GONG, Jing. An Experimental Investigation on Rheology of Condensate Oil/tetrahydrofuran Hydrate Slurry.Proceedings of the 7th ISOPE Ocean Mining Symposium. Lisboa. Portugal. Julho 1-6. 2007

ZYLYFTARI, Genti; AHUJA, Amit; MORRIS, Jeffrey F.. Nucleation of Cyclopentane hydrate by ice studied by morphology and rheology. Chemical Enginerring Science. v. 116. Estados Unidos. p 497-507. 2014. 